$$
\text { كلية الإدارة والاقتصاد -جامعة الموصل }
$$

$$
\begin{aligned}
& \text { الدكتور علاء الدين عادل الرفاتي } \\
& \text { أستاذ الإقتصاد المساعد -قسم الإقتصاد } \\
& \text { عميد كلية التجارة } \\
& \text { الجامعة الإسلامية -غزة }
\end{aligned}
$$

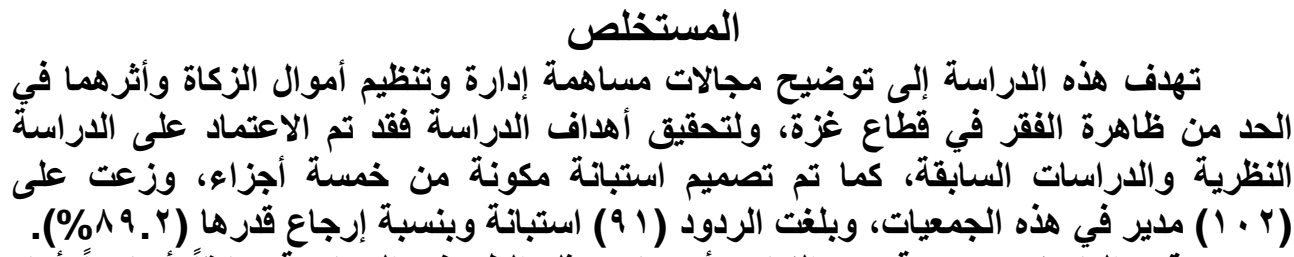

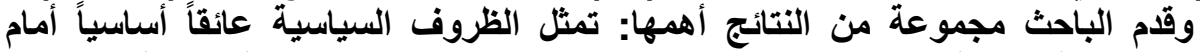

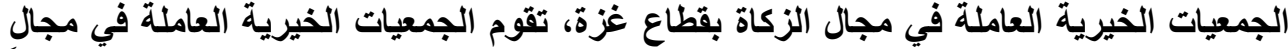

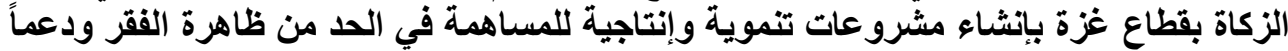

كما قدم الباحثّ مجموعة من التوصيات أهمها: على الجمعيات الخيرية العاملة في مجال التيال لسياسة الاكتفاء الذاتي.

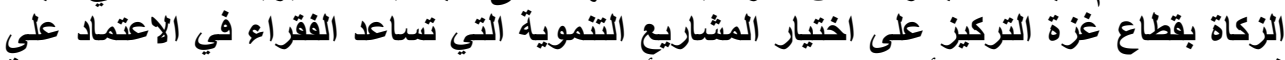

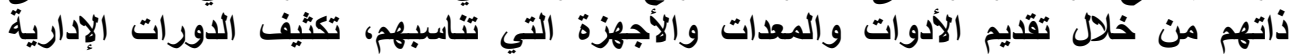

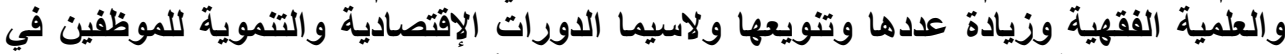

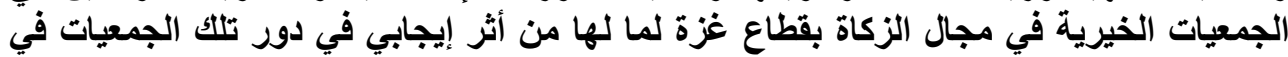

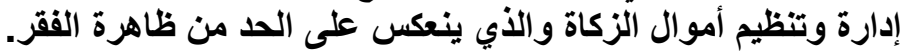

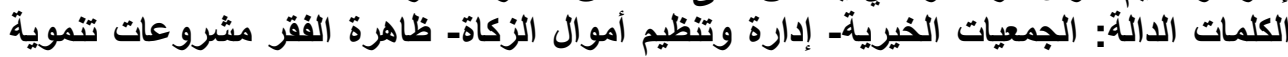

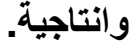




\title{
The Contribution Fields of Managing and Organizing Elzakat Funds and their Effects on Decreasing the Poverty Phenomenon in Gaza Province"
}

\author{
AlaaAldin A. Al - Rifaty (PhD) \\ Dean and Assistant Professor of Economics \\ College of Commerce \\ Islamic University - Gaza
}

\begin{abstract}
This study aims at identifying the contribution fields of managing and organizing Elzakat funds and their effects on decreasing the poverty phenomenon in Gaza Province. To achieve the objectives of this study, a questionnaire has been developed depending on theoretical and previous studies. The questionnaire consisted of five parts, distributed to (102) managers of these societies, and the replied questionnaires were (91), which represent (89.2\%). The researcher introduced a set of results; the political circumstances represent fundamental obstacles against the societies of charity working in Gaza Province. The Societies of charity working in Gaza Province executed productive and growth projects to contribute in decreasing the phenomenon of poverty and to encourage the self - sufficiency policy. The researcher introduced many recommendations; the societies of charity working at Elzakat in Gaza Province must concentrate on establishing the developmental projects which support the poor persons to depend on themselves through introducing suitable tools, Machines and equipments. Increasing the scientific and managerial workshops especially the economic and developmental for the employees at various societies working in Gaza Province will have a positive effect to manage and organize Elzakat funds that may be reflected on decease the poverty phenomenon.

Keywords: Societies of charity- Managing and Organizing Elzakat Funds- Poverty phenomenonDevelopmental and productive projects.
\end{abstract}

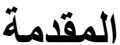

تعد ظاهرة الفقر من أهم القضايا التي تواجه الثعوب، فالفقر مرض بهاب يصيب

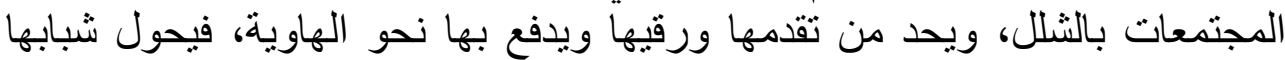

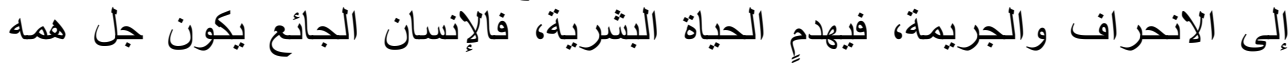

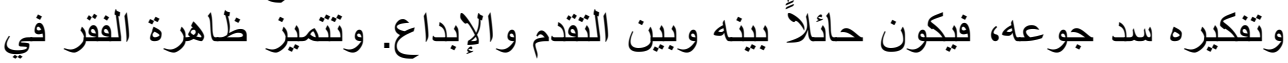

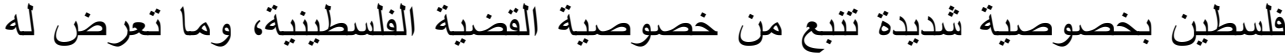
الشعب الفلسطيني من أحداث ومآسي على مدى قرن فرن من الزمن، و لاسيما الاقتلاع

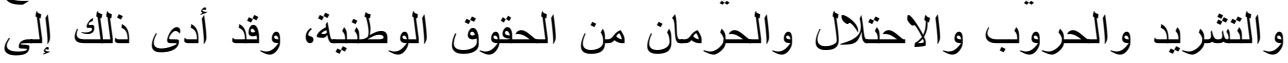

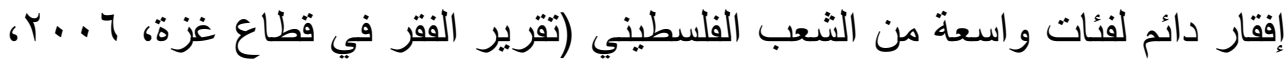

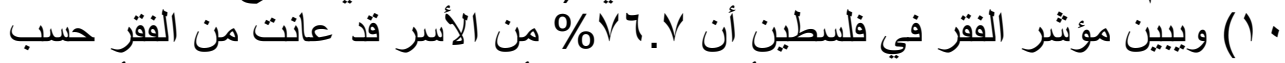

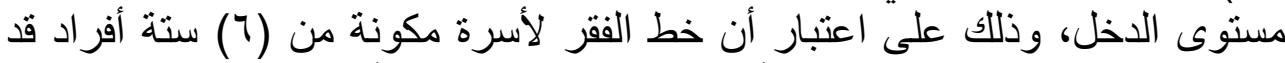

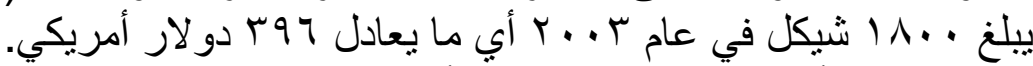

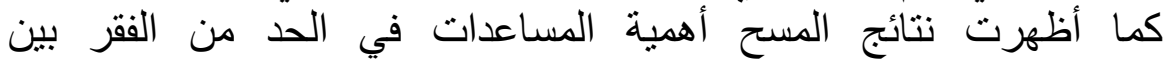

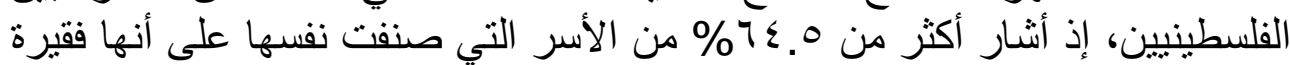


دكتور الرفاتي [ ]

أن توفير المساعدات والحصول عليها يساعدها بشكل رئيس على الخروج من دائرة

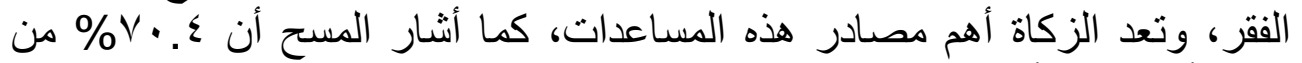

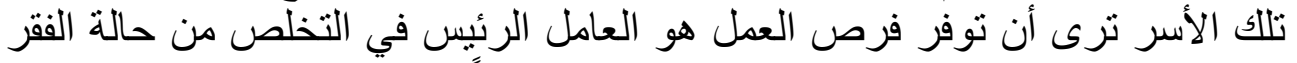

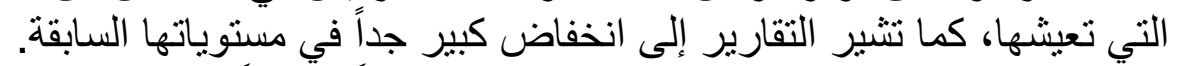

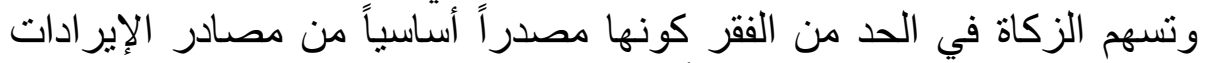

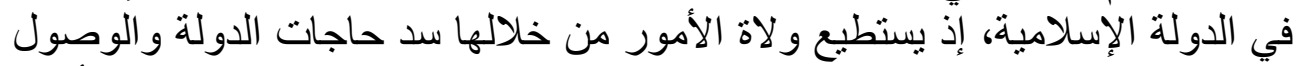

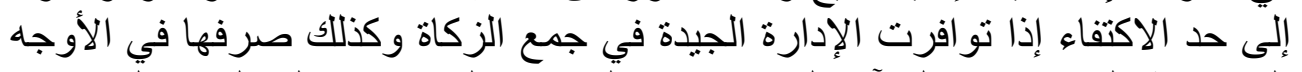

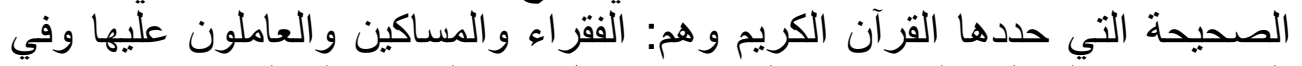

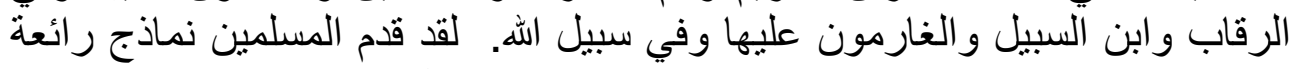

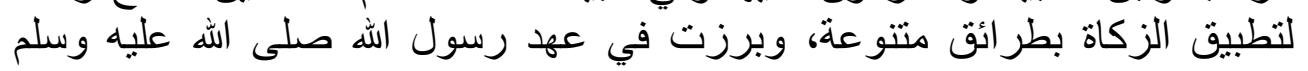

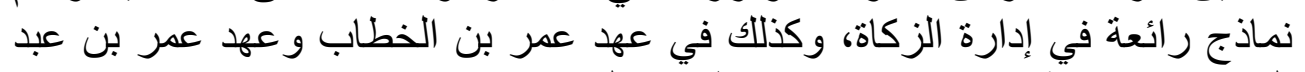
العزيز رضي الله عنهما حتى النتهات وانت ظاهرة في الفقر.

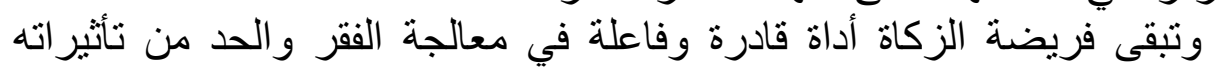

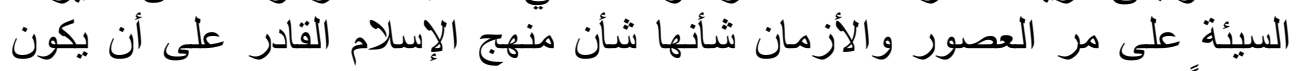
صالحاً لكل زمان ومكان.

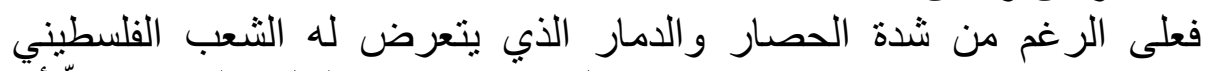

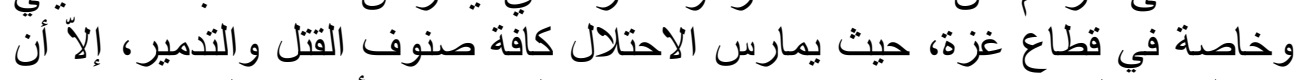

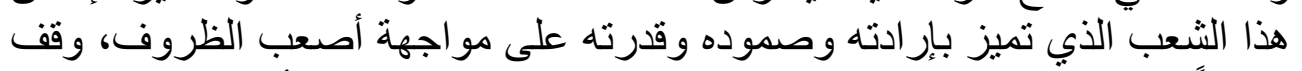

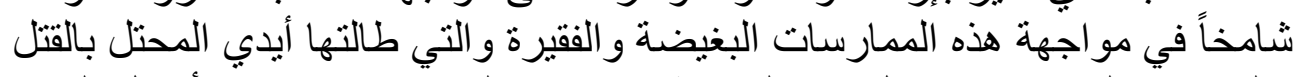

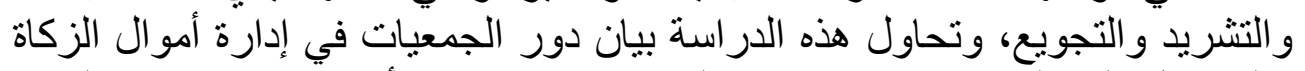

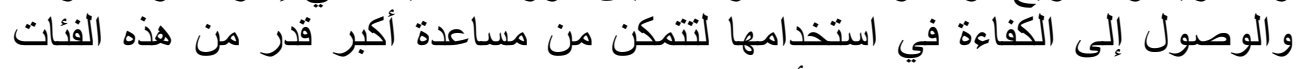

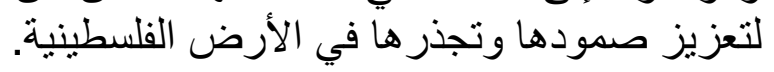

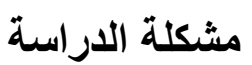

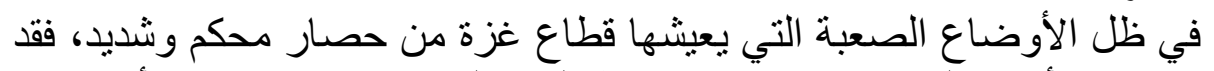

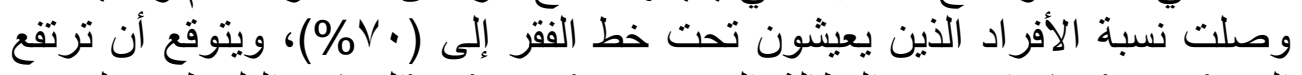

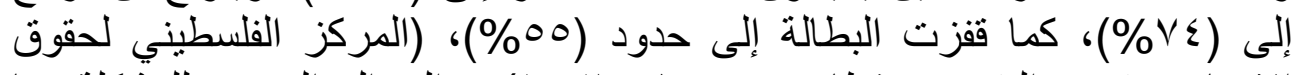

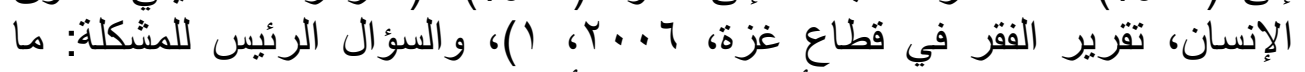

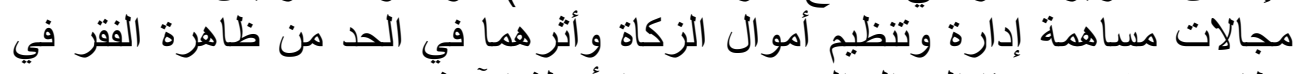

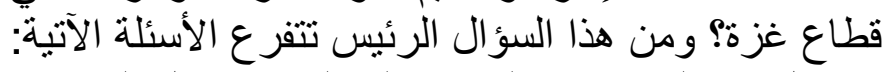

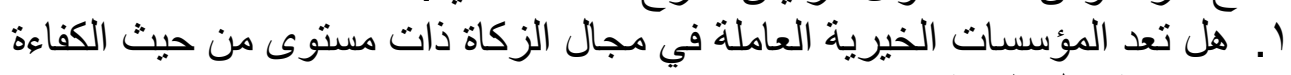

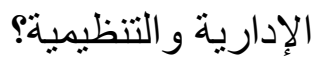
r. هل يوجد تنسيق وسياسات موجهة للعمل بين المؤسسات الخيرية العاملة في

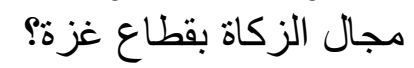

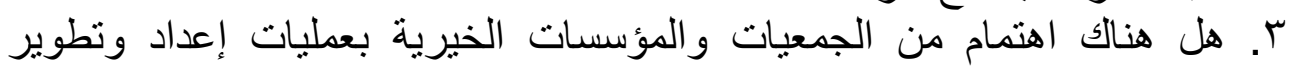
وتدريب للإدارات العاملة في مجال الزكاة بقطاع غزة؛ 
؛. هل تعمل الجمعيات والمؤسسات الخيرية العاملة في مجال الزكاة بقطاع غزة

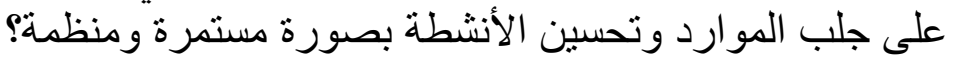
○. هل تسهم أموال وموارد الزكاة في الحد من ظاهرة الفقر بقطاع غزة بصورة و واضحة هل 7. هل توجد علاقة بين مجالات مساهمة إدارة وتنظيم أموال الزكاة و أثرهما في

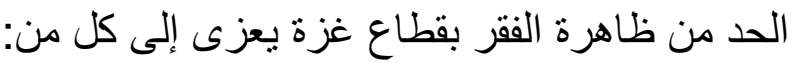

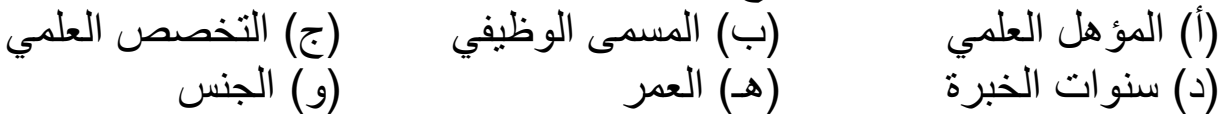

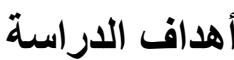
ا ا ـ تسليط الضوء على على الزكاة و إدارة الجمعيات الإسلامية لمصارفها.

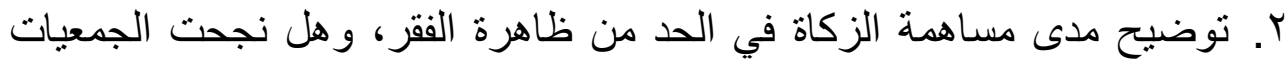

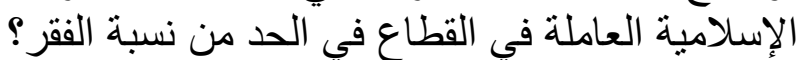

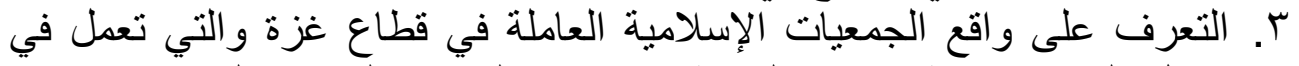

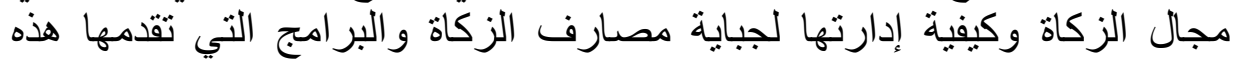

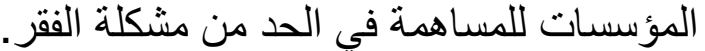
ع. تقديم إطار مقترح لإدارة وتنظيم الزكاة.

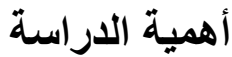
ا. تنبع أهية الدراسة من كونها تعالج قضية مهمة ومؤثرة في حياة الثعب الفلسطيني. r. كما أنها تتعامل مع مصدر مهم من مصادر الأمو ال في المجتمعات الإسلامية.

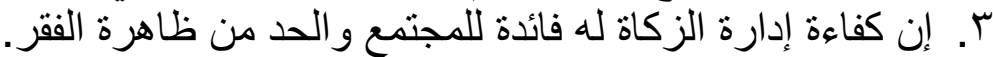
ع. كما أن سوء إدارة الزكاة يعرضها للـأذهاب هدراً من دون فائدة تعود على الأسر

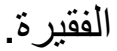

\section{فرضيات الاراسة}

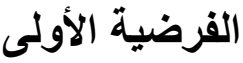
"توجد علاقة ذات دلالة إحصائية بين الكفاءة الإدارية والتنظيمية في المؤسسات الخيرية وبين الحد من ظاهرة الفقر في قطاع غزة" لألة

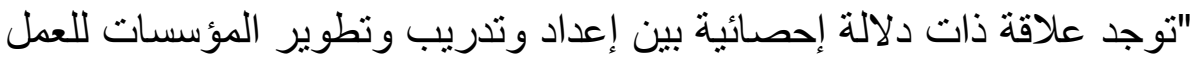
في المؤسسات الخيرية في مجال الزكاة وبين الحد من ظاهرة الفقر فئر في قطاع غزة". 
دكتور الرفاتي [بי[

"توجد علاقة ذات دلالة إحصائية بين إعداد وتدريب ونطوير المؤسسات الخيرية في مجال الزكاة وبين الحد من ظاهرة الفقر في قطاع غزة إعة".

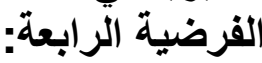

"توجد علاقة ذات دلالة إحصائية بين جلب الموارد وتحسين الأنثطة بصورة الزئية مستمرة ومنظمة في المؤسسات الخيرية في مجال الزكاة وبين الحد من ظاهية الترة الفقر

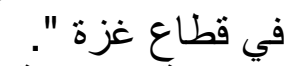
القرضية الخامسة:

"توجد علاقة ذات دلالة إحصائية بين مساهمة أموال الزكاة بصورة واضحة

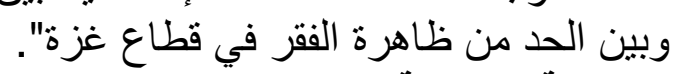

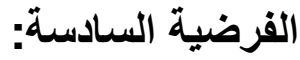

"توجد علاقة ذات دلالة إحصائية بين مجالات مساهمة إدارة تنظيم أموال

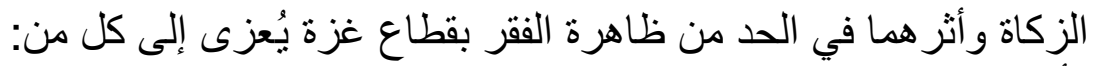

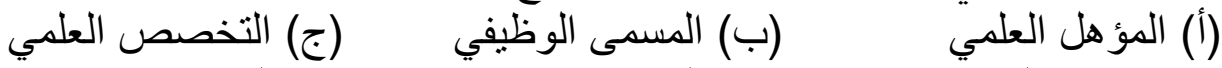

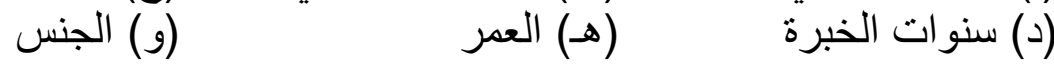

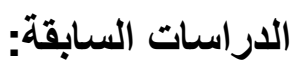

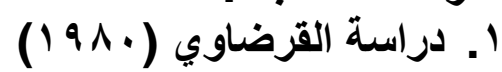

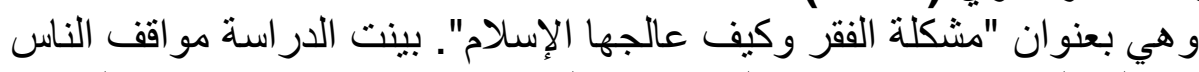

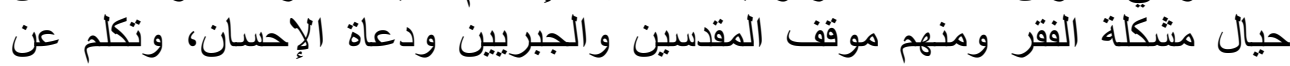

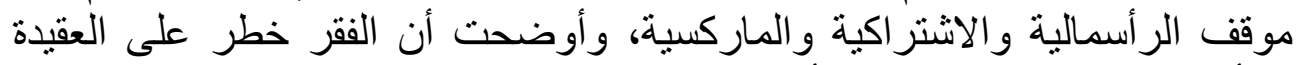
و الأخلاق و السلوك و الفكر والأسرة و المجتمع واستقراره، ثم عرضت الفت ست وسائل

$$
\begin{aligned}
& \text { r. كفالة الموسرين من بـ الزكاة. } \\
& \text { لمعالجة الفقر وهي: } \\
& \text { الأقارب. }
\end{aligned}
$$

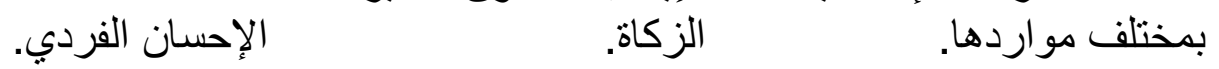

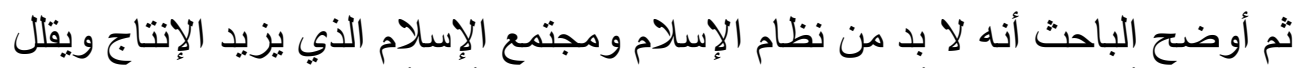

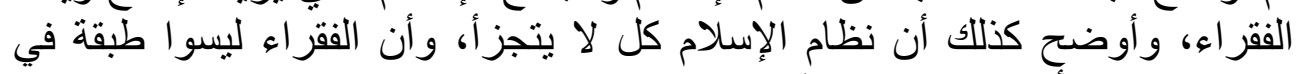
الإسلام ويجب أن تكون كر امة الفقير مصونة.

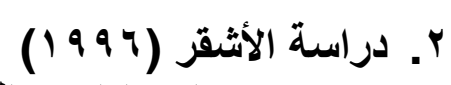

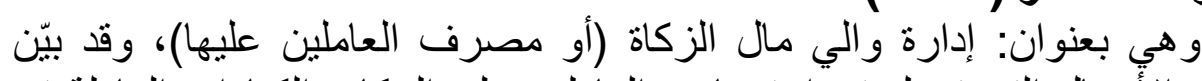

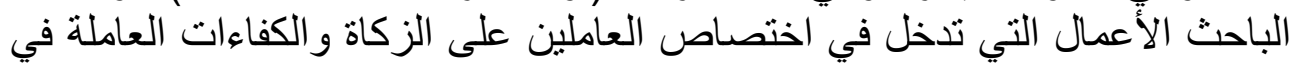

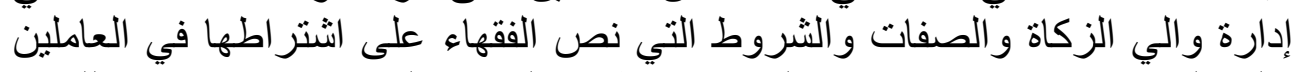

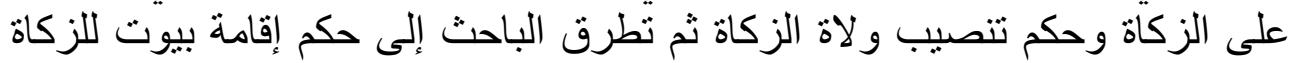

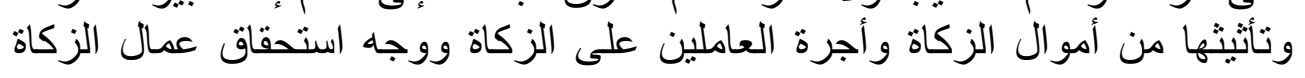


نصيباً من أموال الزكاة وتعرض الباحث لأقو ال أهل العلم في المقار الذي يستحقه

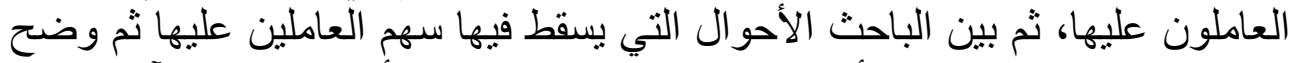

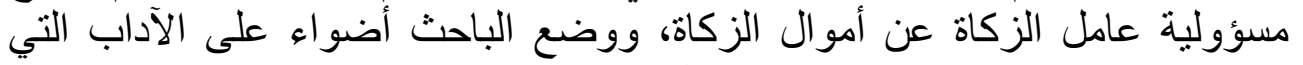

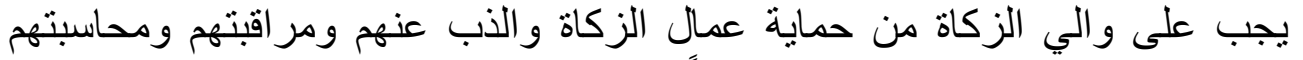
وفي نهاية البحث خصص الباحث مبحثاً عن هدايا العمال ورشوتهم.

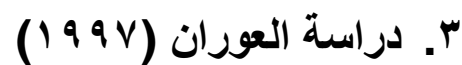

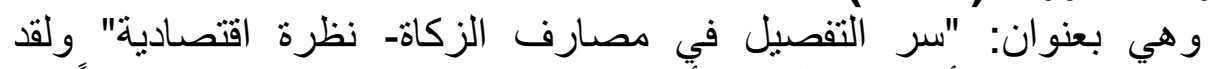
خلصت الدراسة إلى أن التفصيل في أوجهه إنفاق الزكاة إنما جاء ليحقق عدداً من لئن

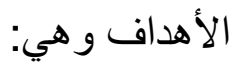
ا ـ إرشاد المجتمع المسلم إلى عدد من القضايا الاجتماعية بالمعنى الثمولي الأكثر

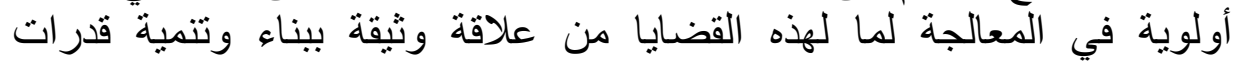

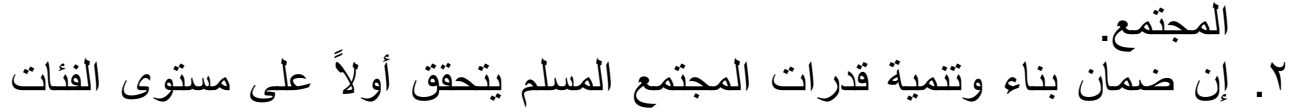

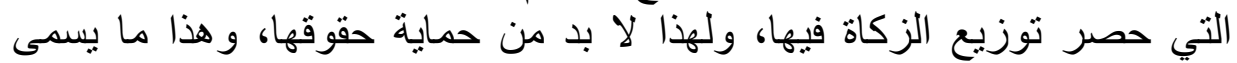
بالحق الخاص في أمو ال الزكاة.

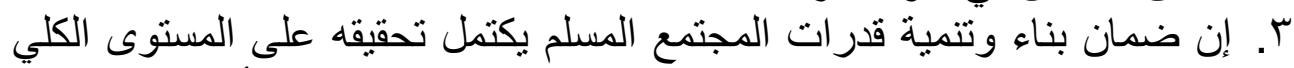

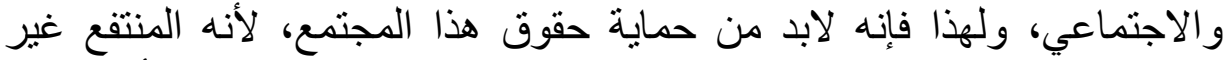

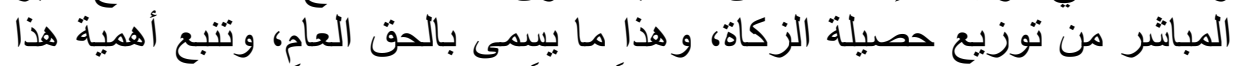

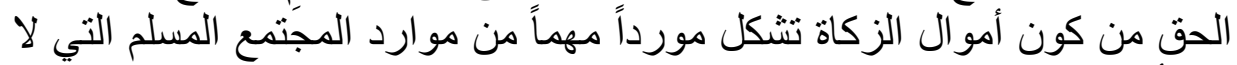

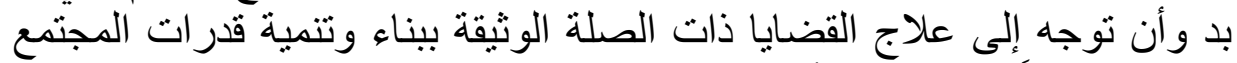

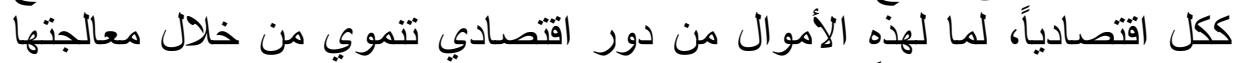

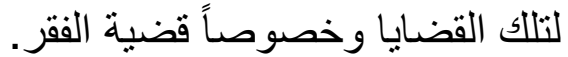

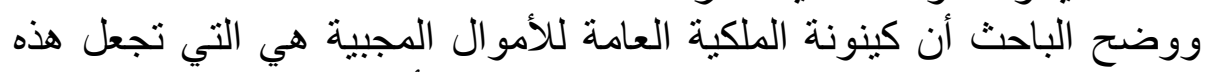

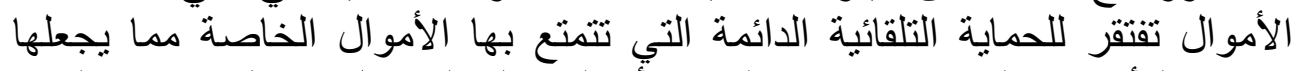

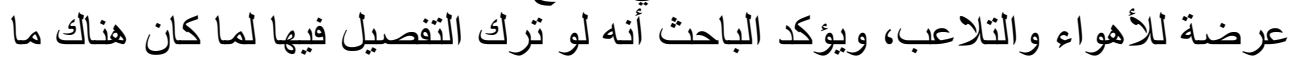

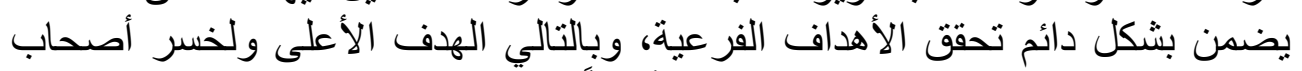
الحقوق حقوقهم وخسر المجتمع ككل حقه أيضاً.

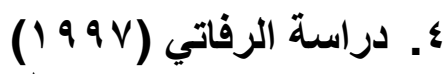

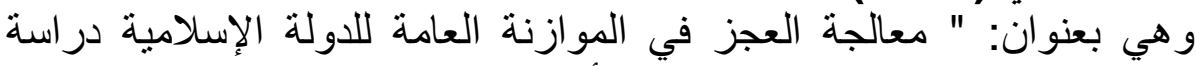

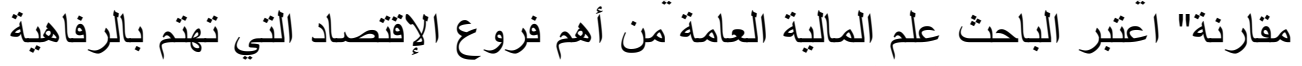

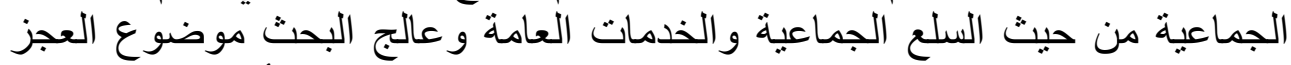

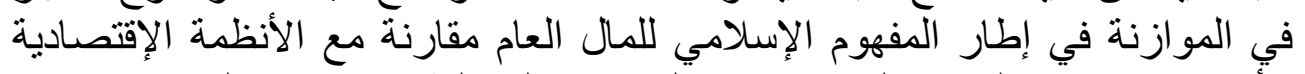

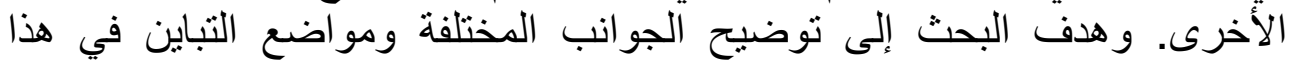
المجال بين النظرة الإسلامية والفكر الوضعي واعتمد الباحث على المنهج الوصفي في الوضي 
وتوصل الباحث إلى عدة نتائج من أهمها: أن النظام المالي الإسلامي كأي نظام

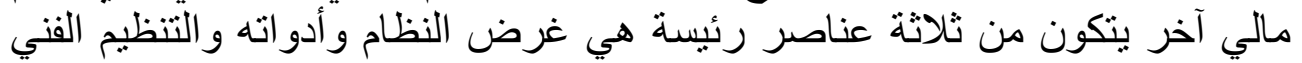

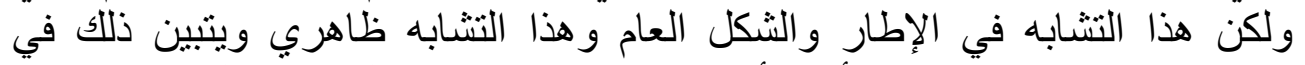

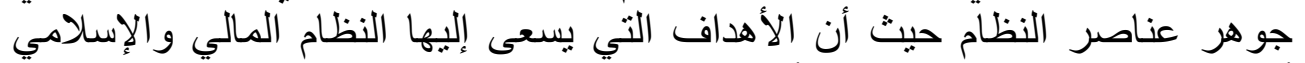

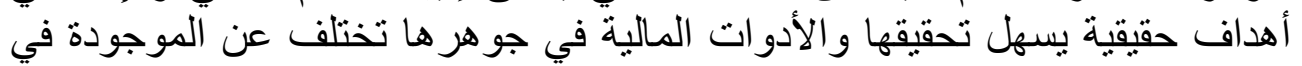

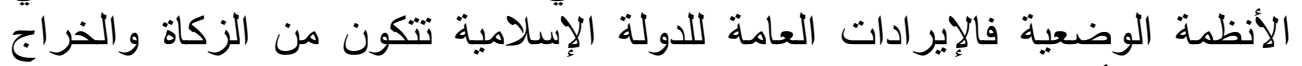

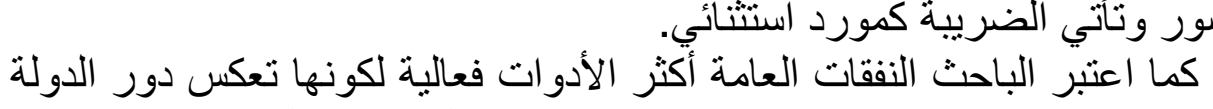

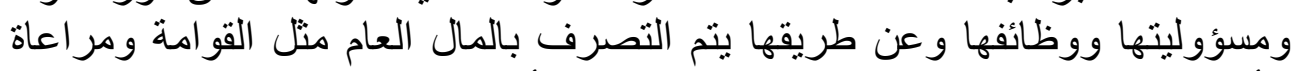

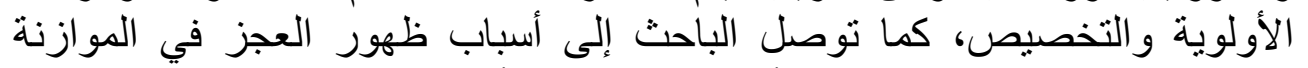

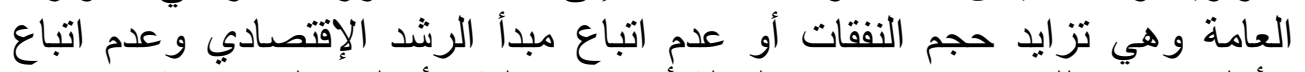

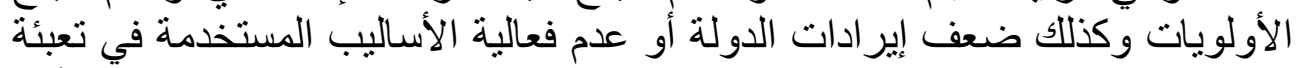

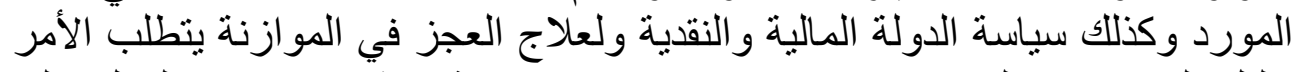

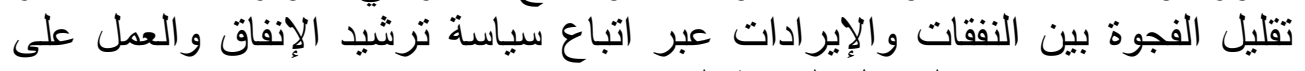
استحداث موارد جديدة لتمويل النشاط الحكومي.

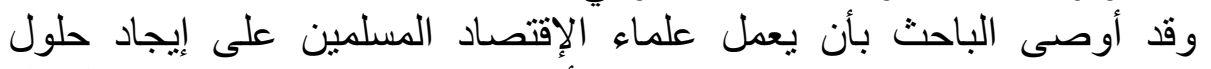

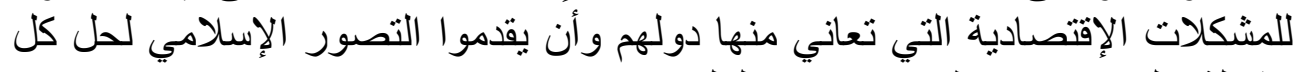
مشكلة على حدا في إطار الإقتصناد الكلي.

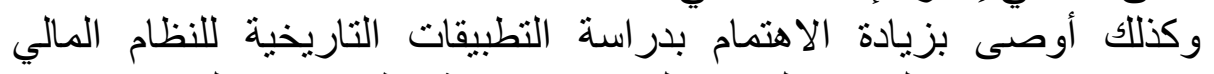

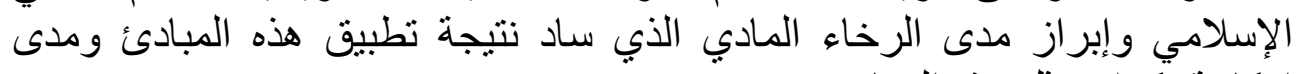

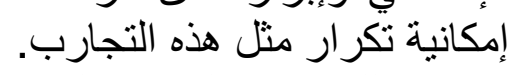
كذلك هدفت الدراسة إلى توضيح العلاقة بين مصرف الزبل الزكاة على الفقراء وبين

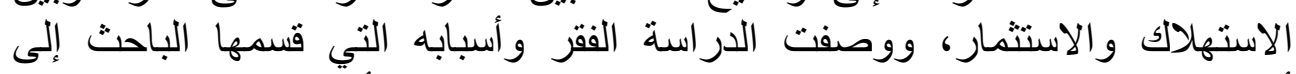

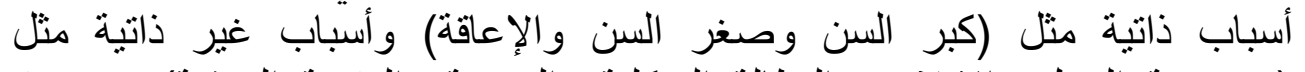

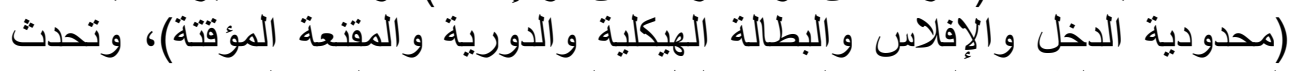

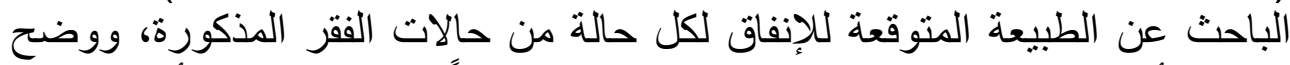

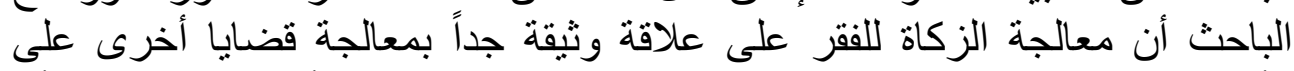

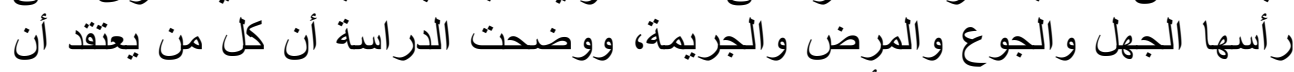

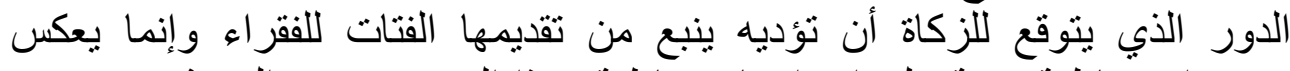

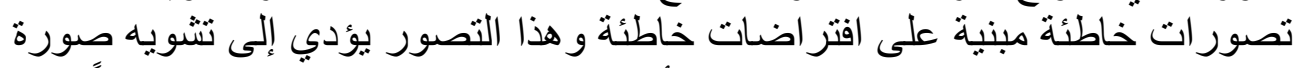

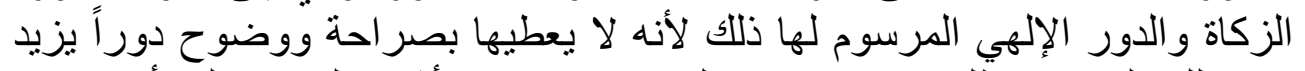

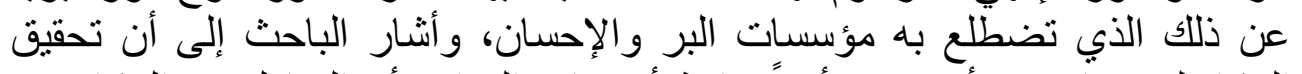

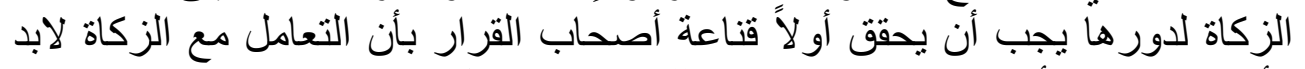

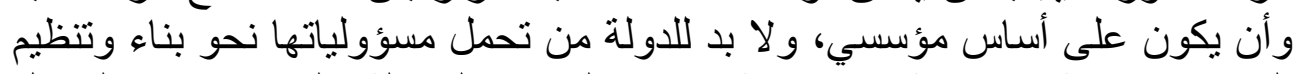

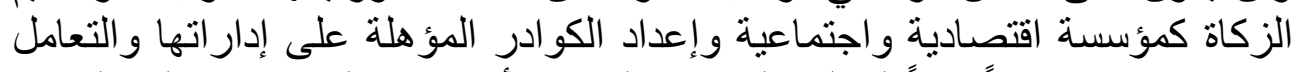

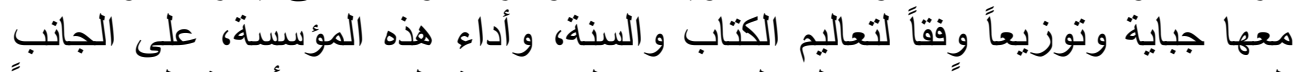

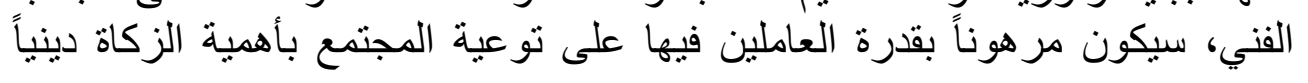


و اقتصادياً واجتماعياً والعمل على دراسة حالات الفقر، ومن ثم نوزيع حصيلة مصرف الفقر اء على هؤ لاء كل حسب حاجنته.

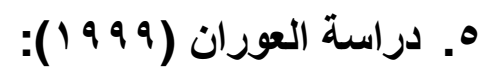

وهي بعنوان: "الدور الإقتصادي التتموي للزكاة من خلال معالجنها لقضية

هدف البحث إلى دراسة الدور الإقتصادي التنموي الذي يمكن للزكاة أن تنهض إنها

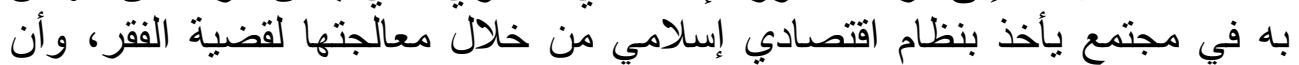

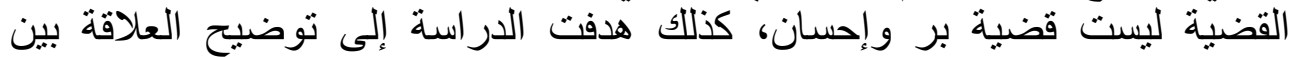

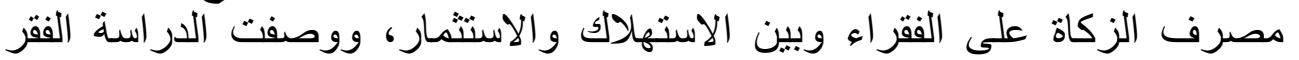

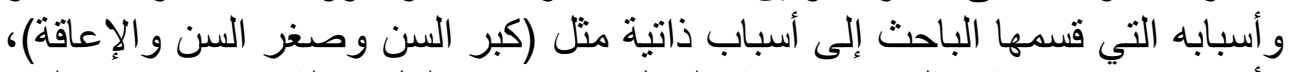

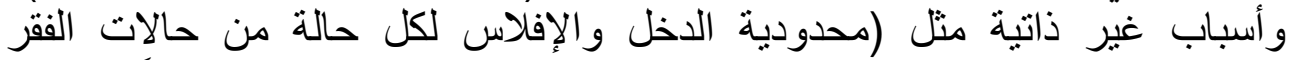

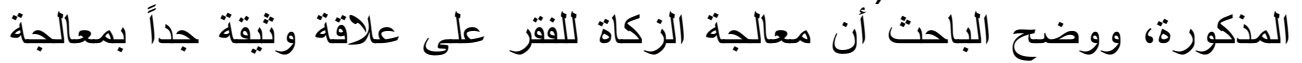

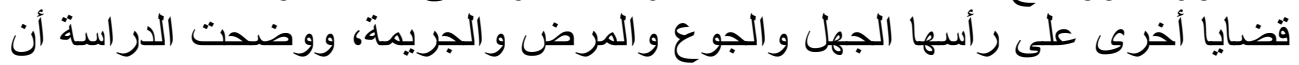

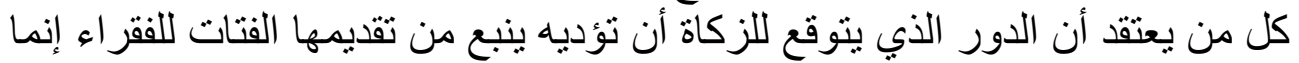

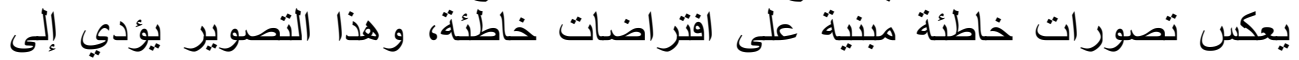

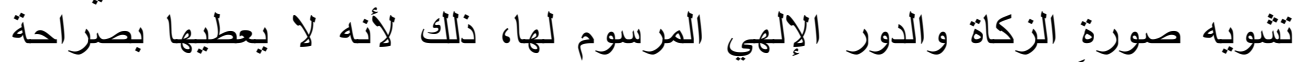

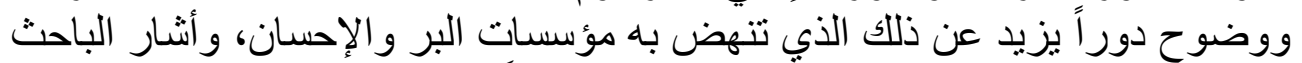

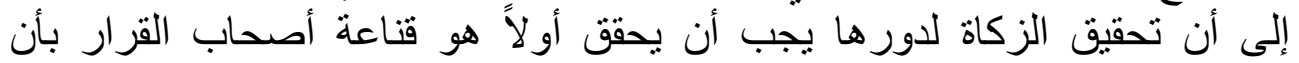

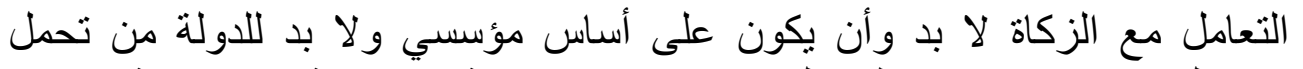

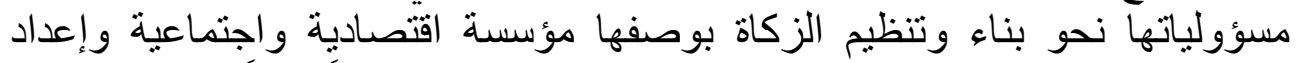

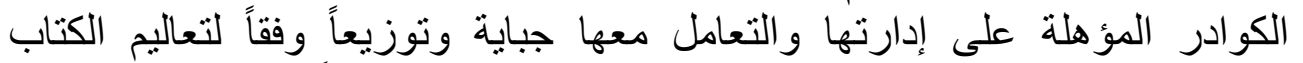

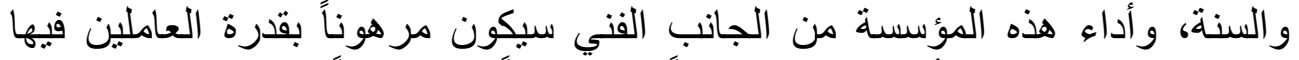

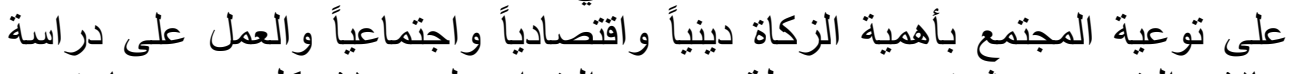

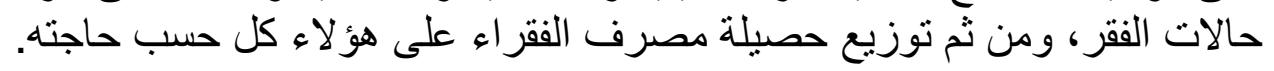

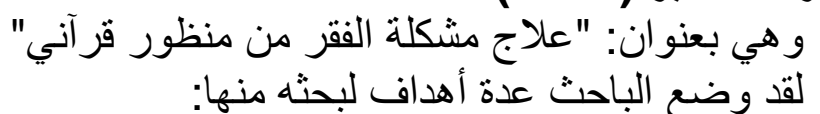

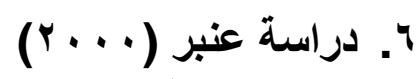$$
\text { لقد وضع الباحث عدة أهداف لبحثثه منها: }
$$

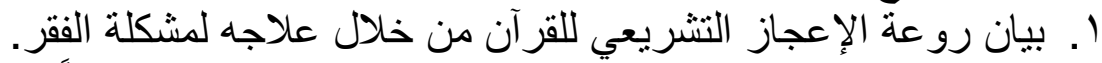

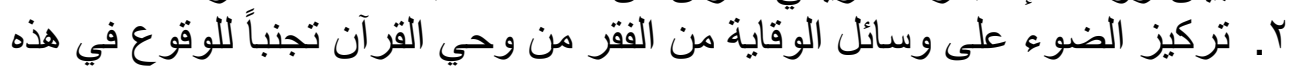

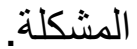

r. إثبات عجز المذاهب الوضعية وفثلها في علاج مشكلة الفقر.

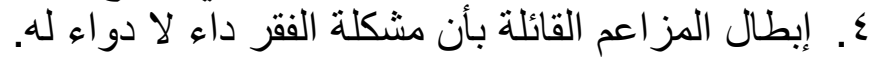

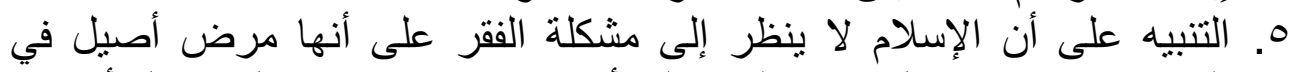

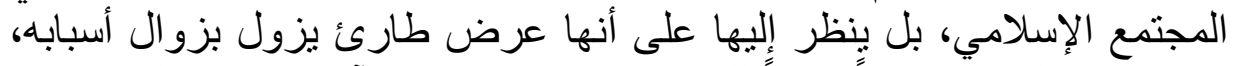

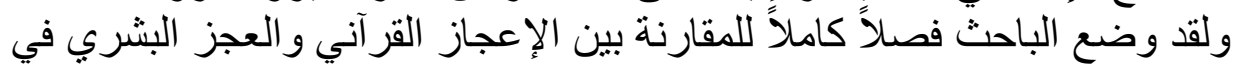




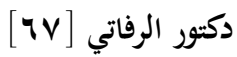

حل مشكلة الفقر، كما تطرق إلى واقع تطبيق الحلول القرآنية لمشكلة الفقر بين

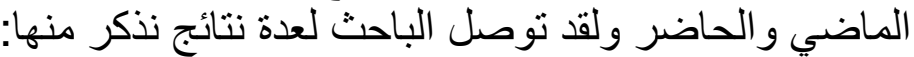

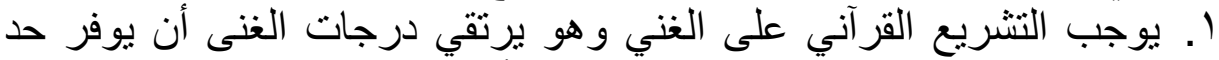

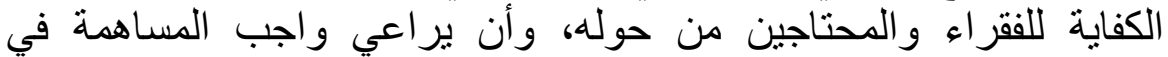
النهوض بأفر اد هم بحاجة إلى مساعدنه. r. ينظر التشريع الإسلامي إلى المال على ألى أنه ملك لله تعالى و أنه مخلوق لعباده

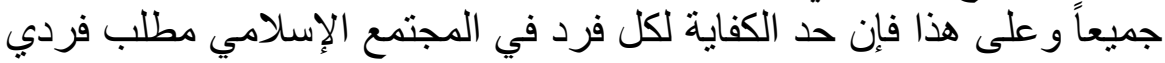

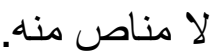
r. إبطال المز اعم القائلة بأن الفقر داء لا دواء لهاء لهيث حيث ثبت لدينا أن الفقر مرض

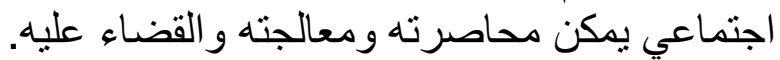
كما خرج الباحث بعدة نوصيات كان من أهمها:

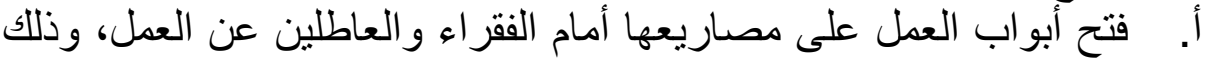

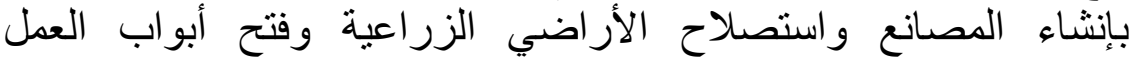

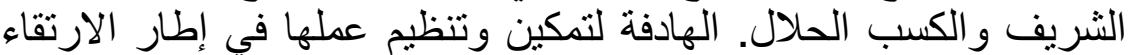
بالمجتمع المدني الفلسطيني بشكلٍ خاص، و المجتمع الفلسطيني بشكلٍ عام.

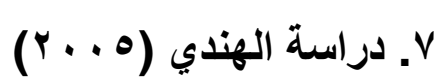

وهي بعنوان: "تقييم دور المنظمات الأهلية في عملية التنمية الإقتصادية في فلسطين" در اسة حالة قطاع غزة دان.

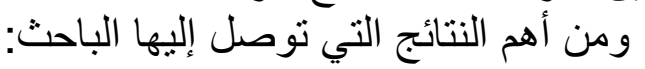
1. عفوية البرامج التي تقوم بها المنظمات وعدم ارتباطها بخطة تتموية شاملة أدت إلى تشتيت جهودهاً. r. ضعف التنسيق بين الجمعيات الأهلية العاملة في فلسطين وبين الجمعيات الأهلية

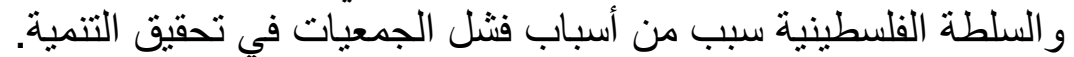

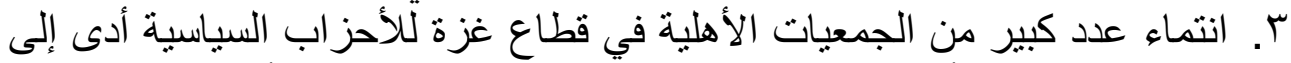

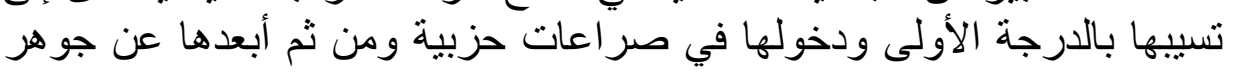

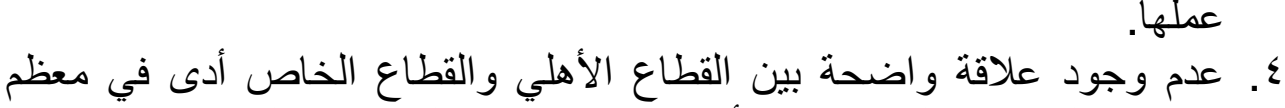

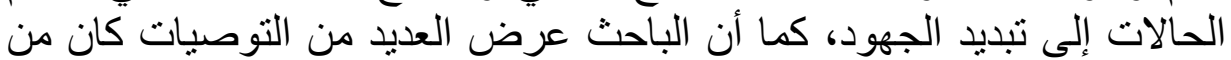

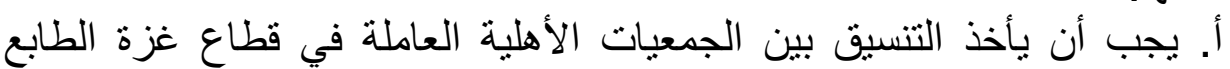

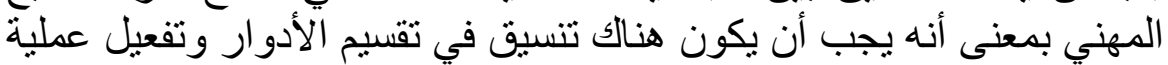

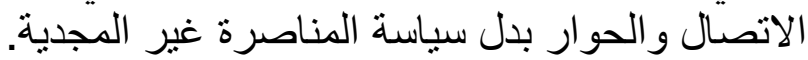

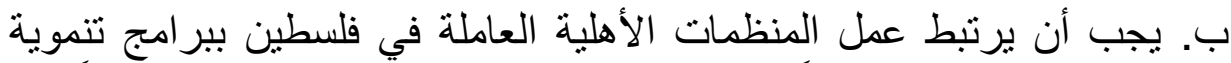

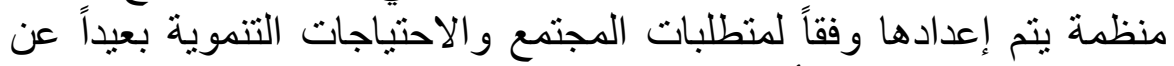

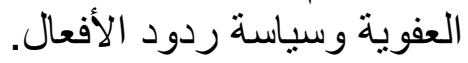




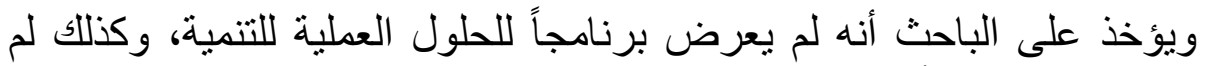

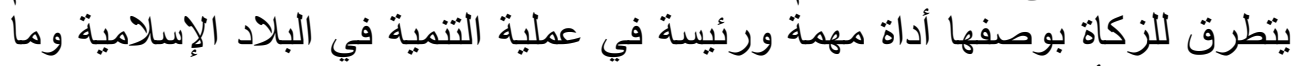
هو دور ها و أثر ها في التنمية والحد من الفقر وكيفية إدارتها في الجمعيات العية العاملة في الإديا

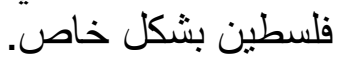

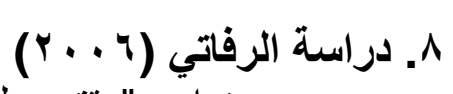

و هي بعنوان: "مقترح لتنظيم و إدارة أمو ال الزكاة" وصف الباتئ الباحث الزكاة بأنها

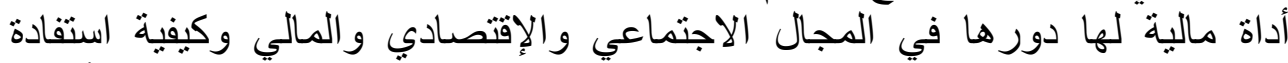

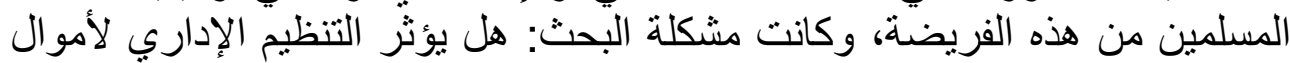

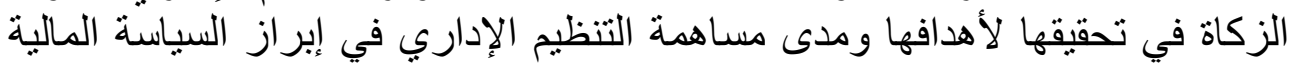

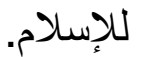

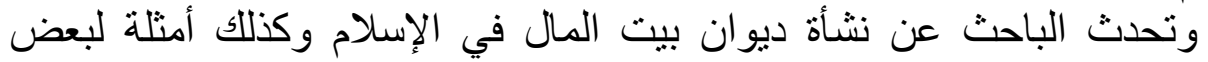

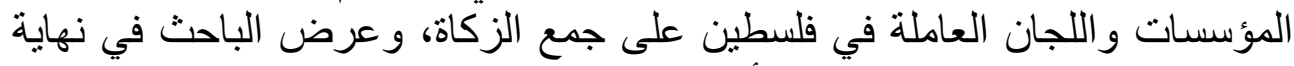
البحث بعض الموازنات المقترحة لأنواع الزكاة.

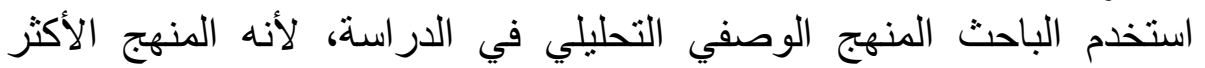

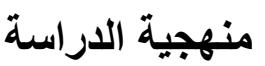

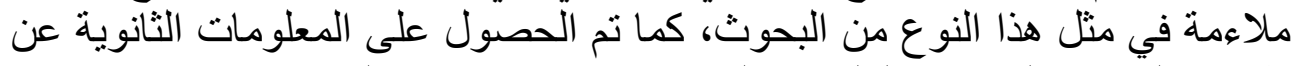

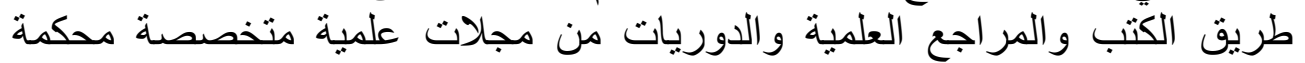

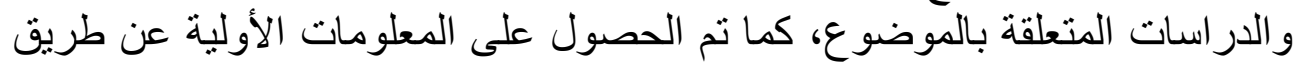

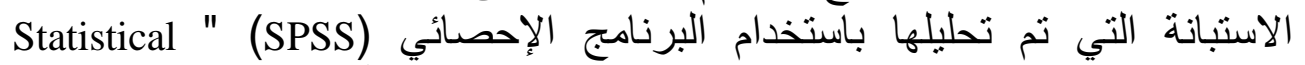
اولامِ Program for Social Sciences

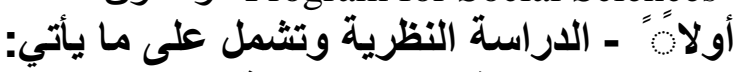

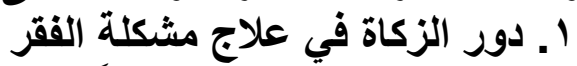

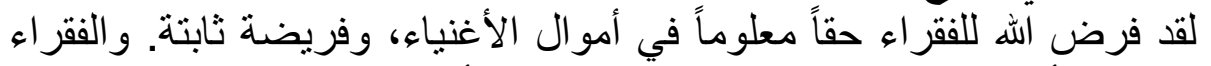

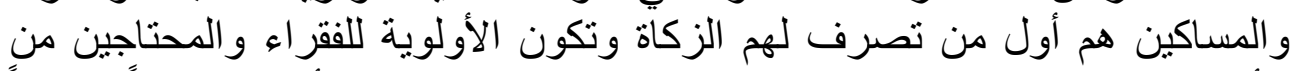

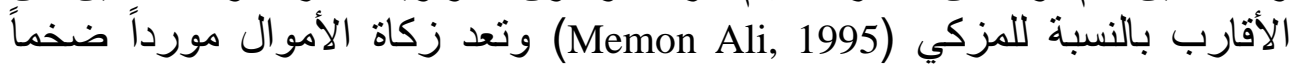

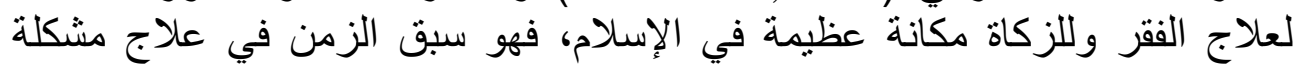

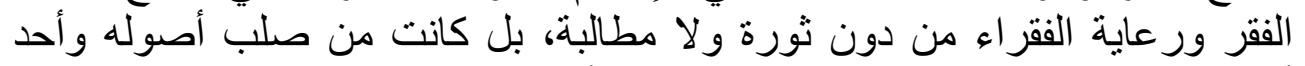

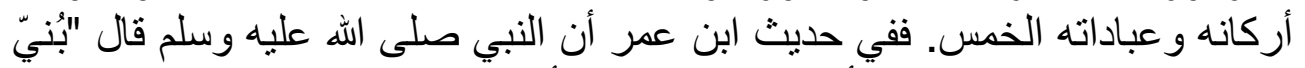

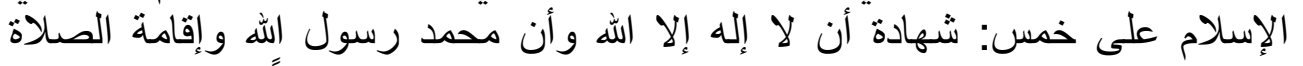

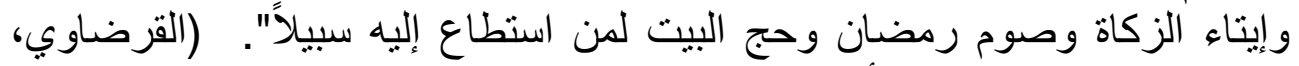

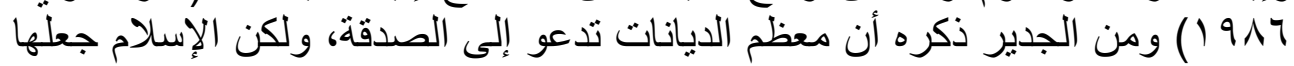

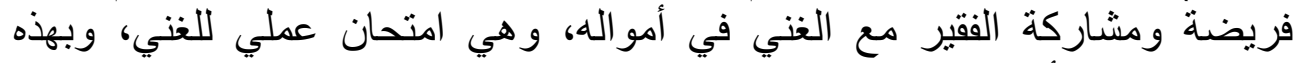
الطريقة تبنى الأخوة الحقيقية بين الغني و الفقير (Galwash, Ahmad). 
دكتور الرفاتي [199]

للزكاة آثار متعددة على المجتمع و والفرد وهي بالثكل الآتي: (Hammudah,1990)

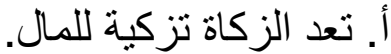
ب. الزكاة تطهر النفس من داء البـاء البخل و الثنح وتزكيها.

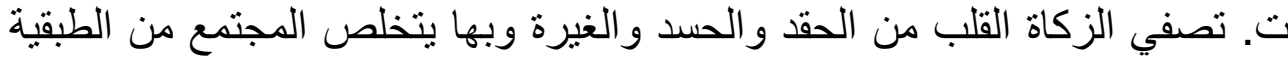

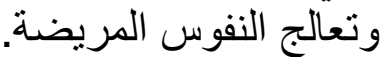
ث. الزكاة شكل صحي للأمان الداخلي ضد الطمع و النزاع الاجتماعي والتجاوز على لئ

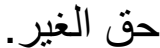

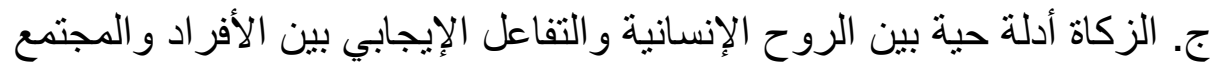

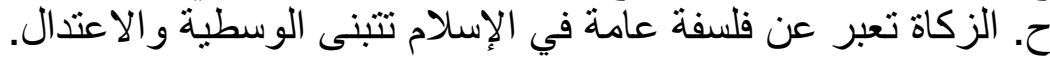

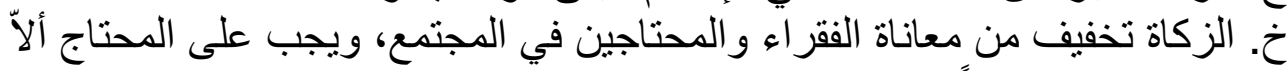
يعتمد عليها كلياً و إنما يعمل قدر المسنطاع.

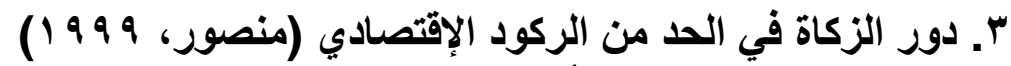

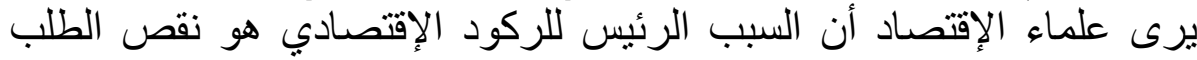

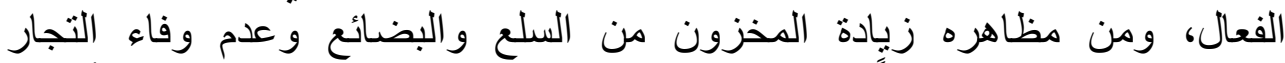

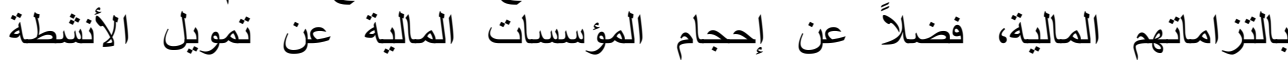

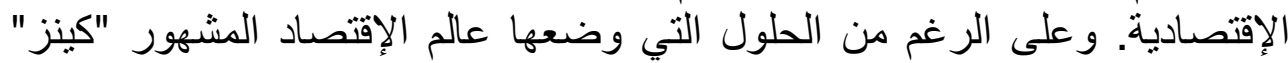

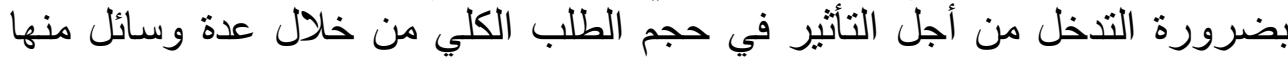

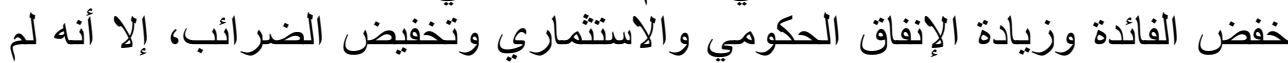

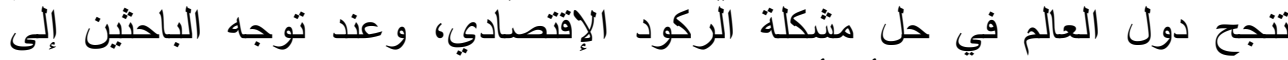

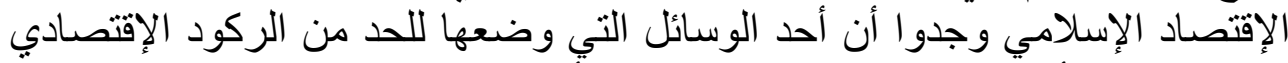

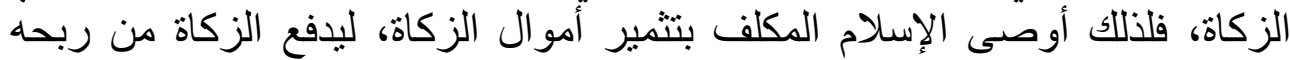

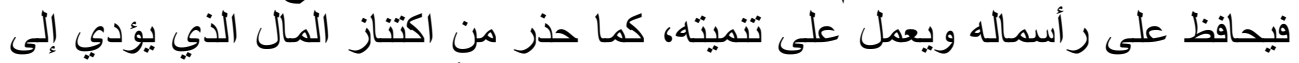

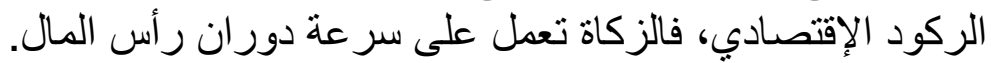

؛ـ أثر الزكاة في توزيع الدخل والثروة (عبد السلام، ـ 9191)

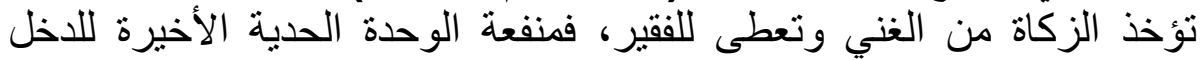

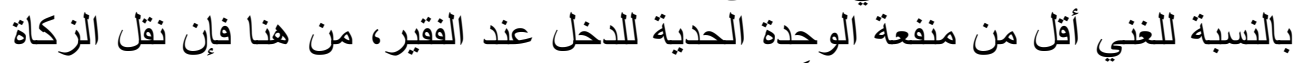

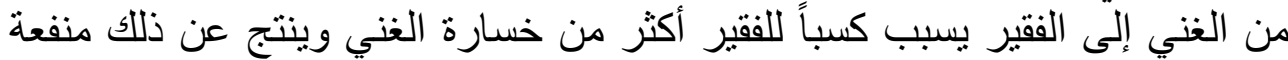

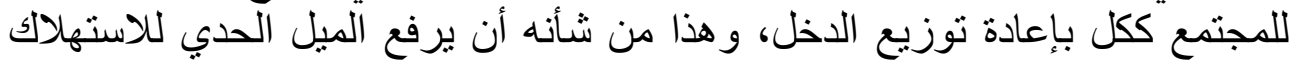

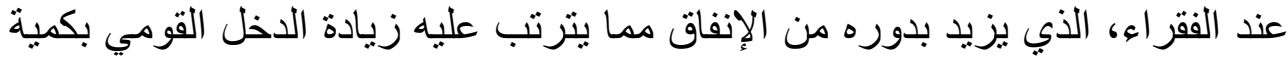

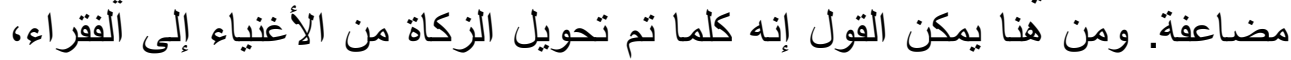

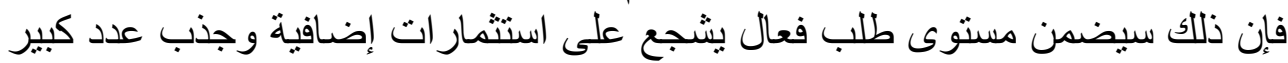
من العمالة فتسهم في الحد من البطالة والركود الرئ الإقتصادي.

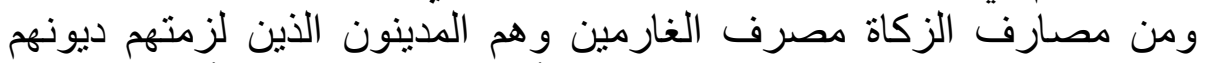
وعجزوا عن سدادها ولم يكن دينهم في معصية، أو الذين استدانوا من أجل الإصلاح 


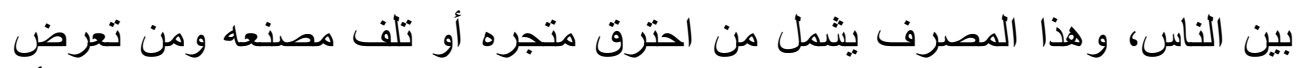

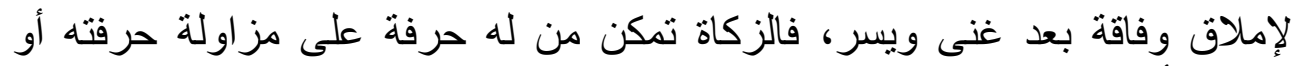

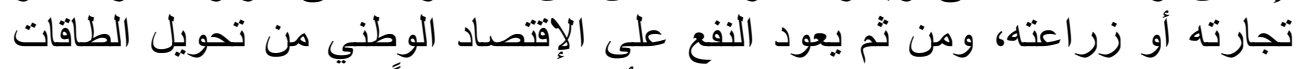

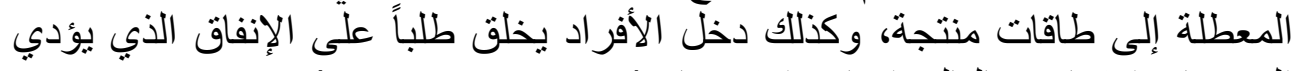
إلى زيادة الانتاج وبالتالي إنعاش الإقتصاد (World Bank, 1996).

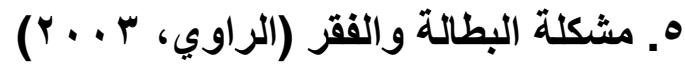

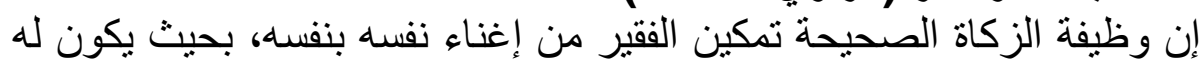

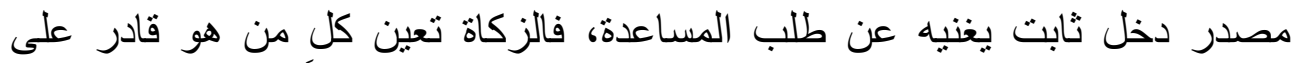

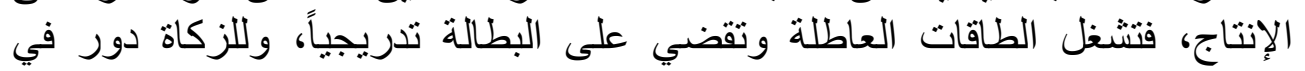

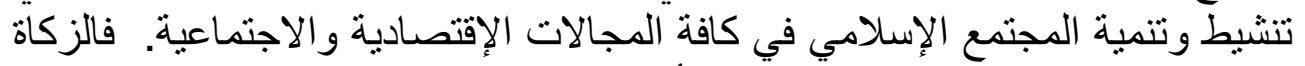

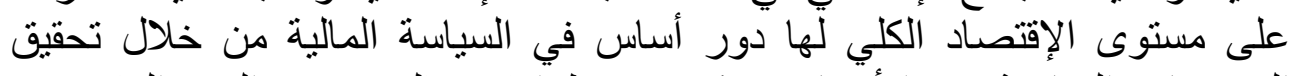

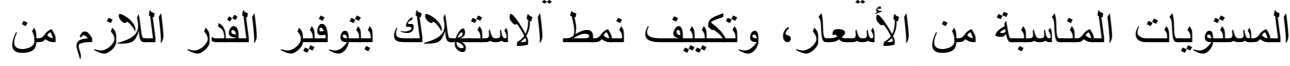

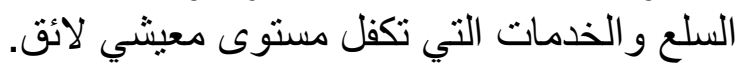

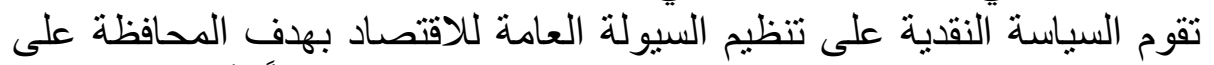

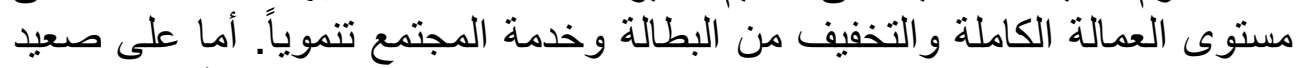

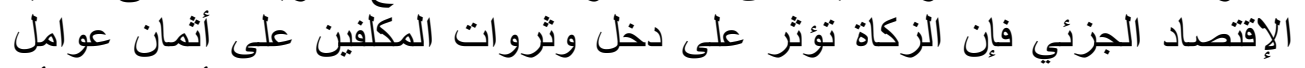

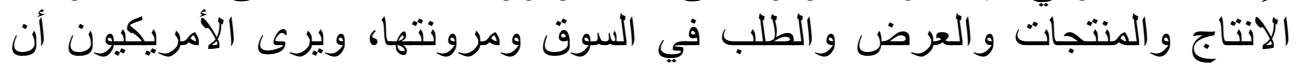

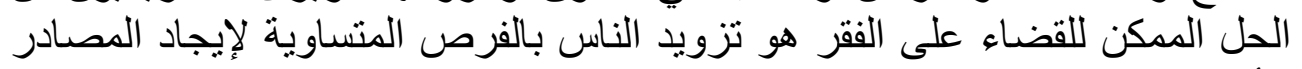

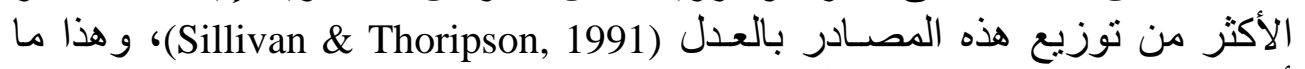

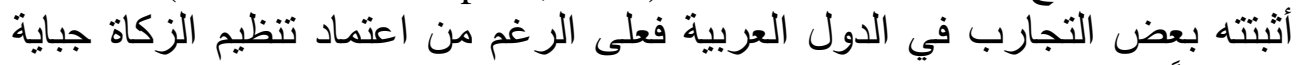

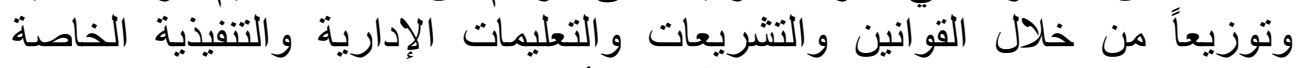

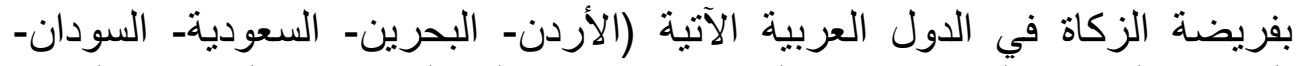

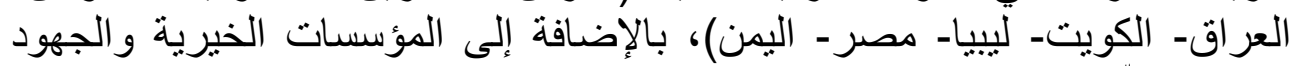

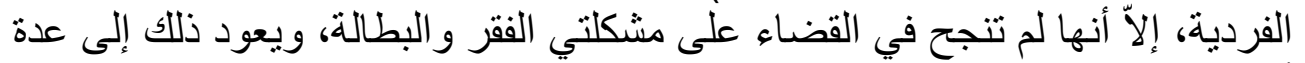
أسباب منها (Amartya, 1997). أ. ضعف الوازب ألوع الديني و غياب الوعي بأحكام الزكاة.

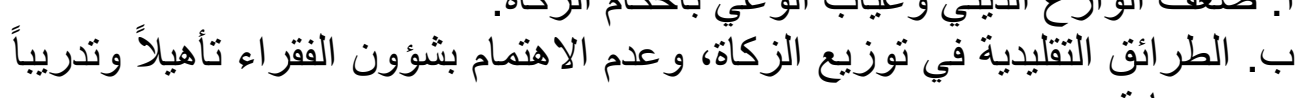
ور عاية. ت. اعتماد مؤسساً الزكاة على التدفقات النقدية و العينية وتصريفها في الوقت نفسه جباية وتوزيعاً. ث. اختلاف طر ائق الإنفاق وتتويع أساليبها بين الأفراد و المؤسسات المختصة

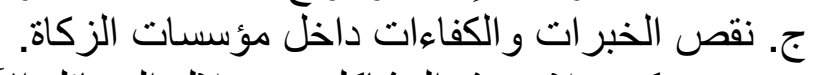
ويمكن علاج هذه الششاكل من خلال الوسائل الآتية:

(http://www.55a.netlalzakat.htm) 1. الاهتمام بمؤسسات الزكاة علماً وعملاً. r. ت تنسيق الجهود بين بيوت الزكاة الزكاة. 
دكتور الرفاتي [ [

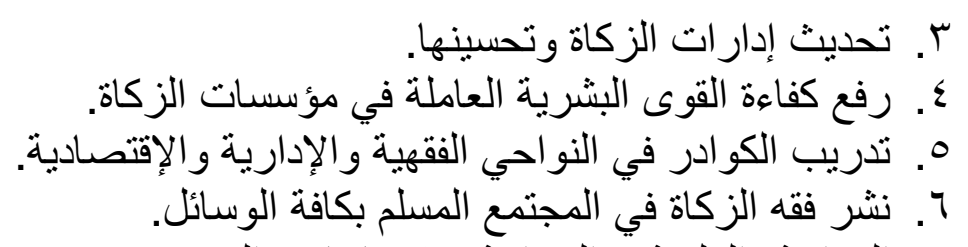

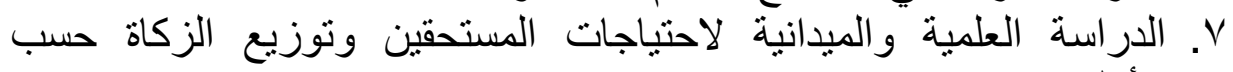

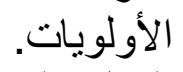

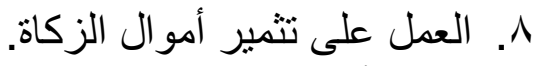

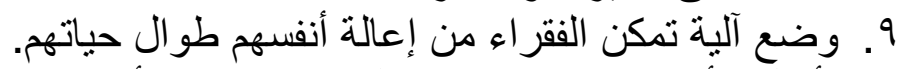

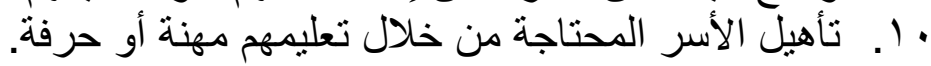

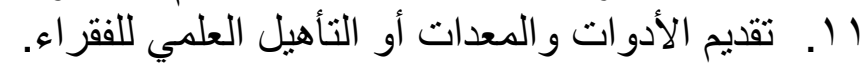

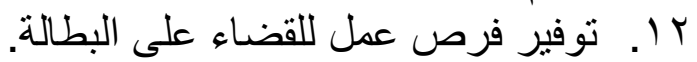

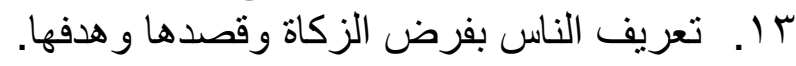

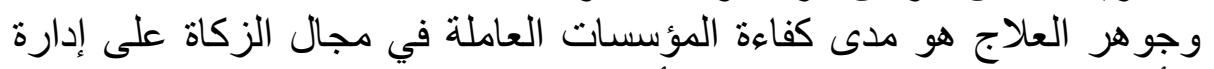

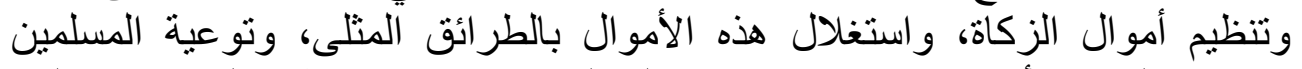

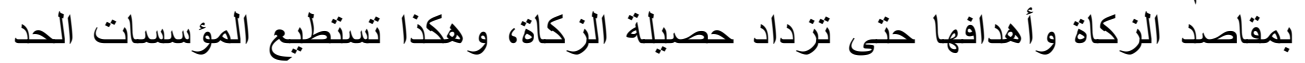
من ظاهرة الفقر و القضاء عليها.

\section{r. - ب الزكاة تكافح الفقر}

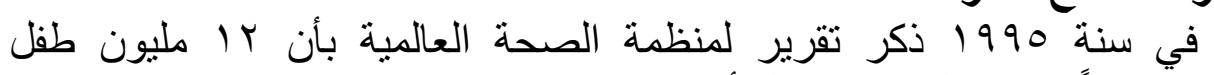

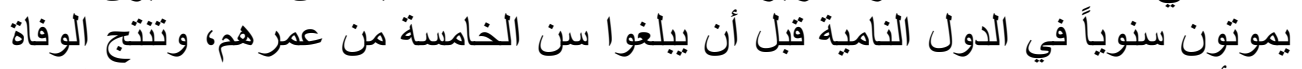

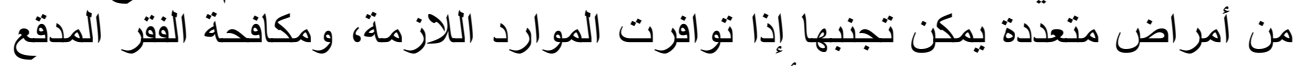

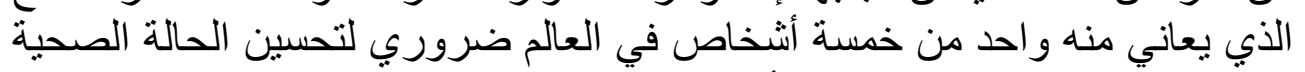

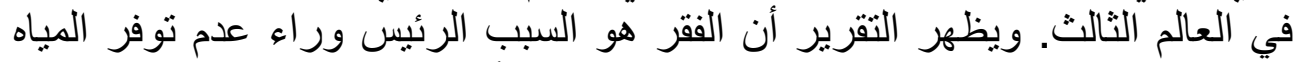

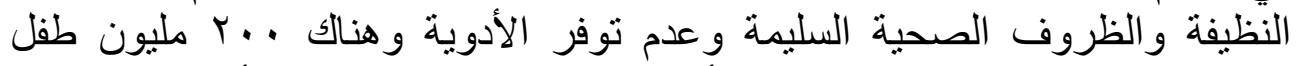

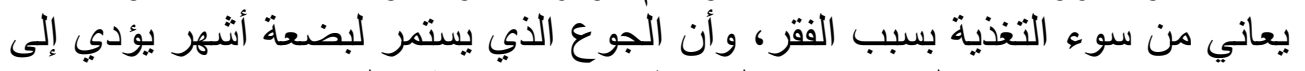

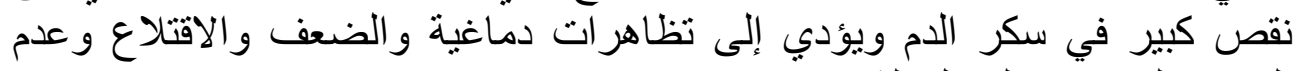

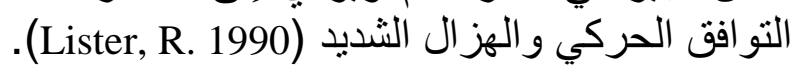

ثانياً - الاراسة التطبيقية

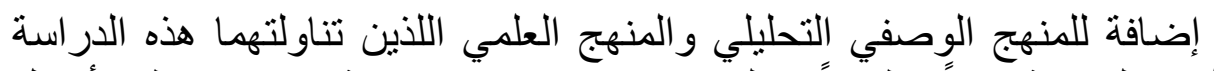

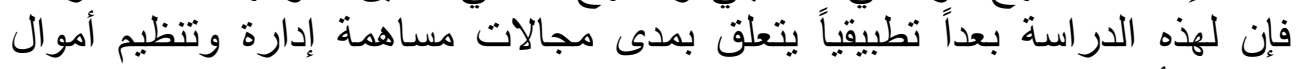

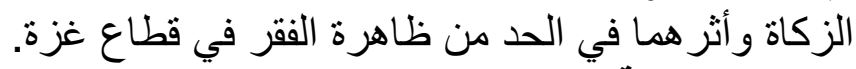
مجتمع الاراسة

يتكون مجتمع الدراسة من العاملين في الوظائف العليا في المؤسسات الخيرية

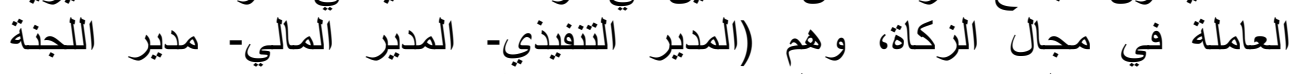

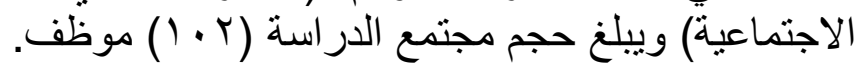




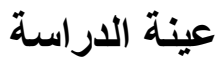

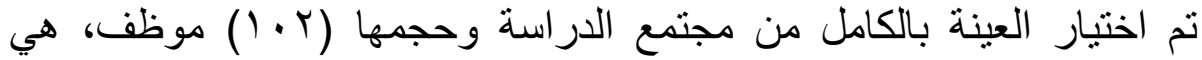

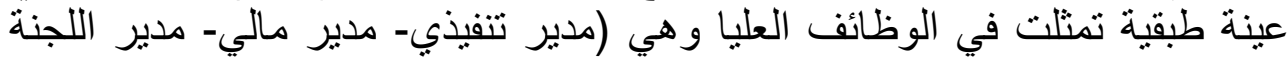

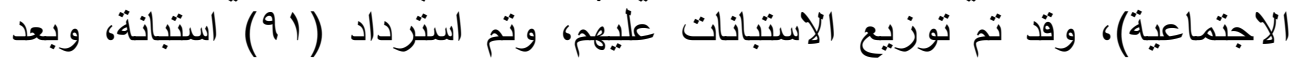

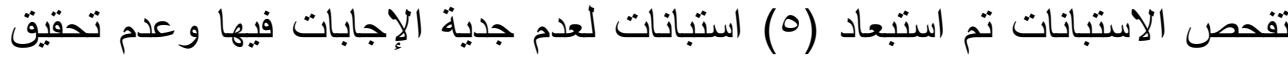

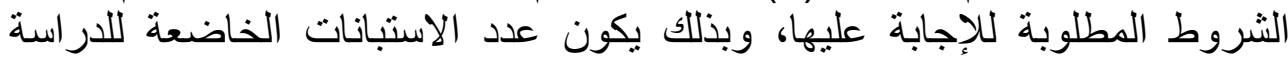

تم استخدام الاستبانة بوصفها إحدى أدوات الدراسة، وقد تم تقسيم الاستبانة إلى الى

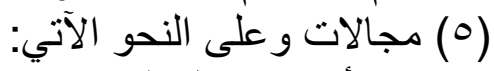

المجال الأول: يتناول الكفاءة الإدارية و التنظيمية، ويتكون من · ب فقرة.

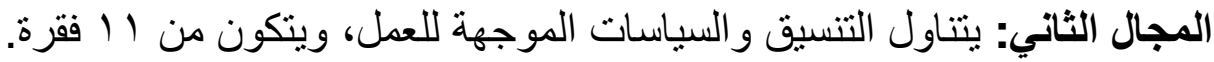

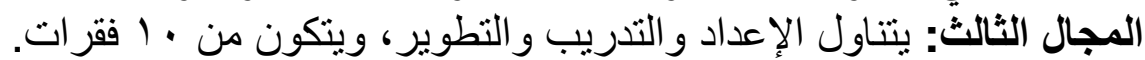

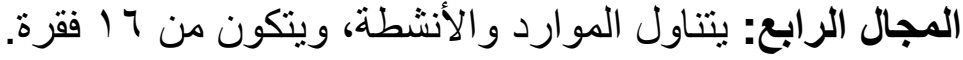

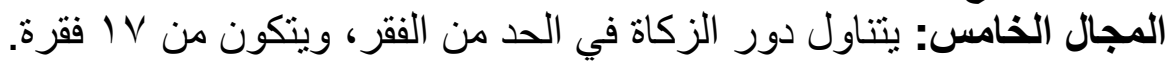
صدق الاستبانة وثباتها - صدق فقرات الاختبار: قام الباحث بالتأكد من صدق فقرات الاختبار بطريقتين.

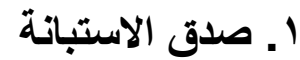

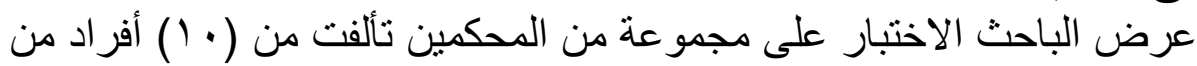

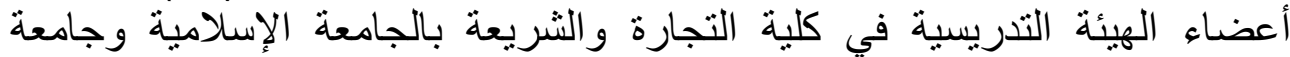

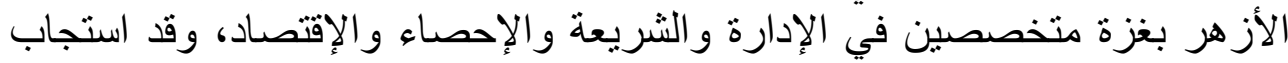

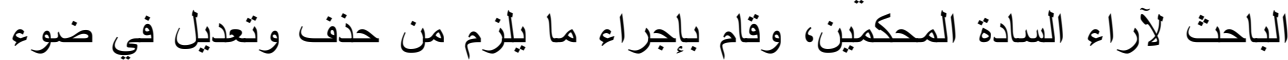

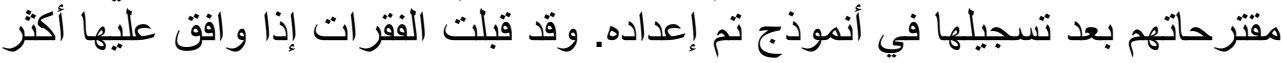

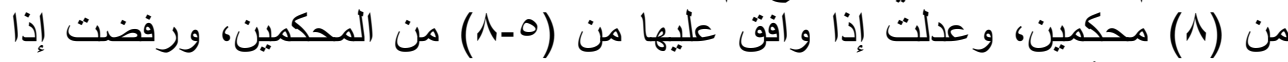

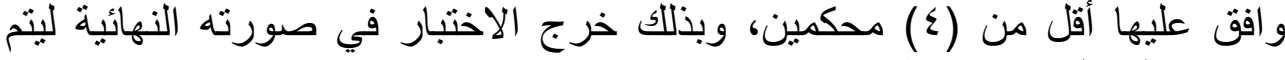
تطبيقه على العينة الاسنطلاعية.

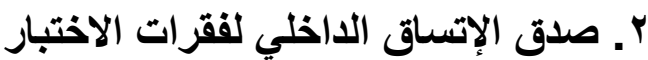

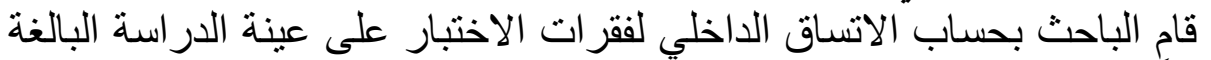

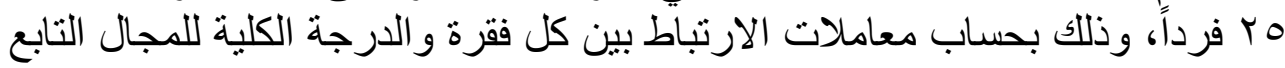

$$
\text { المجال الأول }
$$

يبين الجدول ا معاملات الارتباط بين كل فقرة من فقرات المجال الثالث

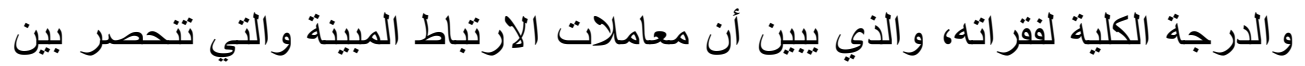


دكتور الرفاتي [Vr

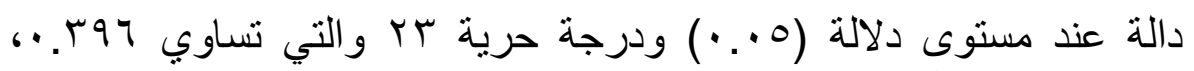
وبذلك تعد فقرات المجال الثالث صادقة لما وضعت لقدياسه.

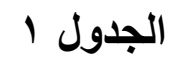

معاملات الارتباط بين كل فقرة من فقرات المجال و الارجة الكلية لفقراته

\begin{tabular}{|c|c|c|c|}
\hline مستوى المعنوية & الارتباط معامل & الققرة & تسلسل \\
\hline$\because \cdots 1$ & .701 & تعد المؤسسة موازنة خاصة للزكاة كل عام & 1 \\
\hline$\because \cdots 1$ & $.70 \leqslant$ & يوجد في المؤسسة هيكل إداري خاص بالزكاة & r \\
\hline$\because \cdots$ & $.0 \vee 7$ & تهتم المؤسسة بالمشاريع التنموية & r \\
\hline$\because$. Tr & $\cdot \Sigma \Gamma \wedge$ & تهنم المؤسسة بالمشاريع الانتاجية & $\varepsilon$ \\
\hline$\because \cdot r r$ & $\because \leqslant 70$ & تضع المؤسسة خطة للوصول للاكتفاء الذاتي & 0 \\
\hline$\because \cdots$ & $\cdot .7 \vee 7$ & تتوقع المؤسسة زيادة إير ادات الزكاة في السنوات القادمة & 7 \\
\hline$\because \varepsilon r$ & $\cdot \varepsilon \cdot V$ & للمؤسسة معايير لتوزيع الزكاة على مستحقيها & $\mathrm{V}$ \\
\hline .10 & $\because \leqslant 9$ & المؤسسة توزع الزكاة وفق موازنة سنوية & $\Lambda$ \\
\hline$\because \cdots$ & $.0 \vee 9$ & تدرس المؤسسة علمياً وميدانياً احتياجات المستحقين للزكاة & 9 \\
\hline$\because \cdots 1$ & $\cdot .7 T \leq$ & لاى المؤسسة معايير لتوزيع الزكاة على مصارفها & $1 \cdot$ \\
\hline$\because \cdots$ & $\because V Y V$ & يوجد في المؤسسة صندوق مستقل لجباية الزكاة & 11 \\
\hline$\therefore \cdots$ & $\cdot .771$ & يتميز أداء العاملين في مجال الزكاة في المؤسسة بالكفاءة & IT \\
\hline$\because r$ & $.09 \mathrm{~V}$ & المؤسسة تقوم بالاستغلال الأمثل لأمو ال الزكاة & 14 \\
\hline 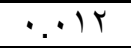 & $.0 . r$ & الظروف السياسية تقف عائقاً أمام المؤسسة و إدارة الزكاة بكفاءة & $1 \varepsilon$ \\
\hline$\because \cdots$ & $\because . O V Y$ & لاى المؤسسة مدقق حسابات داخلي & 10 \\
\hline$\because \cdots$ & $\cdot .79 \mathrm{~V}$ & لاى المؤسسة مدقق حسابات خارجي & 17 \\
\hline$\because \cdots 1$ & $\cdot .7 Y \leqslant$ & المؤسسة نشرف وتوجه العاملين في الزكاة عند جبايتها & iv \\
\hline$\because \cdots$ & $\because \wedge \varepsilon \cdot$ & للمؤسسة لجنة رقابة تنابع الجانب الثرعي للزكاة & 11 \\
\hline$\because \cdots$ & .701 & للمؤسسة لجنة رقابة تتابع الجانب الإداري للزكاة & 19 \\
\hline$\because \cdots$ & $.09 \pi$ & تقدم المؤسسة حو افز للعاملين في جباية الزكاة & r. \\
\hline
\end{tabular}

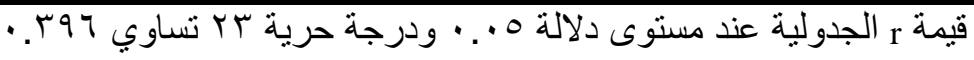

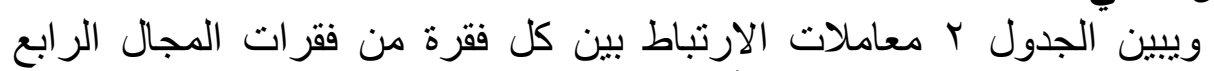

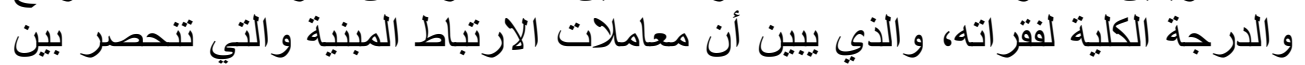

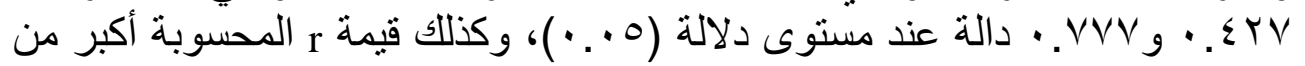

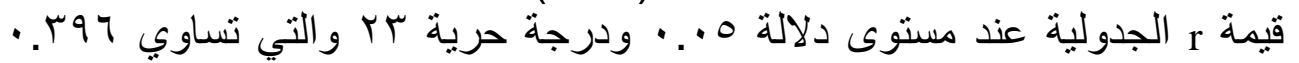
وبذلك تعد فقرات المجال الر ابع صادقة لماندة وضنعت لقياسه.

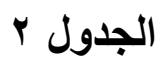

معاملات الارتباط بين كل فقرة من فقرات المجال والارجة الكلية لفقراته

\begin{tabular}{|c|c|c|c|}
\hline المعنوية & الارتباط & الفقرة & تسلسل \\
\hline
\end{tabular}




\begin{tabular}{|c|c|c|c|}
\hline$\because \cdots 1$ & $.7 Y V$ & تجبي المؤسسة الزكاة وتضعها في صندوق موحد بين مؤسسات الزكاة & 1 \\
\hline$\because r q$ & $\cdot \varepsilon r V$ & تتسق المؤسسة مع مثيلاتها عند إنشاء المشاريع & r \\
\hline$\because \cdots$ & $\cdot .7 \wedge \mathrm{V}$ & تضع المؤسسة سياسة موحدة لتوزيع الزكاة مع مثيلاتها & $r$ \\
\hline$\because \cdots$ & $\because V Y I$ & تتصف سياسة المؤسسة مع مثيلاتها بالتكاملية & $\varepsilon$ \\
\hline . & $\cdot \varepsilon r V$ & تعد المؤسسة من ذوات التخصص & 0 \\
\hline$\because \cdots$ & $\because \mathrm{VVV}$ & توجد قاعدة بيانات موحدة بين المؤسسة ومثيلاتها & 7 \\
\hline$\because \cdots \varepsilon$ & $.00 \mathrm{~T}$ & تعمل المؤسسة في مناطق جغر افية محددة & $\mathrm{V}$ \\
\hline$\because \cdots$ & $\cdot .7 \wedge 9$ & حققت المؤسسة أهدافها من خلال الزكاة & $\Lambda$ \\
\hline$\because \cdots r$ & .091 & تحدث المؤسسة إدار ات الزكاة بشكل مستمر & 9 \\
\hline$\because \cdots$ & .09 & تسعى المؤسسة للحد من الازدو اجية بين المؤسسات & 1 . \\
\hline$\because \cdots 1$ & .749 & تتسق المؤسسة مع وزارة الشؤون الاجتماعية & 11 \\
\hline
\end{tabular}

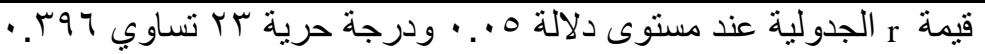

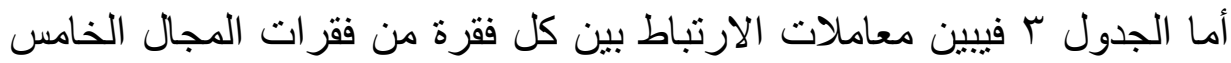

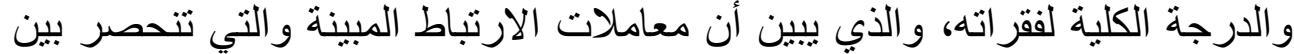

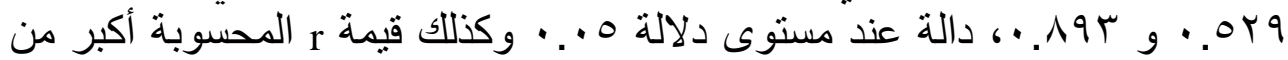

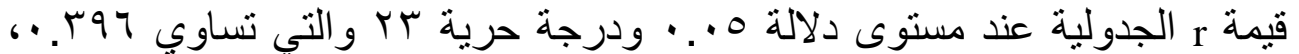
وبذلك تعد فقر ات المجال الخامس صادقة عندة لما وضعت لقياسه.

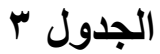

معاملات الارتباط بين كل فقرة من فقرات المجال والدرجة الكلية لفقراته

\begin{tabular}{|c|c|c|c|}
\hline المعنوية مستوى & 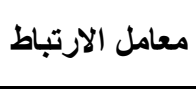 & 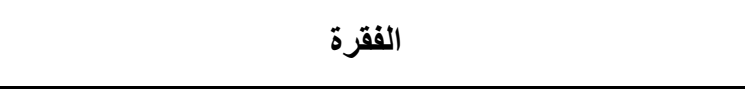 & 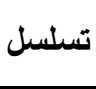 \\
\hline$\because \cdots 1$ & .717 & تو اكب المؤسسة التكنولوجيا عبر حوسبة المعلومات و البيانات & 1 \\
\hline$\because \cdots$ & $.0 \leqslant 7$ & تستخدم المؤسسة وسائل التكنولوجيا الحديثة في مكاتبها & r \\
\hline$\because \cdots$ &.$\vee 991$ & تسعى المؤسسة بشكل مستمر لتطوير أداء العاملين & $r$ \\
\hline$\because \cdots$ &.$\wedge 9 \mu$ & تقوم المؤسسة بتدريب الموظفين فقهياً & $\varepsilon$ \\
\hline$\because \cdots$ &. $\mathrm{VAr}$ & تقوم المؤسسة بتدريب الموظفين إدارياً & 0 \\
\hline$\because \cdots V$ & $.0 Y 9$ & تقوم المؤسسة بتدريب الموظفين اقتصادياً & 7 \\
\hline$\because \cdots$ &.$\vee \wedge \wedge$ & تقدم المؤسسة حو افز للعاملين في جباية الزكاة & $\mathrm{V}$ \\
\hline$\because \cdots$ & $\because \vee 0$ & يوجد في المؤسسة مكان مهيأ ومجهز للعاملين في الزكاة & $\Lambda$ \\
\hline$\because \cdots$ & .790 & تشعر بالرضا عن أداء مؤسستلك & 9 \\
\hline$\because \cdots$ & $.7 \vee 7$ & تختار المؤسسة الموظفين في الزكاة على وفق معايير & $1 \cdot$ \\
\hline
\end{tabular}

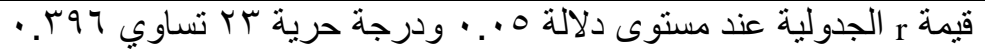

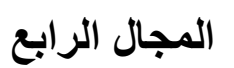

يبين الجدول ع معاملات الارتباط بين كل فقرة من فقرات المجال السادس التهاس

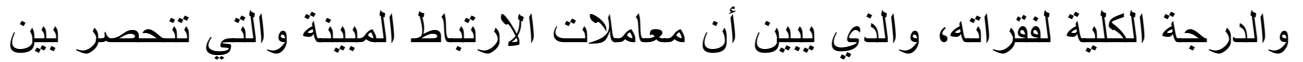

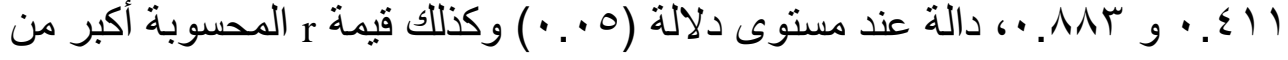


دكتور الرفاتي [V00

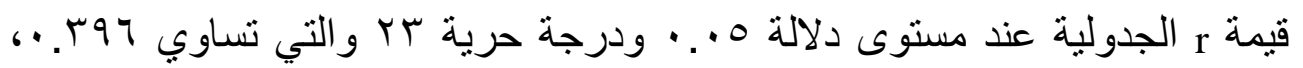
وبذلك تعد فقر ات المجال السادس صلادقة لها لما وضعت لقياسه.

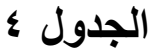

معاملات الارتباط بين كل فقرة من فقرات المجال والارجة الكلية لفقراته

\begin{tabular}{|c|c|c|c|}
\hline مستوى المعنوية & الارتباط معامل & الفقرة & 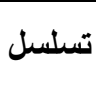 \\
\hline.$\cdot 1 \mathrm{~T}$ & $\cdot .297$ & تجني المؤسسة أغلب الزكاة في رمضان & 1 \\
\hline$\because \cdots 1$ & $.7 \pi r$ & توزع المؤسسة أغلب زكاتها في شهر رمضان & $\bar{r}$ \\
\hline$\because \cdots$ & $.70 \leq$ & تجبي المؤسسة أغلب زكاته في رمضان & r \\
\hline$\because \cdots$ &. .791 & توزع المؤسسة الزكاة على مدار العام & $\varepsilon$ \\
\hline$\cdot \cdots$ & .701 & تدعم المؤسسة جهود العلماء لدر اسة القضايا الفقهية الإقتصادية للزكاة & 0 \\
\hline$\because \cdot 1$ & $\because 0.1$ & تعنمد المؤسسة على التمويل الخارجي للزكاة & 7 \\
\hline. $\mathrm{r \Lambda}$ & $\cdot . \S \wedge$ & تعتمد المؤسسة على التمويل الداخلي للزكاة & $\mathrm{V}$ \\
\hline$\because \cdots$ &. .119 & تنشر المؤسسة فقه الزكاة في المجتمع بشتى الوسائل & $\Lambda$ \\
\hline$\because \cdots$ &.$\vee \vee V$ & تقوم المؤسسة بجباية زكاة المال & 9 \\
\hline$\because \cdots$ & $\cdot \wedge \vee 0$ & تقوم المؤسسة بجباية زكاة الزروع & $1 \cdot$ \\
\hline$\because \leqslant 1$ & $\cdot .211$ & تقوم المؤسسة بجباية الزكاة الفطر & 11 \\
\hline$\because \cdots$ & $. \wedge Y \leq$ & تقوم المؤسسة بجباية زكاة الإبل و الماشية و الأغنام & ir \\
\hline$\because \cdots$ &..$\vee 99$ & تقوم المؤسسة بجباية عروض التجارة & $\pi$ \\
\hline$\because \cdots$ & $\cdot . \wedge \wedge \mu$ & تقوم المؤسسة بجباية زكاة المستغلات "العقارات" & $1 \varepsilon$ \\
\hline$\because \cdots$ &.$V 9 r$ & تقوم المؤسسة بجباية زكاة الأسهم & 10 \\
\hline$\because \cdots$ & .791 & تعد المؤسسة حملات لجباية الزكاة & 17 \\
\hline
\end{tabular}

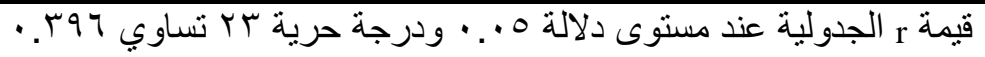

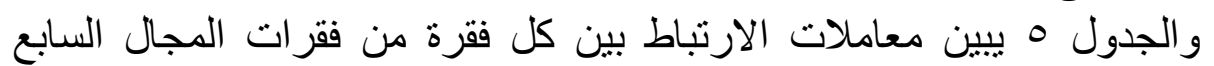

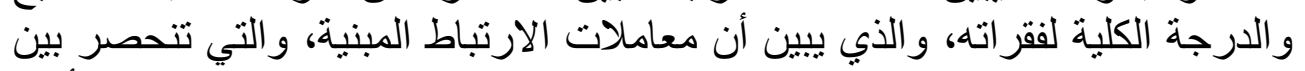

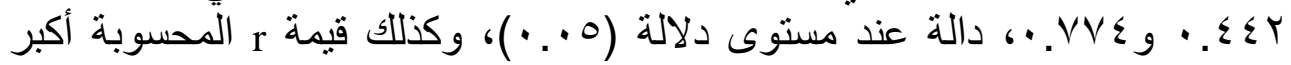
من قيمة r الجدولية عند مستوى دلالة هالة.

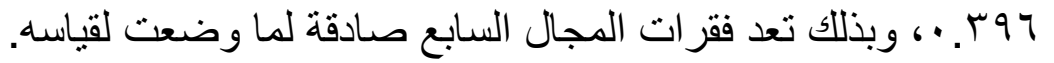

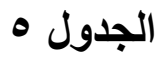

معاملات الارتباط بين كل فقرة من فقرات المجال والارجة الكلية لفقراته

\begin{tabular}{|c|c|c|c|}
\hline المعنوية & الارتباط معامل & الفقرة & 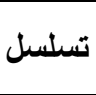 \\
\hline$\because \varepsilon \varepsilon$ & 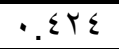 & تقدم المؤسسة الأدو ات و المعدات للفقر اء. & 1 \\
\hline$\because$. YA & 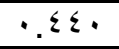 & توزع المؤسسة الزكاة حسب الأولويات. & r \\
\hline. $.1 r$ &.$£ 97$ & تضع المؤسسة آلية لتمكن الفقر اء من إعالة أنفسهم طو ال حياتهح & $r$ \\
\hline$\because \mu$ & .071 & تؤهل المؤسسة الأسر المحتاجة من خلال تعليمهر حرفة & $\varepsilon$ \\
\hline$\because \cdots$ & $\cdot . V \cdot 7$ & تقدم المؤسسة التأهيل العلمي للفقر اء & 0 \\
\hline
\end{tabular}




\begin{tabular}{|c|c|c|c|}
\hline$\because \cdots$ & $\because \vee \vee \varepsilon$ & تقدم المؤسسة التأهيل العملي للفقر اء & 7 \\
\hline$\because \cdots$ & $\because \vee \vee$ & توظف المؤسسة أصحاب الكفاءة من الفقر اء & $7^{\prime}$ \\
\hline$\because \cdots 7$ & .040 & لاى المؤسسة مشاريع بطالة لتشغيل الفقر اء & $\Lambda$ \\
\hline$\therefore \cdots$ &. $\mathrm{VRT}$ & تستو عب المؤسسة الفقر اء في مشاريعها التتموية & 9 \\
\hline$\because \cdots 1$ & $.7 \cdot 7$ & تستو عب المؤسسة الفقر اء في مشاريعها الإنتاجية & 1. \\
\hline$\because \cdots$ & $\because V Y \wedge$ & تخصص المؤسسة جزءاً من الزكاة للتنمية وتشغيل الفقر اء & 11 \\
\hline$\because \cdots 1$ & $\cdot .7 \cdot 1$ & تقدم المؤسسة الإرشـاد الديني للفقر اء & $\overline{T r}$ \\
\hline$\because \cdots$ & $\cdot$ Vor & تقدم المؤسسة الرعاية الصحية للفقر اء & IT \\
\hline$\therefore \cdots$ & $. V / r$ & تقدم المؤسسة الإرشاد النفسي للفقر اء & $1 \varepsilon$ \\
\hline$\because \cdots$ &.$V T r$ & تقدم المؤسسة الإرشاد الاجتماعي للفقر اء & 10 \\
\hline$\because \cdots 1$ & .7 .0 & تقدم المؤسسة المساعدات النقدية للفقر اء & 17 \\
\hline$\because \cdots$ & .071 & تقدم المؤسسة المساعدات العينية للفقر اء & IV \\
\hline
\end{tabular}

\section{الصدأق البناتي لمجالات الاستباتئة}

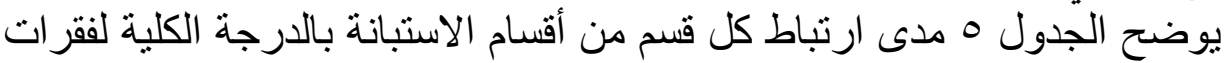

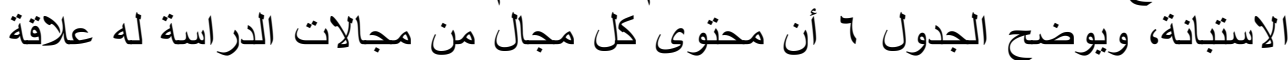

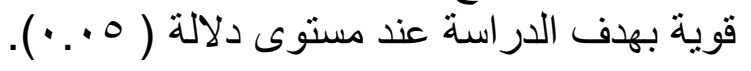

\begin{tabular}{|c|c|c|c|}
\hline \multicolumn{4}{|c|}{ الصدق البنائي لمجالات الدراسة } \\
\hline مستوى الالالة & معامل الارتباط & عنوان المجال & 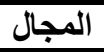 \\
\hline$\because \cdots$ & $\cdot \wedge \varepsilon$ & الكفاءة الإدارية و التنظيمبة & الأول \\
\hline$\because \cdots$ & $\cdot . \wedge \vee q$ & التتسيق و السياسات الموجهة للعمل & الثاني \\
\hline$\because \cdots$ &. .791 & الإعداد و التتريب و التطوير & الثالث \\
\hline$\because \cdots$ & $\therefore$ VYO & المو ارد و الأنشطة & 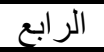 \\
\hline$\because \cdots$ & $\cdot . \mathrm{VO \Lambda}$ & دور الزكاة في الحد من الفقر & 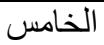 \\
\hline
\end{tabular}

Reliability ثبات الاستبانة وقد أجرى الباحث خطوات الثبات على العينة الاستطلاعية نفسها بطريقتين هما طريقة التجزئة النصفية ومعامل ألفا كرونباخ.

طريقة التجزئة النصفية Split-Half Coefficient تم إيجاد معامل ارتباط بيرسون بين معدل الأسئلة الفردية الرتبة ومعدل الأسئلة

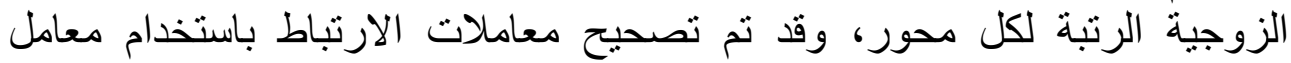
ارتباط سبيرمان- بروان للتصحيح (Brown- Coefficent Spearman) حسب التبات المعادلة

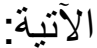
معامل الثبات = هنالك معامل ثبات مرتفع لفقرات الاستبيان. 


\begin{tabular}{|c|c|c|c|c|c|}
\hline \multicolumn{6}{|c|}{ 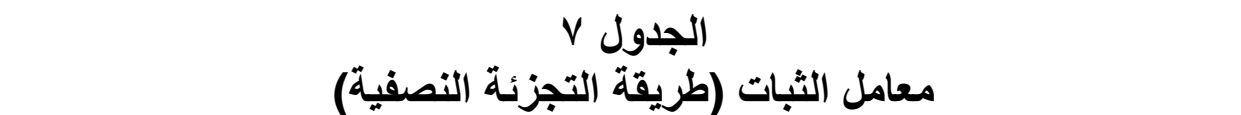 } \\
\hline المعنوية & معامل الثبات & الارتباط & الفقرات & عنوان المجال & 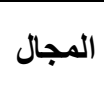 \\
\hline$\because \cdots$ & $\cdot A V \cdot \Lambda Y Y$ &.$V V I Y$ & $r \cdot$ & الكفاءة الإدارية و التنظيمية & الأول \\
\hline$\because \cdots$ & $\cdot \lambda \cdot V \cdot r \Lambda$ & $. .7 \times 70$ & 11 & التتسيق و السياسات الموجهة للعمل & الثاني \\
\hline$\because \cdots$ & $\cdot \wedge \cdot \leqslant 1 \wedge 0$ &. $.7 V Y 0$ & 1. & الإعداد و التنريب و التطوير & الثالث \\
\hline$\because \cdots$ & $\cdot . \wedge$ QVVर & $\because V T K A$ & 17 & المو ارد و الأنشطة & الر ابع \\
\hline$\because \cdots$ & $\cdot \wedge Y \wedge) \leq \Lambda$ & $\cdot . \mathrm{V} \cdot \mathrm{TV}$ & IV & دور الزكاة في الحد من الفقز & 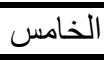 \\
\hline
\end{tabular}

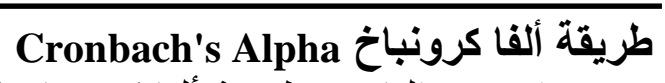

استخدم الباحث طريقة ألفا كرونباخ لقياس ثبات الاستبانة بوصفها طريقة ثانية الانية

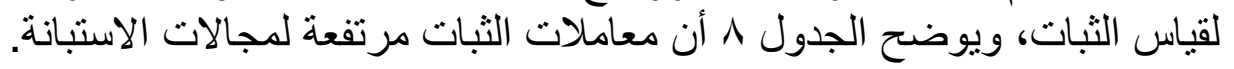

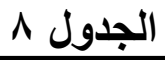

\begin{tabular}{|c|c|c|c|}
\hline \multicolumn{4}{|c|}{ معاملات الثبات (طريقة ألفا كرونباخ) } \\
\hline معامل ألفا كرونباخ & عدد الفقرات & عنوان المجال & 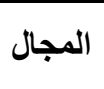 \\
\hline. .1079 & $r$. & الكفاءة الإدارية و التنظيمية & الأول \\
\hline$\cdot .1741$ & 11 & التنسيق والسياسات الموجهة للعمل & 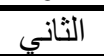 \\
\hline. .1109 & 1. & الإعداد و التدريب و التطوير & 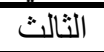 \\
\hline$\cdot . \wedge \wedge{ }^{\prime \prime \Lambda I}$ & 17 & المو ارد و الأنشطة & 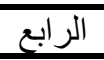 \\
\hline$\cdot . \wedge T 1 \wedge$ & IV & دور الزكاة في الحد من الفقر & 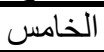 \\
\hline
\end{tabular}

\section{المعالجات الإحصائية}

لقد قام الباحث بتفريغ وتحليل الاستبانة من خلال برنامج SPSS الإحصائي وتم استخدام الاختبار ات الإحصائية الآتية:

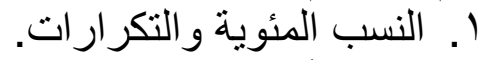

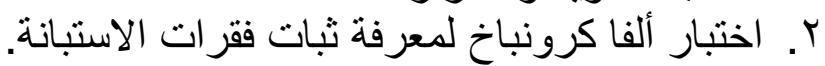

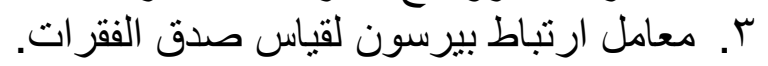

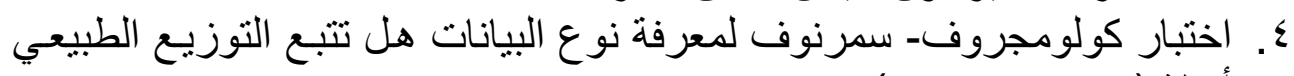

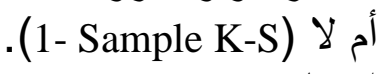

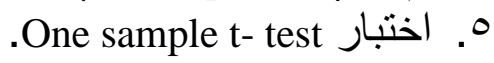
7. اختبار Independent Samples t- test P.

اختبار التوزيع الطبيعي ( اختبار كولمجروف- سمرنوف (1-Sample K-S)) 


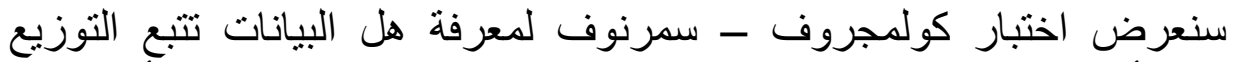

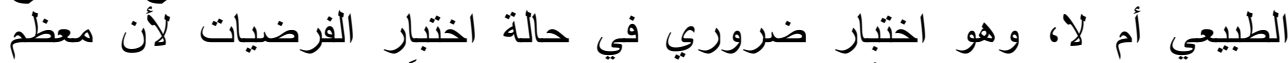

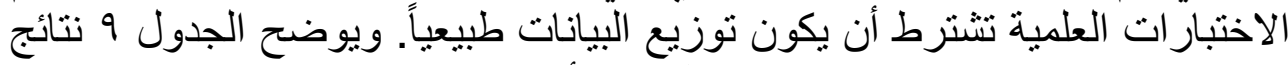

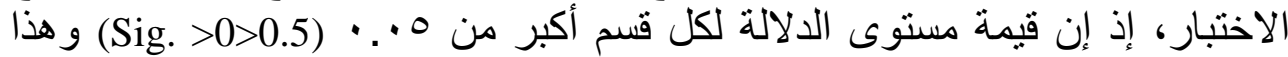
يدل على أن البيانات تتبع التوزيع الطبيعي ويجب استخدام الاختبار ات العلية العية.

\section{الجدول 9}

اختبار التوزيع الطبيعي (One-Sample Kolomgorov-Smirnov)

\begin{tabular}{|c|c|c|c|}
\hline $\begin{array}{l}\text { قيمة مستوى المعنوية } \\
\text { Sig. }\end{array}$ & قيمة Z & عنوان المجال & المجال \\
\hline 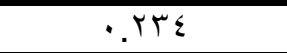 & $1 . \cdot 47$ & الكفاءة الإدارية و التنظيمية & الأول \\
\hline $.7 \mathrm{VO}$ & $\cdot . V Y 1$ & التتسيق و السياسات الموجهة للعمل & الثناني \\
\hline $.0 T \mathrm{~V}$ & $\cdot .1 .0$ & الإعداد و التنريب و التطوير & الثالث \\
\hline$\cdot .177$ &. $.77 \mathrm{~V}$ & الموارد و الأنشطة & الرابع - الر \\
\hline. .101 & .7 .0 & دور الزكاة في الحد من الفقر & الخامس - الخ \\
\hline$\cdot .104$ & $\cdot .7 \cdot 1$ & جميع الفقرات & \\
\hline
\end{tabular}

\section{تحليل فرضيات الدراسة}

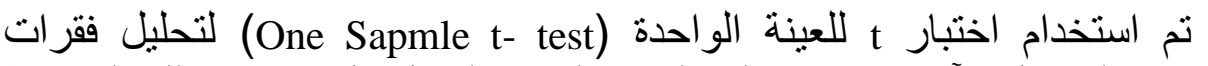
الاستبانة و الجداول الآتية تحتوي على النسبة المئوية لبدائل كل فقرة وكذلك الكئل المنوسط

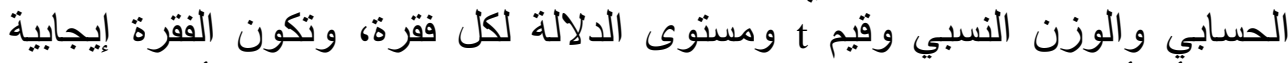

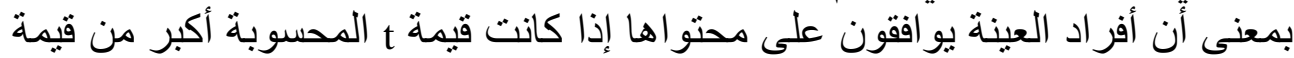

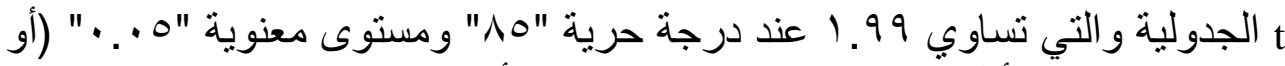

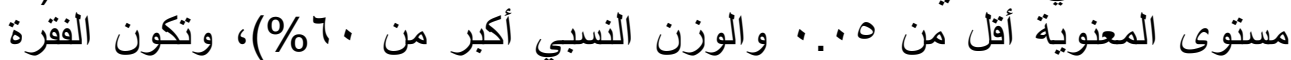

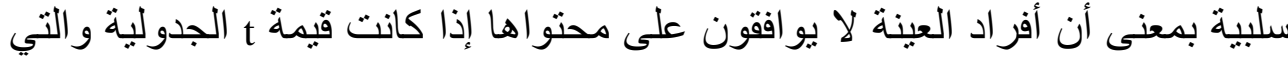

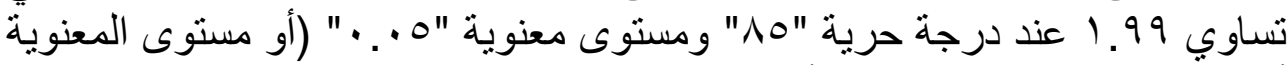

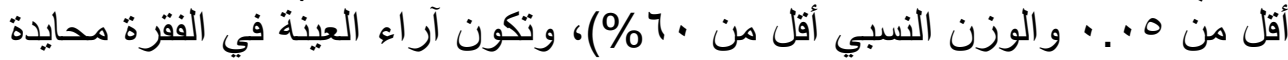

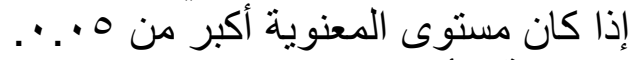
الفرضية الأولى: تعد المؤسسات الخيرية على مستوى مرتفع من الكفاءة الإدارية

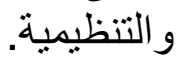

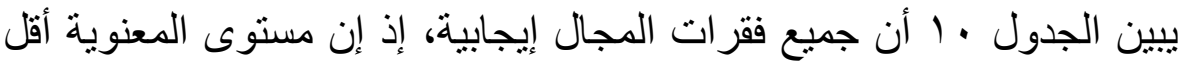

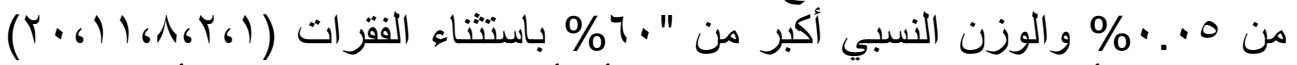

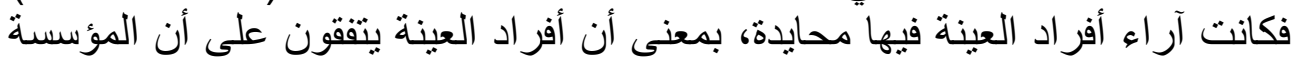

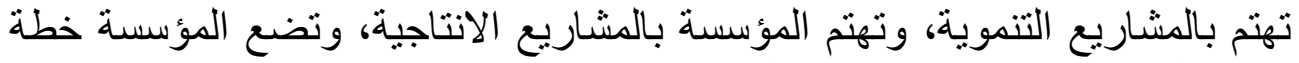

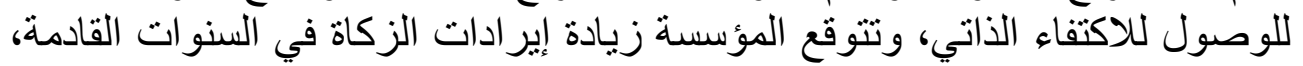




\section{دكa] [كتور الرفاتي}

وأن للمؤسسة معايير لتوزيع الزكاة على مستحقيها، وتدرس المؤسسة علمياً وميدانياً

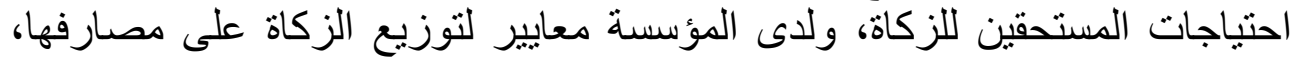

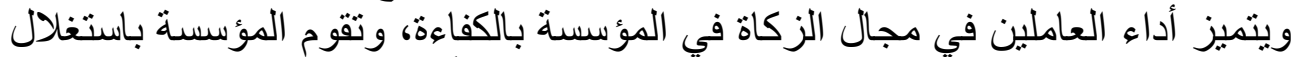

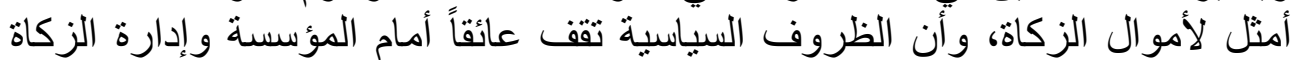

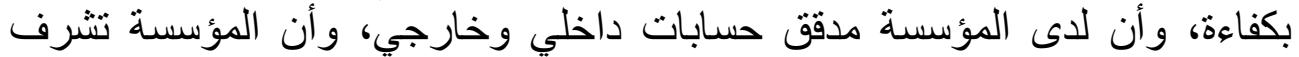

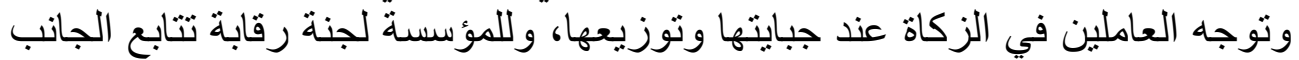

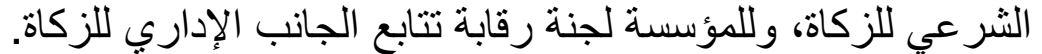

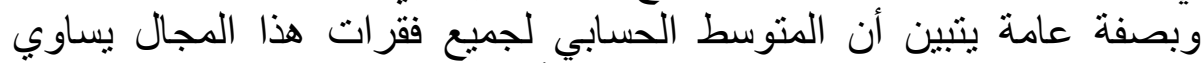

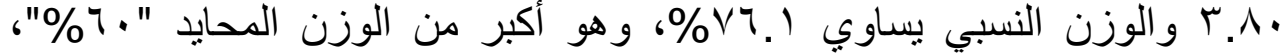

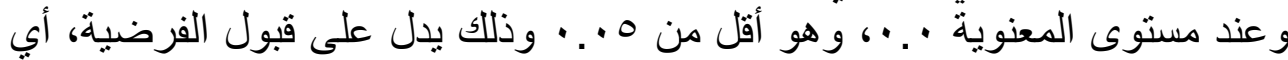
تعد المؤسسات الخيرية على مستوى مرتفع من الكفاءة الإدارية والتنظيمية.

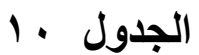

تحليل فقرات المجال الثالث (مجال الكفاءة الإدارية والتنظيمية)

\begin{tabular}{|c|c|c|c|c|c|c|c|c|c|c|}
\hline 寻哥 & :。 & 可雨 & 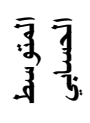 & 承 & $\stackrel{3}{3} \bigcirc$ & dำ & హ) & 高 & 湢 & : \\
\hline .VqY & T & 7.9 & $r . \cdot \varepsilon$ & $1 v .9$ & $r \cdot . q$ & $1 v .9$ & ro. $\varepsilon$ & $1 v .9$ & 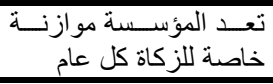 & 1 \\
\hline.$r r v$ & $\cdot .9 V$ & צ.rד & $r .17$ & $1 V . T$ & $1 V .7$ & 11.1 & r.^ & 17.5 & يوجد في إلمؤسسة هيكل & $r$ \\
\hline$\because \cdots$ & Q.YT & NI. & $\varepsilon .7$ & r.q & $\varepsilon . r$ & 11.7 & $\leqslant 7 . \leqslant$ & $r \varepsilon . \wedge$ & تهنتم المؤسسة بالمشاريع & $r$ \\
\hline$\because \cdots$ & $0 . \varepsilon$. & VT. & ז.ד & $r$. & 9.1 & YV.r & rv.q & rY.V & تهنتم المؤسسة بالمشاريع & $\xi$ \\
\hline$\because \cdots$ & 7.71 & Vo.0 & r.VA & 1.0 & $1 \cdot . \varepsilon$ & $1 v .9$ & $\varepsilon q . r$ & $r \cdot . q$ & 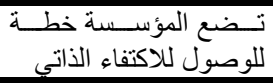 & 0 \\
\hline$\because \cdots$ & $T . M$ & Vo. 7 & r.vA & r. $q$ & $1 \cdot . r$ & $1 V . T$ & $\varepsilon \varepsilon .1$ & ro.. & 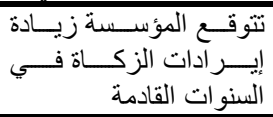 & 7 \\
\hline$\because \cdots$ & $\Lambda . M$ & הr.r & $\varepsilon .17$ & V.r & $\varepsilon . r$ & r.q & r.Y & $\varepsilon 9 . r$ & 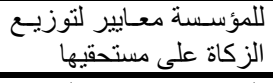 & $\mathrm{v}$ \\
\hline$\because .01$ & 1.94 & $70 . \mathrm{V}$ & T.rA & 9. & 18.9 & ro. & r. & $17 . \varepsilon$ & 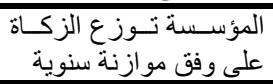 & $\Lambda$ \\
\hline$\because \cdots$ & 11.99 & Nr.r & $\{.17$ & $1 . \varepsilon$ & $\varepsilon . r$ & A.V & $\varepsilon \vee . \wedge$ & rV.V & 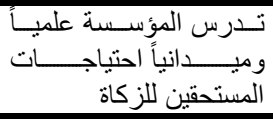 & 9 \\
\hline$\because \cdots$ & $1 ., r_{0}$ & NT.r & $\{.11$ & $1 . \varepsilon$ & $0 . V$ & $1 \cdot$. & $\leq 0 . V$ & rv. 1 & 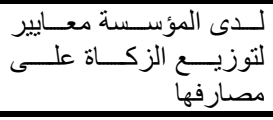 & 1. \\
\hline $.1+9$ & 1.0. & $7 \leqslant .7$ & T.זT & $11 . \varepsilon$ & 11.7 & $r \leqslant . r$ & rV.l & 11.7 & 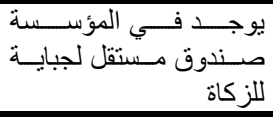 & 11 \\
\hline$\because \cdots$ & V.qr & $V V_{.1}$ & r.Aт & $\varepsilon . r$ & $1 . \varepsilon$ & $1 V . \varepsilon$ & $O \Lambda_{.}$ & $1 \wedge . \wedge$ & 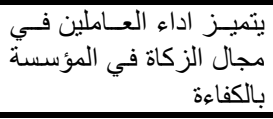 & Ir \\
\hline$\because \cdots$ & $1 Y .47$ & Ar.l & $\varepsilon .10$ & $\because$ & r.9 & $1 T . r$ & $0 \leqslant . \leqslant$ & $r 9 . \varepsilon$ & المؤسسة تقوم بالاستغلال & 14 \\
\hline
\end{tabular}




\begin{tabular}{|c|c|c|c|c|c|c|c|c|c|c|}
\hline 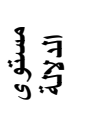 & 雪 & 事雨 & 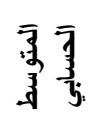 & 3 & 3. & $\stackrel{3}{\circ}$ & के & . & 霈 & 註 \\
\hline & & & & & & & & & الأمتُل لأمو ال الزكاة & \\
\hline$\because \cdots$ & $9 . £ 9$ & $\wedge \varepsilon$. & \&.r. & $r .9$ & $0 . V$ & $1 Y .9$ & ro.r & or. 9 & 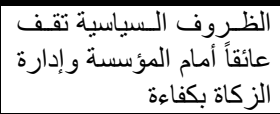 & $T \varepsilon$ \\
\hline$\because \cdots$ & Y.r. & $v a . \varepsilon$ & r.qv & r.9 & 14.9 & 1.7 & ro.v & $\varepsilon \cdot$. & 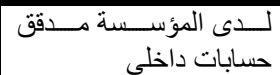 & 10 \\
\hline$\because \cdots$ & $1 \varepsilon . V$ & $\wedge \uparrow . \wedge$ & $\varepsilon, \Gamma \varepsilon$ & $\because$ & r. 9 & $1 \cdot . r$ & 4.1 & $0 .$. & 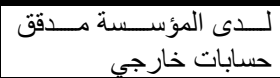 & 17 \\
\hline$\cdot$ & 11.01 & ¿ & $\varepsilon .1 V$ & r. 9 & $1 . \varepsilon$ & $1 \cdot$. & $\varepsilon v .1$ & $r \Lambda .7$ & 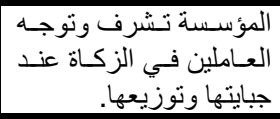 & $T \mathrm{TV}$ \\
\hline$\because \cdots$ & $7.7 \mathrm{~V}$ & V7. 0 & r.人र & r. 9 & ᄉ.V & $1 \wedge .1$ & $\varepsilon r_{.}$. & rv.o & الجانب الثرة لجنة رقابة لتزابة & 11 \\
\hline$\because \cdots$ & $V . T V$ & VI.Y & r.Al & r. 9 & 0.1 & $1 \leqslant .0$ & $7 . .9$ & 10.9 & اللجاؤبس الإدارية للزفة رقابة تتابع & 19 \\
\hline. .170 & $1 . \varepsilon 1$ & 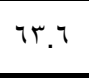 & T.1A & v. 1 & $17 . \varepsilon$ & $r \varepsilon . r$ & $r \varepsilon . r$ & v.o & 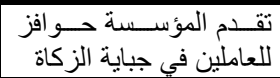 & $r$. \\
\hline$\because \cdots$ & 11.11 & V7.1 & r.A. & \multicolumn{7}{|c|}{ جميع فقرات المجال } \\
\hline
\end{tabular}

الفرضية الثانية: "يوجد تتسيق وسياسات موجهة للعمل بين المؤسسات الخيرية"

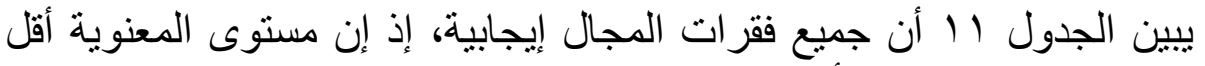

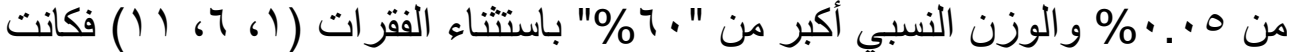

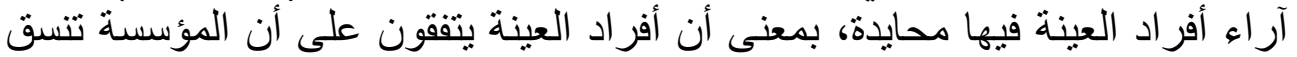

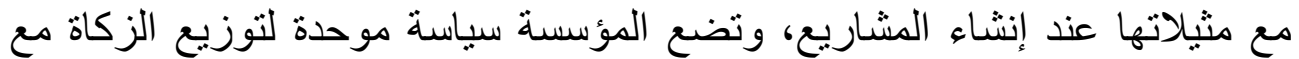

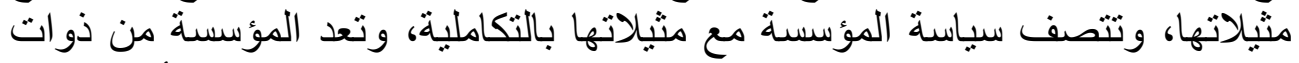

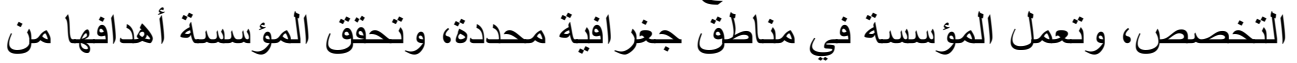
خلال الزكاة، وتحدث المؤسسة إدارات الزكاة بشكل مستمر، وتسعى المؤسسة للحد

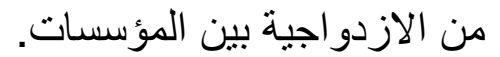

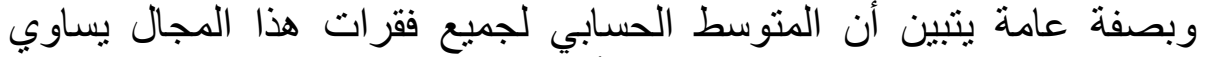

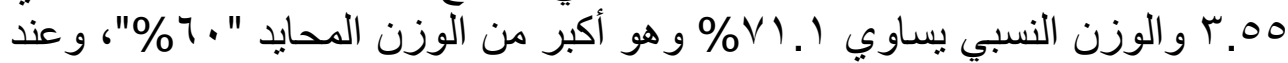

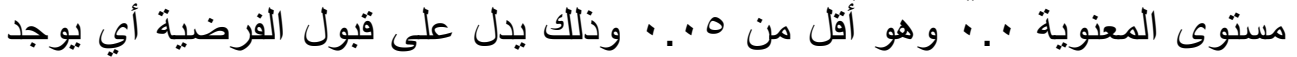
تنسيق وسياسات موجهة للعمل بين المؤسسات الخيرية.

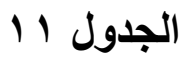

تحليل فقرات المجال الرابع (التنسيق و السياسات الموجهة للعمل)

\begin{tabular}{|c|c|c|c|c|c|c|c|c|c|c|}
\hline 裹零 & s: & $\begin{array}{l}\overline{3} \\
\overline{3} \\
\overline{3}\end{array}$ & 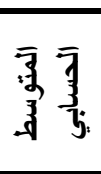 & 3 & $\begin{array}{l}\frac{3}{3} \\
\frac{3}{8} \\
\frac{3}{9}\end{array}$ & $\begin{array}{l}\frac{1}{3} \\
\frac{7}{0} \\
\end{array}$ & 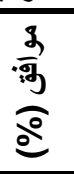 & 高 & 浔 & \\
\hline..$\varepsilon 0 \mathrm{~V}$ &. $\mathrm{YO}$ & or. & r.9. & 1. & $r \cdot$. & To. & $r 4$. & $\begin{array}{ll}Y . \varepsilon \\
\end{array}$ & تجبـــي المؤسسـسة & \\
\hline
\end{tabular}


د د

\begin{tabular}{|c|c|c|c|c|c|c|c|c|c|c|}
\hline 劣 & 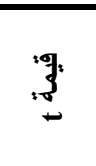 & $\begin{array}{l}\overline{9} \\
: 3 \\
\overline{7} \\
3\end{array}$ & 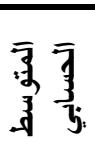 & . & $\frac{3}{3}$ & $\frac{j}{y^{2}}$ & $\frac{\text { के }}{\text { ஓ }}$ & 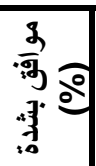 & 歌 & :星 \\
\hline & & 9 & & $r$ & 9 & 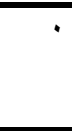 & 0 & & 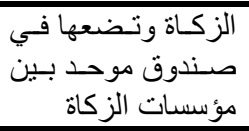 & \\
\hline$\because \cdots$ & 0.19 & $\frac{V T}{1}$. & r.7人 & r.q & A. $\vee$ & $r \leqslant$. & $\varepsilon \varepsilon$ & 11 & 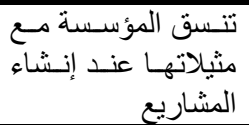 & r \\
\hline$\because \cdots 9$ & T.TV & TV. & ס. r. & $\varepsilon . r$ & 11. & rq. & r. & $1 \leq$ & 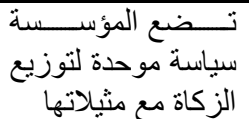 & $r$ \\
\hline$\because \cdots$ & 0.1 & $\begin{array}{l}\text { VT. } \\
\text { r. }\end{array}$ & $r .71$ & $1 . \varepsilon$ & $\begin{array}{l}10 . \\
V\end{array}$ & $\begin{array}{c}r r \\
q\end{array}$ & $\varepsilon \cdot$ & $r \cdot$ & بالتكاملية & $\varepsilon$ \\
\hline$\because \cdots$ & $V . .0$ & $\begin{array}{l}V V . \\
\varepsilon\end{array}$ & r.AV & $\because \cdot$ & $\begin{array}{l}\text { IV. } \\
1\end{array}$ & 1.7 & ז & $r \cdot$ & ذوعـــ المؤسـسـة مــن & 0 \\
\hline$\cdot r$ & $1 . \cdot \varepsilon$ & r. & $r .17$ & $1 \cdot$ & ru. & $\begin{array}{l}\text { IV. } \\
\varepsilon\end{array}$ & $\dot{r \cdot}$ & 10. & 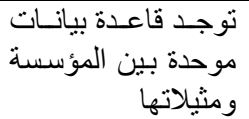 & 7 \\
\hline$\because \cdots$ & $9 . r \leqslant$ & Ar. & $\varepsilon .1 \mathrm{~V}$ & r.q & $1 \cdot$ & $\because \cdot$ & $\leq 1$ & $\leq 0$. & 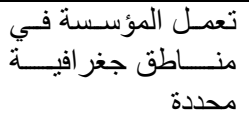 & V \\
\hline$\because \cdots$ & 0.94 & $\frac{d r}{k T}$ & r.TV & $1 . \varepsilon$ & $\frac{11}{7}$ & $\begin{array}{l}Y 1 . \\
r\end{array}$ & $\begin{array}{c}\varepsilon q . \\
r\end{array}$ & $\begin{array}{c}10 . \\
9\end{array}$ & 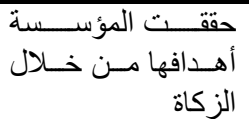 & $\wedge$ \\
\hline$\cdots$ & $\varepsilon . Y T$ & $v \cdot$ & r.or & r. 9 & $\begin{array}{c}1 \leq . \\
0\end{array}$ & $\begin{array}{c}r 7 . \\
1\end{array}$ & $\varepsilon \cdot$ & $\begin{array}{c}10 \\
9\end{array}$ & تحداث المؤسسة إدارات & 9 \\
\hline$\because \cdots$ & $1 Y . \varepsilon$ & Ar. & $\varepsilon .1$ & $\because$ & $\varepsilon . r$ & 11. & r. & $r \cdot$ & 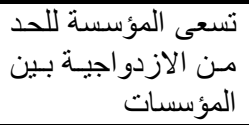 & 1. \\
\hline $.9 r 0$ & .1 & r. & $r .1$ & $1 \cdot$ & r. & $\begin{array}{c}10 . \\
9\end{array}$ & $\begin{array}{c}r 7 . \\
1\end{array}$ & $\begin{array}{c}1 \varepsilon \\
0\end{array}$ & 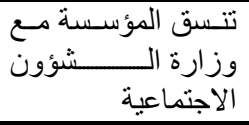 & 11 \\
\hline$\because \cdots$ & $\wedge . \leqslant 0$ & $\frac{1}{1}$. & $r .00$ & \multicolumn{7}{|c|}{ جميع فقرات المجال } \\
\hline
\end{tabular}

الفرضية الثالثة: هنالك اهتمام من الجمعيات بعمليات الإعداد و التدريب و التطوير

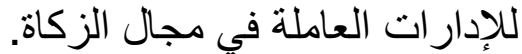

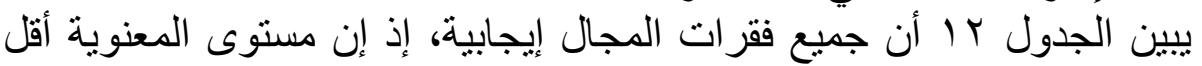

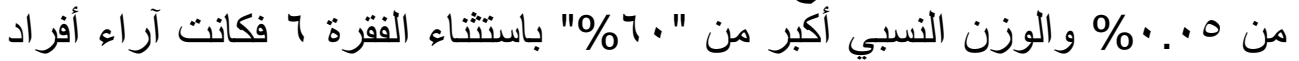

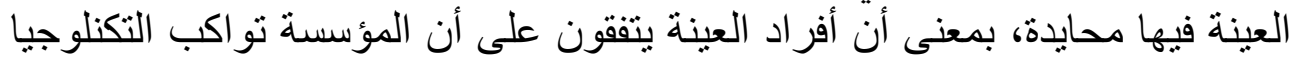

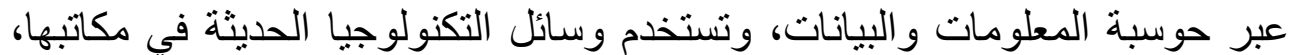
وتسعى بشكل مستمر لنطوير أداء العاملين، وتقوم المؤسسة بتدريب الموظفين فقياً 


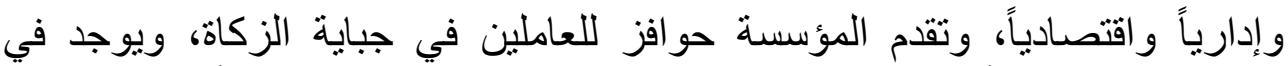

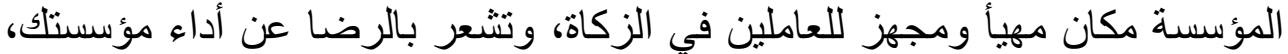
وتختار المؤسسة الموظفين في الزكاة على وفئ في الزئ معايير.

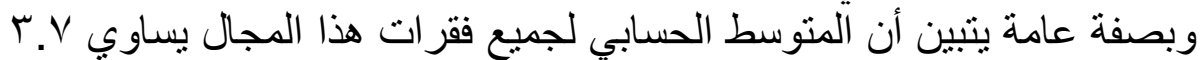

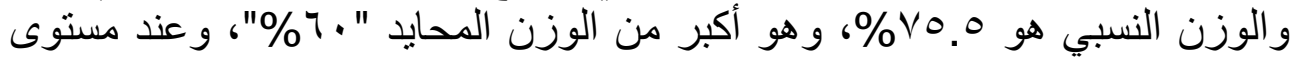

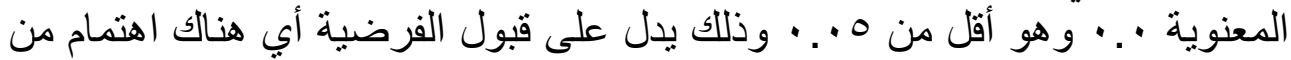
الجمعيات بعطليات الإعداد و التدريب و التطوير للادار ات العادلة العلة في مجال الزكاة.

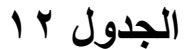

تحليل فقرات المجال الخامس (الإعداد و التدريب و التطوير)

\begin{tabular}{|c|c|c|c|c|c|c|c|c|c|c|}
\hline 芧存 & :98: & 牙雨 & 牙 $\overline{3}$ & 争 & $\stackrel{3}{3}$ ○ & $\frac{d}{y^{2}}$ & హ) & 3. & 湾 & : \\
\hline$\because \cdot$ & 10. & Av. & ס. & $\because$ & $\varepsilon . r$ & r. .9 & $\leqslant 7$. & $\leqslant 7 . \leqslant$ & 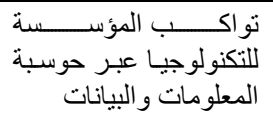 & 1 \\
\hline$\because \cdot$ & $\begin{array}{l}17.1 \\
V\end{array}$ & NV. & $\varepsilon . r q$ & $\because$ & r. $q$ & r. .9 & $\varepsilon v$. & $\leq \vee .1$ & 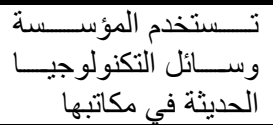 & r \\
\hline$\because \cdot$ & $\begin{array}{c}1 \cdot .9 \\
0\end{array}$ & $\stackrel{\Lambda}{q}$. & $\leq .1 \leq$ & $\because$ & v. 1 & $1 \cdot$ & r. & r^. ${ }^{\top}$ & 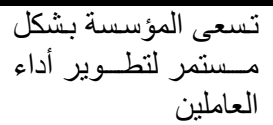 & $r$ \\
\hline$\because \cdot$ & T.VT & $\begin{array}{c}79 . \\
\varepsilon\end{array}$ & $r . \Sigma V$ & '. & $\begin{array}{r}r \cdot \\
\cdot\end{array}$ & $\begin{array}{l}r V . \\
1\end{array}$ & $\begin{array}{c}r r . \\
q\end{array}$ & 11.7 & تقوم المؤسسة بتدريب & $\varepsilon$ \\
\hline$\because \cdot$ & $v .09$ & $\begin{array}{l}\text { Vo. } \\
V\end{array}$ & r.vq & $\because$ & 1. 7 & $\begin{aligned} r \varepsilon . \\
r\end{aligned}$ & $\varepsilon v$. & $r .$. & تقوم المؤسسة بتدريب إداريب & 0 \\
\hline$\because \cdot V$ & $1 . \wedge \varepsilon$ & Tะ. & $r . r$. & !. & $\begin{array}{c}r r \\
q\end{array}$ & ro. & re. & $0 . V$ & تقوم المؤسسة بتدريب اقتصادياً & 7 \\
\hline$\because \cdot$ & $\varepsilon . r$ & $\begin{array}{c}79 . \\
9\end{array}$ & $r . \leqslant q$ & !. & 11. & iv. & or. & ^. V & 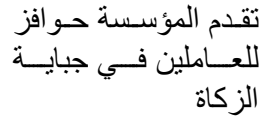 & V \\
\hline$\because \cdot$ & T.V & $v \cdot$ & r.or & $\stackrel{0}{i}$ & $\begin{array}{c}10 . \\
9\end{array}$ & 11. & $\begin{array}{r}49 . \\
1\end{array}$ & $r \cdot . r$ & 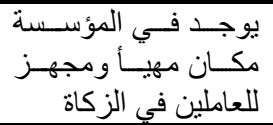 & $\wedge$ \\
\hline$\because \cdot$ & $\Lambda . r \Lambda$ & $\begin{array}{c}V V \\
1\end{array}$ & r.یT & $\because$ & 1.7 & $\begin{array}{c}11 . \\
7\end{array}$ & $\begin{array}{c}01 . \\
\varepsilon\end{array}$ & YI. & تشؤستر بالرضا عن أداء & 9 \\
\hline$\because \cdot$ & $\varepsilon . \wedge \Lambda$ & ri. & r.ov & r. & $1 \cdot$ & 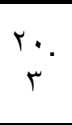 & 00 & $1 . .1$ & 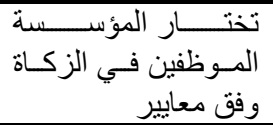 & 1. \\
\hline$\because$ & $\begin{array}{l}11 . \\
9\end{array}$ & $\frac{1}{1}$ & r.V & \multicolumn{7}{|c|}{ جميع فقرات المجال } \\
\hline
\end{tabular}


دكتور الرفاتي [^r]

الفرضية الرابعة: تعمل المؤسسات الخيرية على جلب الموارد وتحسين الأنشطة بصورة مستمرة ومنظمة.

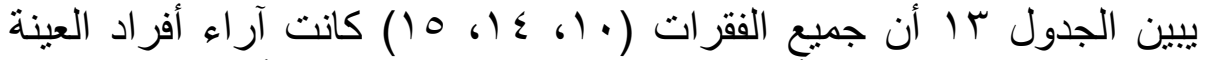

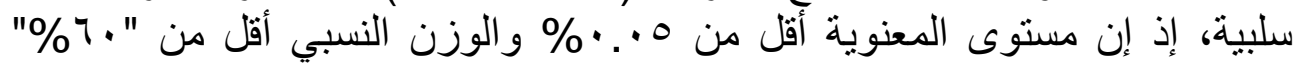

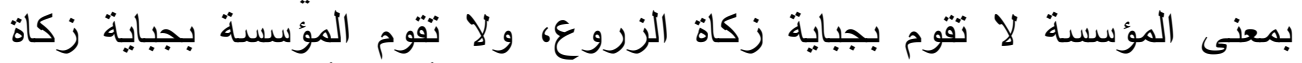

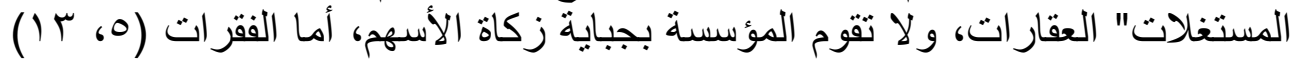

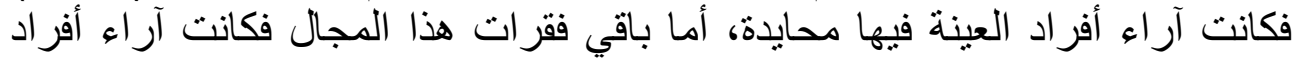

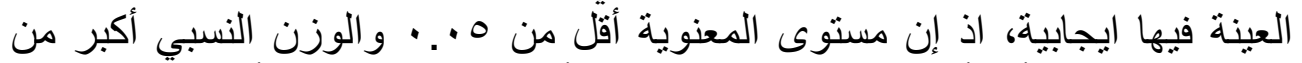

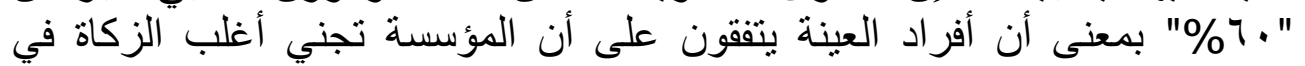

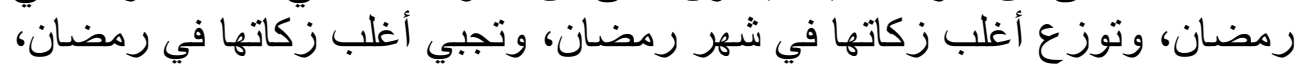

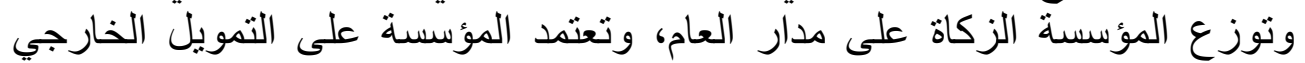

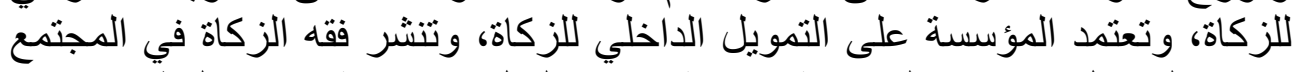

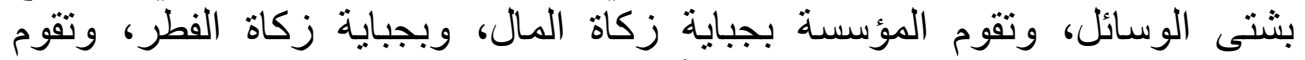

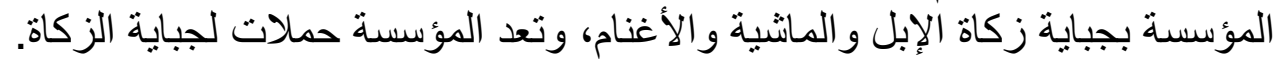

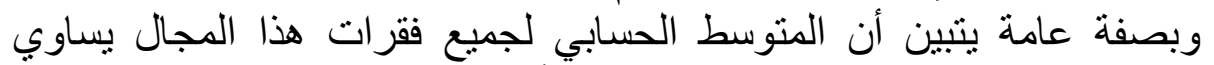

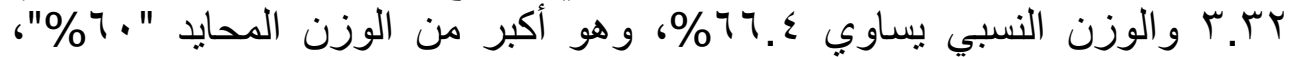

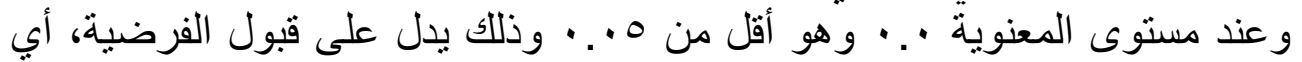
تعمل المؤسسات الخيرية على جلب الموارد وتحسين الأنشطة بصورة مستمرة

\begin{tabular}{|c|c|c|c|c|c|c|c|c|c|c|}
\hline \multicolumn{11}{|c|}{ (الموارد والأنشطة) } \\
\hline $\begin{array}{l}3 \\
3 \\
y \\
\bar{y} \\
73\end{array}$ & 搨' & $\begin{array}{l}\overline{3} \\
. \overline{3} \\
\overline{7} \\
3\end{array}$ & $\begin{array}{l}\overline{9} \\
\overline{3} \\
\overline{3}\end{array}$ & $\overbrace{3}^{3}$ & $\frac{3}{3}$ & $\frac{d}{d}$ & $\frac{3}{9}$ & 高 & 司 & : \\
\hline$\because \cdot$ & $\begin{array}{c}1 \Gamma . r \\
\varepsilon\end{array}$ & 10. & $\varepsilon . T V$ & $\because \cdot$ & $0 . V$ & $\varepsilon . r$ & $\varepsilon v$. & $\begin{array}{c}\varepsilon Y . \\
q\end{array}$ & الزجني المؤسسة اغلب & 1 \\
\hline$\because$ & $7.7 \varepsilon$ & $\begin{array}{c}\text { VI. } \\
\text { r. }\end{array}$ & r..1 & $1 . \varepsilon$ & 10. & $v_{.} .1$ & $\begin{array}{l}01 . \\
\varepsilon\end{array}$ & $\begin{array}{c}r \varepsilon . \\
r\end{array}$ & 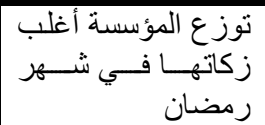 & $r$ \\
\hline$\because \cdots$ & r.10 & $\begin{array}{c}7 V . \\
9\end{array}$ & r. $\varepsilon$. & $\varepsilon . \varepsilon$ & $\begin{array}{l}r T . \\
0 .\end{array}$ & $\frac{17}{r}$ & $\begin{array}{r}r q \\
v\end{array}$ & $\frac{17 .}{r}$ & تجلي المؤسسة الزكاة & $r$ \\
\hline$\because$ & r. & $\begin{array}{r}v \cdot \\
i\end{array}$ & $r .01$ & Y.r & $\begin{array}{c}11 \\
\Lambda\end{array}$ & ir. & $\begin{array}{r}r v . \\
v\end{array}$ & $\stackrel{r r}{r}$. & توزلى مدار العأس الزكاة & $\varepsilon$ \\
\hline$\cdot \pi$ & $1 . r$ & $\begin{array}{c}T r \\
9\end{array}$ & T.1 & v.. & ro. & rv. & ro. & $\begin{array}{l}1 \leqslant . \\
\mu\end{array}$ & 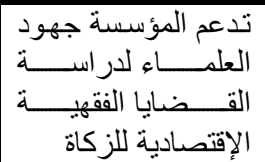 & 。 \\
\hline$\because$ & 7.90 & $\begin{array}{c}V V . \\
\varepsilon\end{array}$ & r.Av & r. .9 & 11. & $\because$ & $\frac{\varepsilon V}{1}$ & $\begin{array}{c}r \wedge . \\
T\end{array}$ & 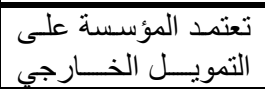 & 7 \\
\hline
\end{tabular}




\begin{tabular}{|c|c|c|c|c|c|c|c|c|c|c|}
\hline $\begin{array}{l}3 \\
3 \\
y \\
\bar{y} \\
z\end{array}$ & "g." & $\begin{array}{l}\overline{3} \\
.3 \\
\overline{3} \\
3\end{array}$ & 牙 & 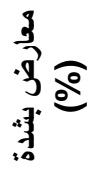 & $\frac{3}{3} \frac{3}{3}$ & $\frac{j}{y^{2}}$ & $\frac{3}{\frac{3}{9}}$ & 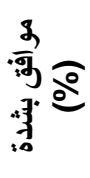 & 滒 & 济 \\
\hline & & & & & & & & & للزكاة & \\
\hline$\because \cdot$ & A.ru & $\frac{V 7 .}{7}$ & r.یr & $1 . \varepsilon$ & $0 . V$ & $\frac{11 .}{7}$ & ov. & $\frac{1 V}{1}$ & 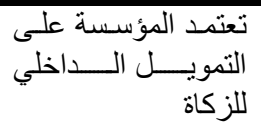 & V \\
\hline$\because \cdots$ & $Y . \wedge V$ & $\begin{array}{l}77 . \\
V\end{array}$ & תוז & $\varepsilon . r$ & ir. & ru. & $\begin{array}{l}r v \\
V\end{array}$ & ^. $\vee$ & 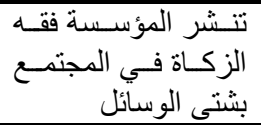 & $\wedge$ \\
\hline$\because \cdot$ & 0.0 & Vะ. & $r . v$. & V.1 & 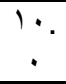 & $\begin{array}{c}1 \% \\
9\end{array}$ & $\varepsilon$. & $\begin{array}{c}r \varepsilon . \\
r\end{array}$ & زتقوم المؤسسة بجبايـة & 9 \\
\hline$\ddot{r}$ & r.19- & 01 . & r.00 & $\begin{array}{l}\text { Yl. } \\
\text { r. }\end{array}$ & $\dot{r} \cdot$ & $r$ ru. & r. & $\varepsilon . r$ & زتقوم المؤسسة بجبايـة & 1. \\
\hline$\because \cdot$ & $\Lambda . \cdot r$ & $\begin{array}{c}19 . \\
1\end{array}$ & r.97 & r.9 & 1. 7 & ^. 7 & $0 \cdot$ & $r \cdot$ & زتقوم المؤسسة بجبايـة & 11 \\
\hline$\because \cdot$ & r.90_ & $\varepsilon \wedge$. & $r . \leqslant r$ & rq. & $\begin{array}{l}r V . \\
0\end{array}$ & $\begin{array}{r}r \cdot \\
r\end{array}$ & 11. & $\varepsilon . r$ & 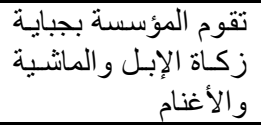 & Ir \\
\hline$\ddot{r}_{r} \leqslant r$ & $\because \vee q_{-}$ & $\begin{array}{c}O V \\
\varepsilon\end{array}$ & Y.AV & 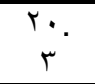 & $\begin{array}{c}r \varepsilon . \\
T\end{array}$ & $\begin{array}{c}\text { IV. } \\
\varepsilon\end{array}$ & $r$ r. & $1 \leqslant$. & تقور المؤسسة بجبايـة & $1 \pi$ \\
\hline$\because \ddot{0}$ & r.91- & 01. & T.OV & $\begin{array}{r}r \leqslant . \\
T\end{array}$ & rv. & 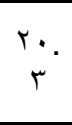 & Yl. & 0.1 & 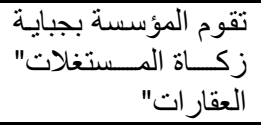 & $1 \leq$ \\
\hline$\because \cdots$ & $\varepsilon . V V-$ & $\varepsilon v$. & r. rq & $r$ r. & ru. & $\begin{array}{c}r \uparrow . \\
1\end{array}$ & $\begin{array}{c}10 . \\
9\end{array}$ & $1 . \varepsilon$ & زتوم الأسؤسـة بجبايـة & 10 \\
\hline$\ddot{9} \cdot 1$ & $Y . \leqslant 1$ & $\begin{array}{c}T V \\
Y\end{array}$ & דז." & $\frac{11}{7}$ & $\begin{array}{c}10 . \\
9\end{array}$ & 11. & $\leqslant 7$. & $1 \varepsilon$. & لجعد المؤسسة حمـلات & 17 \\
\hline$\because \cdots$ & $\varepsilon . \Gamma \varepsilon$ & 77.8 & T.MT & \multicolumn{7}{|c|}{ جميع فقرات المجال } \\
\hline
\end{tabular}

الفرضية الخامسة: تسهم أمو ال الزكاة في الحد من ظاهرة الفقر بصورة واضحة.

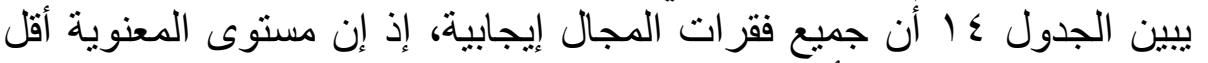

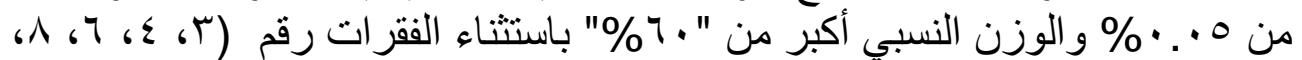

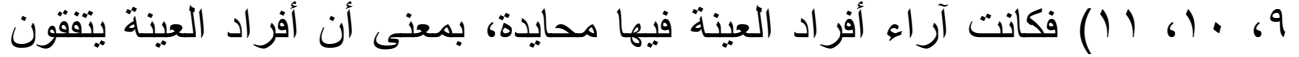

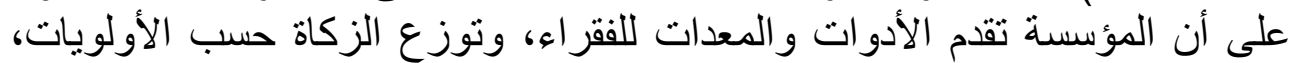

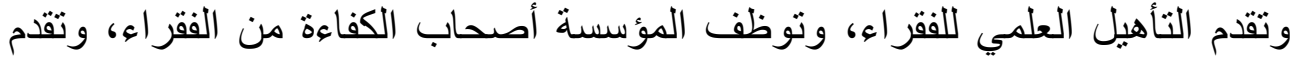

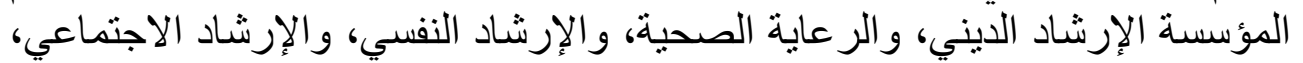
و المساعدات النقدية، و المساعدات العينية للفقر اء.

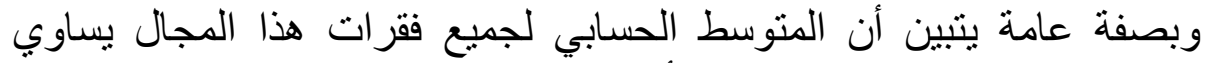

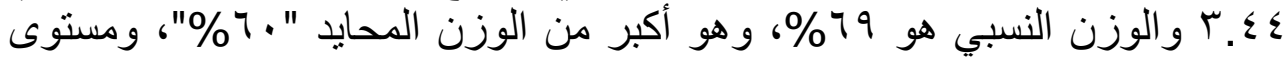




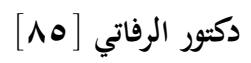

المعنوية هو ·. • و هو أقل من ه •. . وذلك يدل على قبول الفرضية أي تسهم أموال الزكاة في الحد من ظاهرة الفقر بصورة هن و واضحة.

\begin{tabular}{|c|c|c|c|c|c|c|c|c|c|c|}
\hline \multicolumn{11}{|c|}{ تحليل فقرات المجال السابع (دور } \\
\hline 雪 & "g. & 牙 & 牙示 & 象 & . & $\frac{1}{3}$ 。 & क & 高 & 哥 & 高 \\
\hline$\because$ & T.r & $\begin{array}{c}4 \Lambda . \\
\Lambda\end{array}$ & $r . \varepsilon \varepsilon$ & 0.9 & $\begin{array}{c}1 \varepsilon . \\
V\end{array}$ & $\begin{array}{c}r Y . \\
1\end{array}$ & $\leqslant \varepsilon$. & ${ }_{r}^{T r}$. & 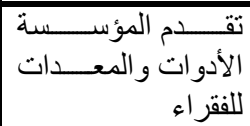 & 1 \\
\hline$\because$ & 19.87 & 10. & $\varepsilon . \Upsilon \wedge$ & $\because \cdot$ & $\because$ & £. & $\frac{\pi}{r}$. & $\begin{array}{c}r r . \\
\varepsilon\end{array}$ & 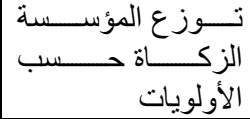 & $r$ \\
\hline$\because \cdots$ & & $\because$ & r... & V.r & ry. & $\begin{array}{c}r \varepsilon . \\
\wedge\end{array}$ & $\stackrel{r r}{r}$. & A.V & 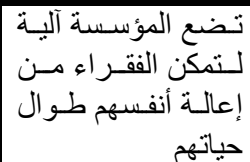 & $r$ \\
\hline $\begin{array}{l}\cdot \wedge \\
\wedge\end{array}$ & $\cdot Y \varepsilon_{-}$ & $\begin{array}{c}09 . \\
\varepsilon\end{array}$ & r. $.9 \mathrm{~V}$ & $\varepsilon . r$ & rq. & rq. & $r_{r}^{r}$. & V.r & 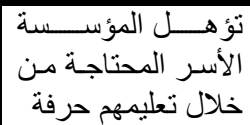 & $\varepsilon$ \\
\hline$\because{ }^{\prime \prime}$ & T. $\varepsilon \varepsilon$ & $\begin{array}{c}70 . \\
1\end{array}$ & r.rq & $\varepsilon . \Gamma$ & $\begin{array}{l}Y Y . \\
\varepsilon\end{array}$ & $\begin{array}{r}r \cdot . \\
\varepsilon\end{array}$ & $\because \because$ & $V . r$ & 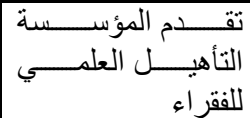 & 0 \\
\hline $\begin{array}{l}v^{v} \\
v^{\prime}\end{array}$ & . דז. & 7. & $r . \varepsilon \varepsilon$ & $V .0$ & $\begin{array}{c}r Y . \\
\varepsilon\end{array}$ & r. & $\begin{array}{c}\text { ro. } \\
\wedge\end{array}$ & r. & 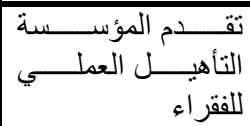 & 7 \\
\hline$\because$ & r.АT & $\begin{array}{c}\text { TV. } \\
1\end{array}$ & r.ro & $\varepsilon . \varepsilon$ & 19 & $r \cdot$. & $\begin{array}{c}\text { 纟^. } \\
0\end{array}$ & $\gamma . \varepsilon$ & 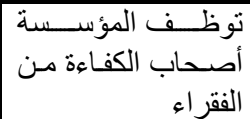 & $\mathrm{v}$ \\
\hline 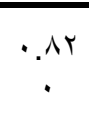 & rז' & $\because 7$ & $r . r r$ & $\gamma . \varepsilon$ & ro. & $\begin{array}{c}r Y . \\
\varepsilon\end{array}$ & $\begin{array}{c}r v . \\
q\end{array}$ & $V . \varepsilon$ & 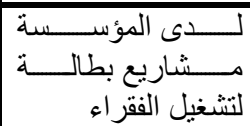 & $\lambda$ \\
\hline $\begin{array}{c}e^{r V} \\
\varepsilon\end{array}$ & $\cdot \wedge 9$ & $\begin{array}{l}r r \\
r\end{array}$ & $r .1 T$ & $1 \leqslant$. & $\begin{array}{c}17 . \\
\varepsilon\end{array}$ & $\begin{array}{c}17 . \\
\varepsilon\end{array}$ & $\begin{array}{l}\varepsilon \varepsilon . \\
\Lambda\end{array}$ & $Y .0$ & التفتر اءو في مشاريعهاة & 9 \\
\hline$\ddots_{1}^{\prime \wedge r}$ & $\cdot\left(r^{\prime}\right.$ & $\because 4$ & $r . r$ & ${ }_{r}^{1 T}$. & 17. & $r \cdot$. & $\begin{array}{c}r r . \\
\Lambda\end{array}$ & 0.9 & الالفقراء في مشاريعة المؤسة & 1. \\
\hline${ }_{r}^{17}$ & $1 . \leqslant 1-$ & $\begin{array}{c}00 . \\
9\end{array}$ & r.A. & 10. & $\begin{array}{l}r Y . \\
0\end{array}$ & 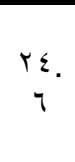 & $\begin{array}{c}r \varepsilon . \\
T\end{array}$ & $V . r$ & 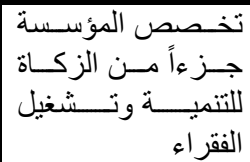 & 11 \\
\hline$\because \cdots$ & $0 . \wedge 7$ & $\begin{array}{c}V Y \\
q\end{array}$ & r.70 & $\varepsilon$ \& & 0.9 & $r_{1} \cdot$ & $\begin{array}{c}0 \Lambda \\
\Lambda\end{array}$ & ${ }_{r}^{\prime}$. & 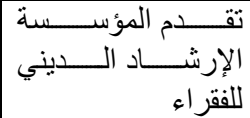 & $1 T$ \\
\hline
\end{tabular}




\begin{tabular}{|c|c|c|c|c|c|c|c|c|c|c|}
\hline 㞼 & 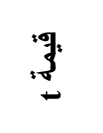 & 可 & 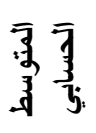 & ؛ & $\frac{3}{3}$ & 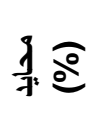 & क & 承 & 司 & 次 \\
\hline$\because \cdots$ & $0 . r \wedge$ & $\begin{array}{c}Y Y . \\
\varepsilon\end{array}$ & T.Tr & r.q & ${ }_{r}^{1 T}$. & ${ }_{1}^{1 r}$. & $\stackrel{r}{r}$. & $\ddot{r} \cdot$ & 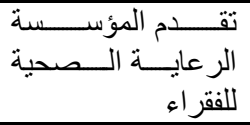 & 14 \\
\hline$\because$ & T.VT & $\begin{array}{c}79 . \\
\varepsilon\end{array}$ & $r . \varepsilon V$ & $\varepsilon . \varepsilon$ & ${ }_{r}^{17}$. & 19 & $\begin{array}{c}\varepsilon \wedge \\
0\end{array}$ & $\begin{array}{l}11 . \\
1\end{array}$ & 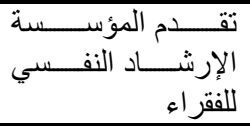 & $1 \varepsilon$ \\
\hline$\because$ & V. $1 \varepsilon$ & $\begin{array}{c}\text { Vo. } \\
r\end{array}$ & T.TV & 1.0 & $\ddot{r} \cdot$ & ${ }^{1 r}$. & $\ddot{r}$. & $\begin{array}{l}1 \leq . \\
v\end{array}$ & 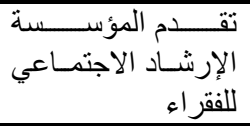 & 10 \\
\hline$\because \cdots$ & $10,0 \mathrm{~V}$ & 10. & $\varepsilon . r q$ & $\because$ & r.q & $\varepsilon . r$ & or. & rq. & 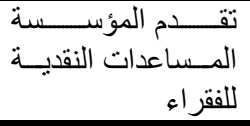 & 17 \\
\hline$\because \cdots$ & 10.70 & 17. & $\varepsilon . \mu$. & $\because$ & r.q & $\varepsilon . r$ & $\stackrel{o r}{r}$. & $\varepsilon$. & 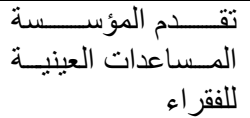 & IV \\
\hline$\because \ldots$ & 8.01 & 79. & T. & & & & مجال & يع فقرات & & \\
\hline
\end{tabular}

\section{النتائج والتوصيات} أولاً النتائج التوص

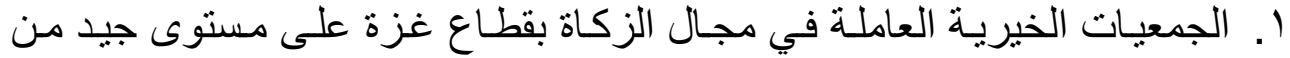

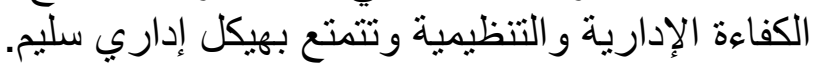

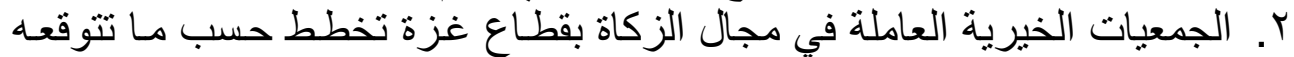

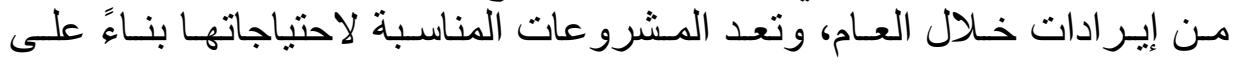
توقعاتها. r. تمثل الظروف السياسية عائقاً أساسياً أمسام الجمعيات الخيريـة العاملة في مجال الز كاة بقطاع غزة. ع. تقوم الجمعيات الخيرية العاملة في مجال الزكاة بقطاع غزة بتطوير أداء موظفيها

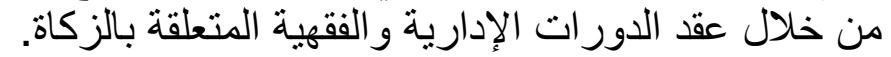

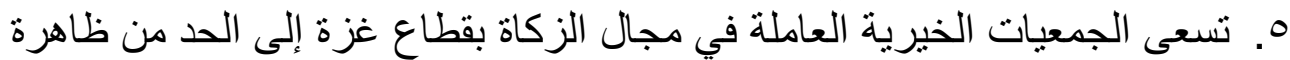

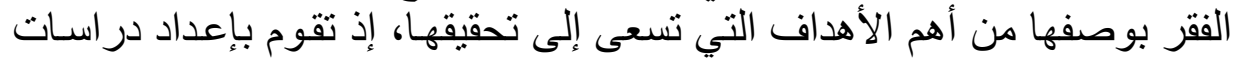

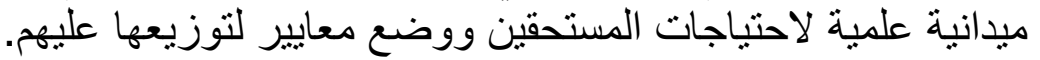

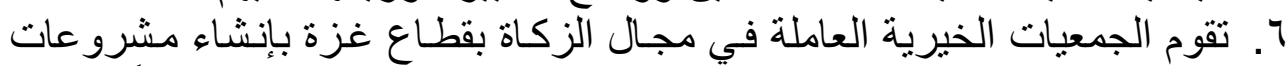

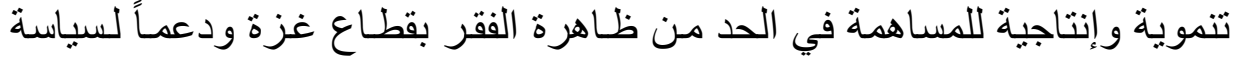

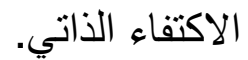
V. تتم عملية جبآية الزكاة على مدار العام وتزيد في شهر رمضان المبارك، لإقبال

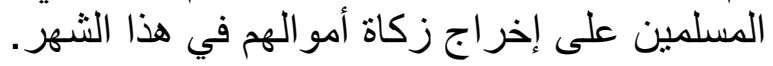




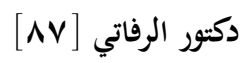

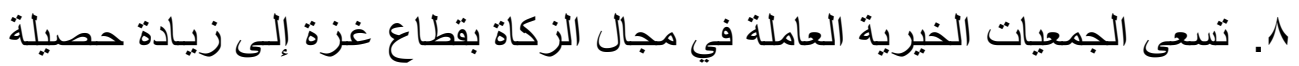

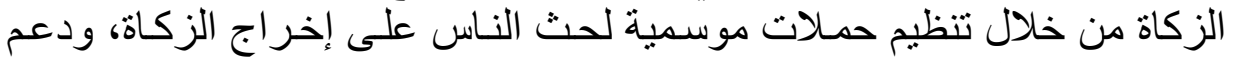
جهود العلماء الخاصة بدر اسة القضايا الفقهية والإقتصادية للزية الزاة.

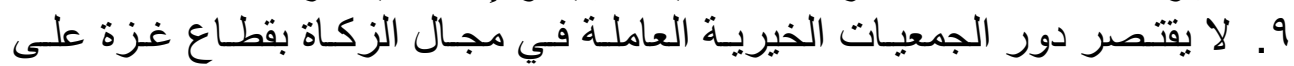

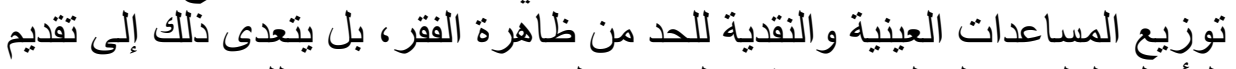
التأهيل العلمي و العملي و الإرشاد الديني و النفسي و الاجتماعي للفقراء.

\section{ثانياً- التوصيات}

1. ضرورة إنشاء سلطة عليا مكونة من الجمعيات الخيرية العاملة في مجال الزكاة

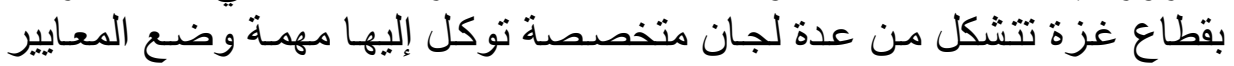
و السياسات وتطوير المشرو عات بات بالاستعانة بذوي الخبرة في المجالات التي تخدم التبان تطوير العمل في مجال الزكاة.

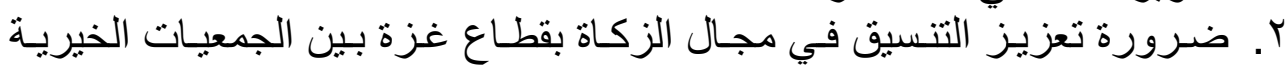
ووزارة الثؤون الاجتماعية.

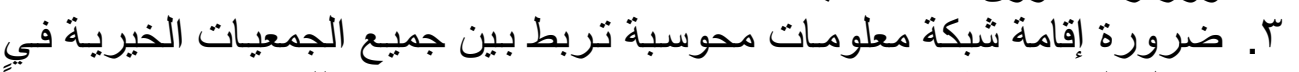

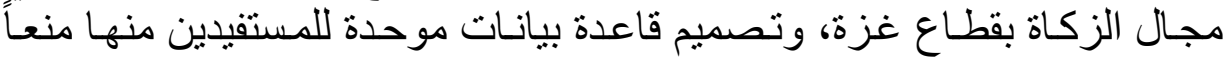
لكلازدو اجية وتوسيع دائرة المستفيدين.

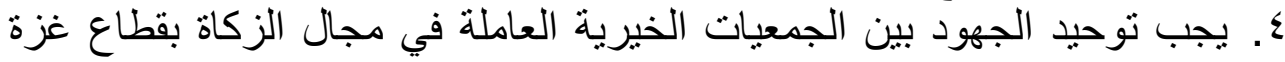

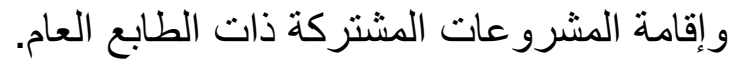

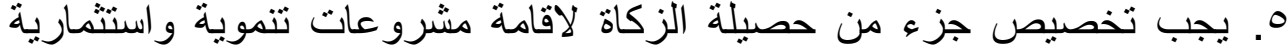

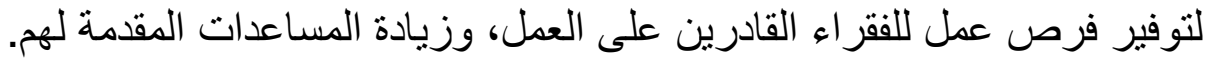

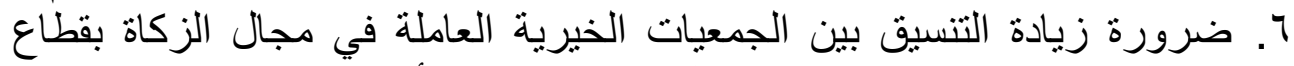

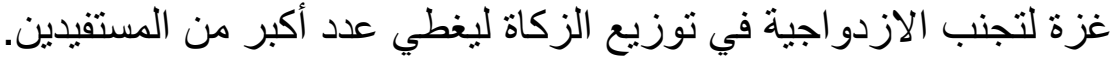

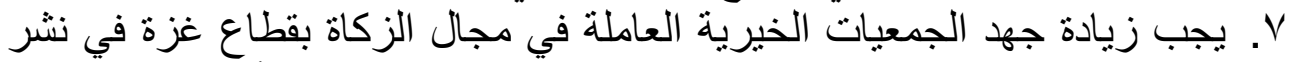

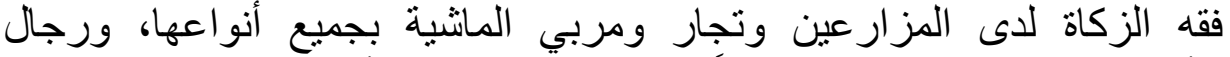

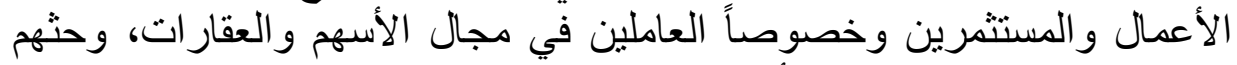
على إخر اج الزكاة لما لله من أثر في زيادة حصيلة الزئل الزكاة.

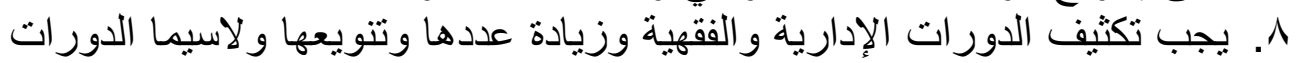

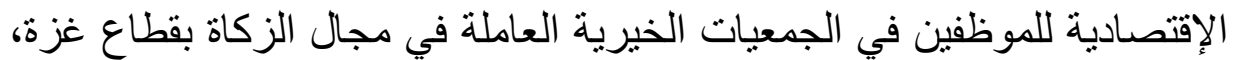

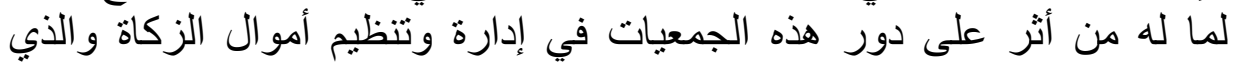

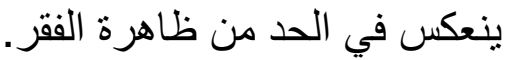

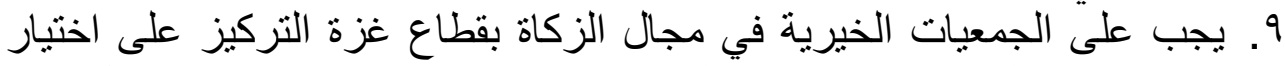

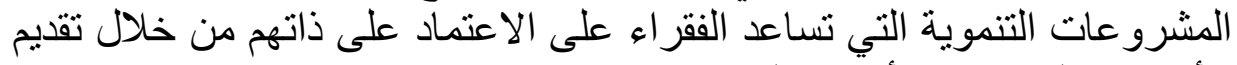

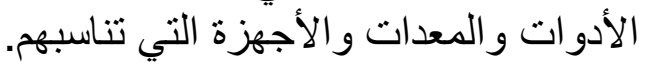

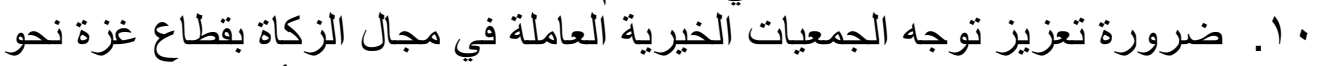

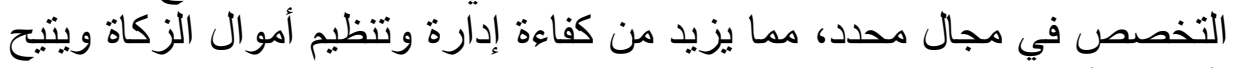

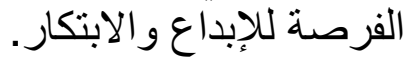




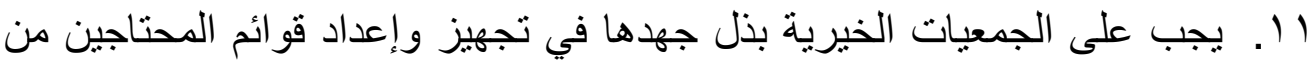

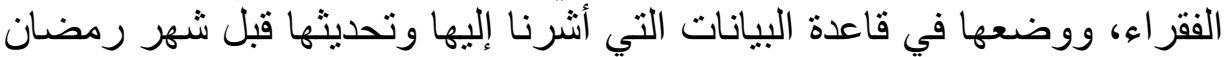

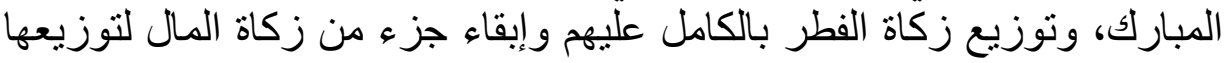
على مدار العام.

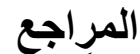

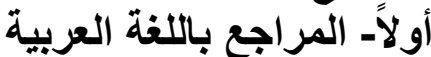

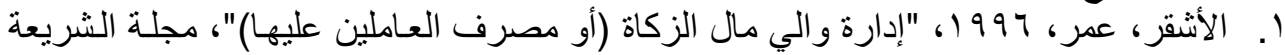

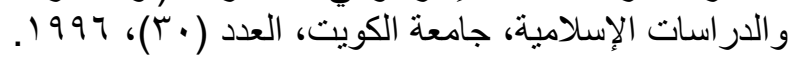

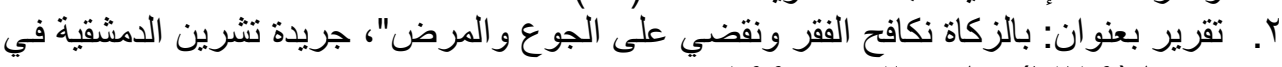

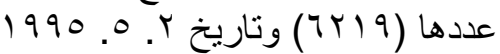

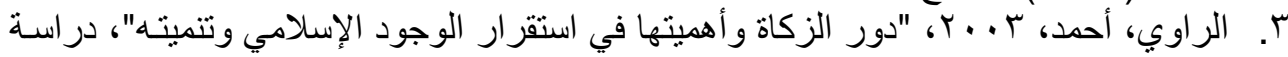

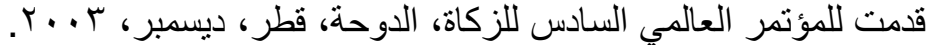

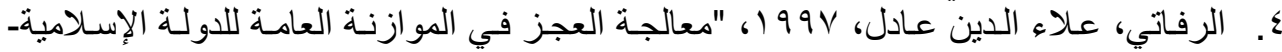

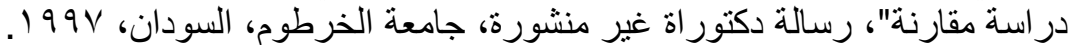

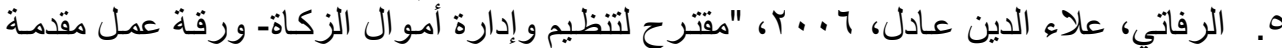

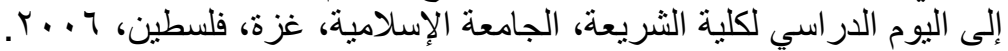

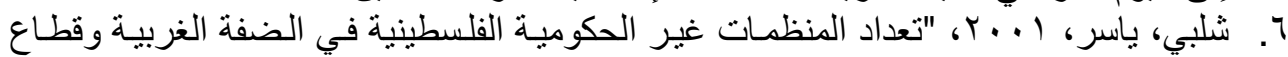

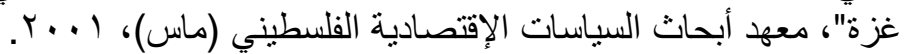

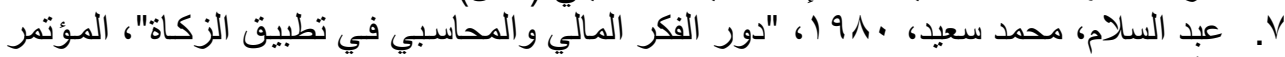

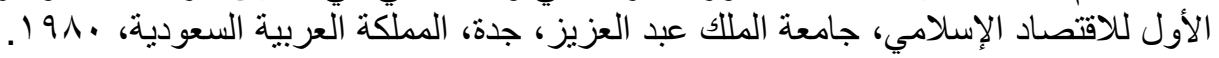

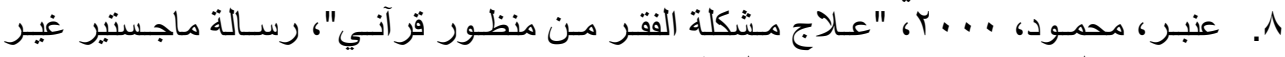

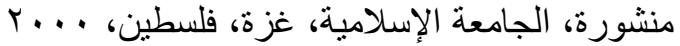

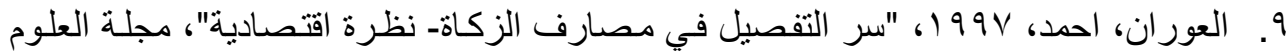

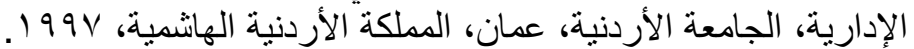

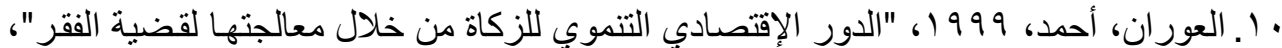

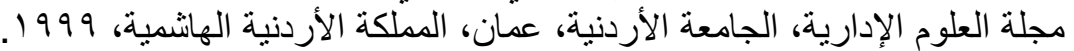

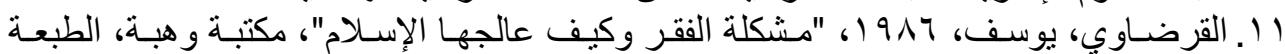

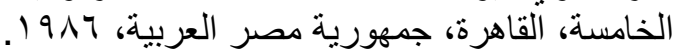

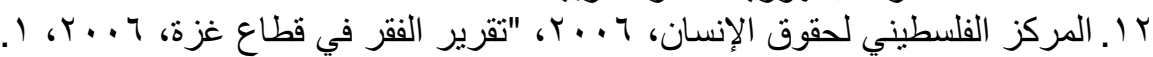

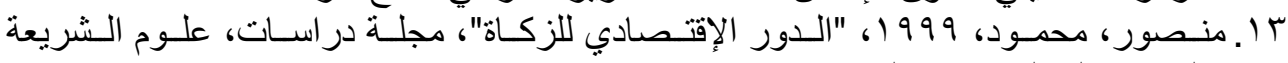

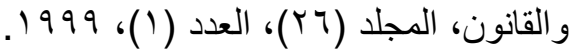

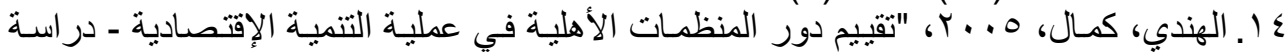

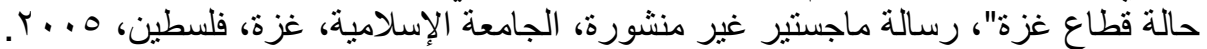

\section{ثانياً. المراجع باللغة الأجنبية}

1. Galwash, Ahmad, "The Religion of Islam", Doha Modern Printing Press, Doha, Qatar.

2. Infocus 1990, "International and Islamic Federation of Student Organizations, 1990.

3. Lister, Ruth 1990, "The Exclusive Society, Citizenship and the poor", Culverts Press, London, 1990.

4. Memon, Ali 1995, "The Islamic Nation", International Graphics, Maryland, USA, 1995. 


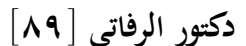

5. Sen, Amartya 1987, "poverty and Famines", University press, Oxford,, United Kingdom. 1987.

6. Sullivan, Thomas, and Thompson, Kenricks". 1991, "introduction to Social Problems:, Macmillan Publishing Company. New Yourk, Second Edition, 1991, 00. 150-151

7. The World Bank 1996, "Poverty Reduction and the world Bank", Washington, USA, 1996. 